\title{
Highly Selective 1,3-Isomerization of Allylic Alcohols Via Rhenium Oxo Catalysis
}

\author{
Christie Morrill and Robert H. Grubbs* \\ Contribution from the Arnold and Mabel Beckman Laboratory of Chemical Synthesis, \\ Division of Chemistry and Chemical Engineering, California Institute of Technology, \\ Pasadena, CA 91125 \\ rhg@caltech.edu
}

\section{Supporting Information}

Experimental procedures and characterization data $\left({ }^{1} \mathrm{H}\right.$ and ${ }^{13} \mathrm{C}$ NMR, HRMS $)$ for compounds 2-22.

General Experimental Section. NMR spectra were recorded on an Oxford $300 \mathrm{MHz}$ NMR spectrometer running Varian VNMR software. Chemical shifts are reported in parts per million (ppm) downfield from tetramethylsilane (TMS) with reference to internal solvent. Multiplicities are abbreviated as follows: singlet (s), doublet (d), triplet (t), quartet (q), quintet (quint), multiplet (m), and broad (br). The reported ${ }^{1} \mathrm{H}$ NMR and ${ }^{13} \mathrm{C}$ NMR data refer to the major olefin isomer (which is identified) except for cases in which the minor isomer showed significantly prominent peaks, in which case the two isomers were separated and individually characterized. Assignments of $E / Z$ stereochemistry were made for compounds 12, 14, 16, and 18 based on NOE experiments performed on each isomer of 12 and $\mathbf{1 8}$ and the $E$-isomers of $\mathbf{1 4}$ and 16. High-resolution mass spectra (EI and $\mathrm{CI})$ were provided by California Institute of Technology Mass Spectrometry Facility. Molecular mass calculations were performed with ChemDraw Ultra 8.0.3 (Cambridge Scientific). 
GC and HPLC data were obtained using an Agilent 6850 Series GC system and an Agilent 1100 Series HPLC, respectively. Optical rotations were measured using a Jasco P1010 Polarimeter. Reactions temperatures from $-10{ }^{\circ} \mathrm{C}$ to $-50{ }^{\circ} \mathrm{C}$ were obtained using a Neslab CC-100 Cryotrol. Analytical thin-layer chromatography (TLC) was performed using silica gel 60 F254 precoated plates $(0.25 \mathrm{~mm}$ thickness $)$ with a fluorescent indicator. Visualization was performed with standard potassium permanganate stains. Flash column chromatography was performed using silica gel 60 (230-400 mesh) from EM Science. Catalyst 1 was synthesized in a glove box according to the published procedure, purified by filtration of the reaction solution through Celite and subsequent recrystallization from diethyl ether, and stored the glove box. Benzaldehyde was distilled from calcium hydride. Diethyl ether, dichloromethane, benzene, and tetrahydrofuran were purified and dried by passage through a solvent column. ${ }^{\mathrm{i}}$ All other chemicals were used as purchased.

\section{Experimental Procedures and Characterization Data.}

(E)-3-cyclohexyl-1-phenylprop-2-en-1-ol (2). To a flame-dried, round-bottomed flask under argon atmosphere, added $\mathrm{CH}_{2} \mathrm{Cl}_{2}(15 \mathrm{~mL}), 1$-phenyl-2-propenyl acetate $(1.0 \mathrm{~mL}, 6.2$ mmol), and vinylcyclohexane $(700 \mu \mathrm{L}, 5.1 \mathrm{mmol})$. Then added, via cannula transfer, a solution of $\mathrm{RuCl}_{2}\left(\mathrm{PCy}_{3}\right)\left(\mathrm{H}_{2} \mathrm{IMes}\right) \mathrm{CHPh}(136 \mathrm{mg}, 0.16 \mathrm{mmol})$ and $\mathrm{CH}_{2} \mathrm{Cl}_{2}(10 \mathrm{~mL})$. Placed in $45{ }^{\circ} \mathrm{C}$ oil bath and let stir for approximately 24 hours. Allowed to cool to room temperature, removed solvent in vacuo, and added $3.0 \mathrm{M}$ aqueous $\mathrm{NaOH}(1.2 \mathrm{~mL}, 3.6$ $\mathrm{mmol})$, THF (45 mL), and $\mathrm{MeOH}(9 \mathrm{~mL})$. Let stir at room temperature for approximately 3 hours. Added $40 \mathrm{~mL}$ aqueous ammonium chloride, extracted 3 times with $25 \mathrm{~mL}$ ether, and dried with $\mathrm{Na}_{2} \mathrm{SO}_{4}$. The product was purified via silica gel chromatography (8:2 
pentane:ether) to obtain $636 \mathrm{mg}$ of an orange oil (58\% yield). ${ }^{1} \mathrm{H} \mathrm{NMR}\left(300 \mathrm{MHz}, \mathrm{CDCl}_{3}\right.$, ppm): $\delta 7.20(5 \mathrm{H}, \mathrm{m}), 5.63(1 \mathrm{H}, \mathrm{dd}, J=15.5,5.9 \mathrm{~Hz}), 5.51(1 \mathrm{H}, \mathrm{ddd}, J=15.5,6.5,0.9$ $\mathrm{Hz}), 5.05(1 \mathrm{H}, \mathrm{d}, J=6.6 \mathrm{~Hz}), 1.9(2 \mathrm{H}, \mathrm{m}), 1.6(5 \mathrm{H}, \mathrm{m}), 1.1(5 \mathrm{H}, \mathrm{m}) .{ }^{13} \mathrm{C} \mathrm{NMR}(300 \mathrm{MHz}$, $\left.\mathrm{CDCl}_{3}, \mathrm{ppm}\right): \delta 143.6,138.7,130.0,128.6,127.6,126.4,75.5,40.4,32.92,32.88,26.3$, 26.2. HRMS (EI) calcd. for $\mathrm{C}_{15} \mathrm{H}_{20} \mathrm{O}: 216.1514$, found: 216.1507.

(E)-1-cyclohexyl-3-phenylprop-2-en-1-ol (3). In glove box, added 1 (4 mg, $0.008 \mathrm{mmol})$ to 4-mL vial. Removed from glove box, added ether $(2 \mathrm{~mL})$, placed in Cryotrol set to -50 ${ }^{\circ} \mathrm{C}$, and let stir for approximately 10 minutes. Added $4(86.2 \mathrm{mg}, 0.4 \mathrm{mmol})$ via syringe and let stir at $-50{ }^{\circ} \mathrm{C}$ for 30 minutes. Removed from Cryotrol, immediately added $20 \mu \mathrm{L}$ triethylamine, and let stir until warmed to room temperature. Concentrated in vacuo and purified directly via silica gel chromatography (8:2 pentane:ether) to obtain $80.2 \mathrm{mg}$ of a clear oil (93\% yield). ${ }^{1} \mathrm{H}$ NMR $\left(300 \mathrm{MHz}, \mathrm{CDCl}_{3}, \mathrm{ppm}\right): \delta 7.3(5 \mathrm{H}, \mathrm{m}), 6.58(1 \mathrm{H}, \mathrm{d}, J=$ $15.9 \mathrm{~Hz}), 6.26(1 \mathrm{H}, \mathrm{ddd}, J=15.8,7.1,1.1 \mathrm{~Hz}), 4.05(1 \mathrm{H}, \mathrm{t}, J=6.6 \mathrm{~Hz}), 1.95(1 \mathrm{H}, \mathrm{d}, J=$ $13.5 \mathrm{~Hz}), 1.75(5 \mathrm{H}, \mathrm{m}), 1.55(1 \mathrm{H}, \mathrm{m}), 1.2(5 \mathrm{H}, \mathrm{m}) .{ }^{13} \mathrm{C} \mathrm{NMR}\left(300 \mathrm{MHz}, \mathrm{CDCl}_{3}, \mathrm{ppm}\right): \delta$ 137.0, 131.4, 131.2, 128.8, 127.8, 126.6, 77.8, 44.1, 29.1, 28.8, 26.7, 26.32, 26.26. HRMS (EI) calcd. for $\mathrm{C}_{15} \mathrm{H}_{20} \mathrm{O}: 216.1514$, found: 216.1516 .

(Z)-3-cyclohexyl-1-phenylprop-2-en-1-ol (4). To flame-dried, round-bottomed flask under argon atmosphere, added (Z)-(2-bromovinyl)cyclohexane ${ }^{\mathrm{ii}}(374 \mathrm{mg}, 2.0 \mathrm{mmol})$ and ether (10 mL). Placed in dry ice/acetone bath and let stir for approximately 10 minutes. Added dropwise a $1.7 \mathrm{M}$ pentane solution of $t$-butyllithium $(3 \mathrm{~mL}, 5.1 \mathrm{mmol})$. Let stir for 1 hour. Added benzaldehyde $(200 \mu \mathrm{L}, 2.0 \mathrm{mmol})$ via syringe, let stir for 20 minutes at $-78{ }^{\circ} \mathrm{C}$ for 
20 minutes, removed dry ice/acetone bath, and let stir for 20 minutes. Slowly added 10 $\mathrm{mL}$ aqueous ammonium chloride, extracted 3 times with ether, and dried with $\mathrm{Na}_{2} \mathrm{SO}_{4}$. Purified via silica gel chromatography to obtain $288 \mathrm{mg}$ of a cloudy oil, which turned out to be a 1.5:1 mixture of $\mathbf{4}$ and 3-cyclohexyl-1-phenylprop-2-yn-1-ol. To convert this mixture to the desired product, it was added to $\mathrm{MeOH}(3 \mathrm{~mL})$ and Lindlar catalyst $(5 \% \mathrm{Pd}$ on $\mathrm{CaCO}_{3}$, poisoned with $\mathrm{Pb}, 45 \mathrm{mg}$ ), degassed via 3 freeze-pump-thaw cycles, and placed under $\mathrm{H}_{2}$ atmosphere for approximately 26 hours. The reaction solution was filtered through Celite, rinsing with ether, and purified via silica gel chromatography $(8: 2$ pentane:ether) to obtain $165 \mathrm{mg}$ of a clear oil, which was $\geq 97 \% 4$ by GC (37\% yield). ${ }^{1} \mathrm{H}$ NMR (300 MHz, $\left.\mathrm{CDCl}_{3}, \mathrm{ppm}\right): \delta 7.35(5 \mathrm{H}, \mathrm{m}), 5.5(3 \mathrm{H}, \mathrm{m}), 2.5(1 \mathrm{H}, \mathrm{m}), 1.7(6 \mathrm{H}, \mathrm{m}), 1.2$ (5H, m). ${ }^{13} \mathrm{C}$ NMR (300 MHz, $\left.\mathrm{CDCl}_{3}, \mathrm{ppm}\right): \delta 144.0,138.6,130.0,128.7,127.6,126.1$, 70.1, 37.1, 33.6, 33.3, 26.1, 26.0, 25.9. HRMS (EI) calcd. for $\mathrm{C}_{15} \mathrm{H}_{20} \mathrm{O}: 216.1514$, found: 216.1519.

1-(2-nitrophenyl)prop-2-en-1-ol (5b). To flame-dried, round-bottomed flask under argon atmosphere, added 2-nitrobenzaldehyde $(7.5 \mathrm{~g}, 50 \mathrm{mmol})$ and ether $(100 \mathrm{~mL})$. Placed in ice bath and let stir approximately 10 minutes. Added 1.0 M THF solution of vinylmagnesium bromide dropwise, over approximately 30 minutes. Let stir at $0{ }^{\circ} \mathrm{C}$ for 1 hour, then slowly added $150 \mathrm{~mL}$ aqueous dilute acid, extracted 3 times with $100 \mathrm{~mL}$ ether, and dried with $\mathrm{Na}_{2} \mathrm{SO}_{4}$. Purified via silica gel chromatography (7:3 pentane:ether) to obtain approximately $1.8 \mathrm{~g}$ of a reddish-brown oil (20\% yield). ${ }^{1} \mathrm{H}$ NMR $(300 \mathrm{MHz}, \mathrm{CDCl}-$ 3, ppm): $\delta 7.92(1 \mathrm{H}, \mathrm{dd}, J=8.1,1.2 \mathrm{~Hz}), 7.77(1 \mathrm{H}, \mathrm{dd}, J=7.8,1.5 \mathrm{~Hz}), 7.65(1 \mathrm{H}, \mathrm{td}, J=$ 7.6, $1.2 \mathrm{~Hz}), 7.45(1 \mathrm{H}$, ddd, $J=8.3,7.4,1.5 \mathrm{~Hz}), 6.09(1 \mathrm{H}, \mathrm{ddd}, J=17.3,10.4,5.3 \mathrm{~Hz})$, 
$5.80(1 \mathrm{H}, \mathrm{dt}, J=5.1,1.5 \mathrm{~Hz}), 5.42(1 \mathrm{H}, \mathrm{dt}, J=17.1,1.4 \mathrm{~Hz}), 5.27(1 \mathrm{H}, \mathrm{dt}, J=10.5,1.4$ $\mathrm{Hz}), 2.6(1 \mathrm{H}, \mathrm{br}) .{ }^{13} \mathrm{C} \mathrm{NMR}\left(300 \mathrm{MHz}, \mathrm{CDCl}_{3}, \mathrm{ppm}\right): \delta 148.5,138.1,137.7,133.8,129.1$, 128.7, 124.8, 116.4, 70.2. HRMS (CI) calcd. for $\mathrm{C}_{9} \mathrm{H}_{9} \mathrm{NO}_{3}+\mathrm{NH}_{4}$ : 197.0926 , found: 197.0918.

1-(2-methoxyphenyl)prop-2-en-1-ol (5c). Followed same procedure as for $\mathbf{5 b}$ using $\boldsymbol{o}$ anisaldehyde (5.5 mL, $46 \mathrm{mmol})$, ether (90 mL), and 1.0 THF solution of vinylmagnesium bromide (90 mL, $90 \mathrm{mmol})$. Purified via silica gel chromatography (7:3 hexanes:ethyl acetate) to obtain $6.7 \mathrm{~g}$ of a yellow oil (89\% yield). ${ }^{1} \mathrm{H}$ NMR $\left(300 \mathrm{MHz}, \mathrm{CDCl}_{3}, \mathrm{ppm}\right): \delta$ $7.2(2 \mathrm{H}, \mathrm{m}), 6.85(2 \mathrm{H}, \mathrm{m}), 6.07(1 \mathrm{H}, \mathrm{ddd}, J=17.3,10.4,5.6 \mathrm{~Hz}), 5.34(1 \mathrm{H}, \mathrm{t}, J=5.7 \mathrm{~Hz})$, $5.24(1 \mathrm{H}, \mathrm{d}, J=17.4 \mathrm{~Hz}), 5.10(1 \mathrm{H}, \mathrm{d}, J=10.5 \mathrm{~Hz}), 3.79(3 \mathrm{H}, \mathrm{s}), 2.70(1 \mathrm{H}, \mathrm{d}, J=6.0 \mathrm{~Hz})$. ${ }^{13} \mathrm{C}$ NMR (300 MHz, $\left.\mathrm{CDCl}_{3}, \mathrm{ppm}\right): \delta 156.9,139.6,130.9,129.0,127.6,121.1,114.7$, 110.9, 71.8, 55.6. HRMS (EI) calcd. for $\mathrm{C}_{10} \mathrm{H}_{12} \mathrm{O}_{2}$ : 164.0837, found: 164.0839 .

(E)-3-(2-nitrophenyl)prop-2-en-1-ol (6b). In glove box, added 1 (4 mg, $0.008 \mathrm{mmol})$ to 4$\mathrm{mL}$ vial. Removed from glove box, added $\mathrm{CH}_{2} \mathrm{Cl}_{2}(2 \mathrm{~mL})$, and let stir at room temperature for approximately 10 minutes. Added $\mathbf{5 b}(71.9 \mathrm{mg}, 0.4 \mathrm{mmol})$ via syringe and let stir at room temperature for 30 minutes. Added $20 \mu \mathrm{L}$ triethylamine, concentrated in vacuo, and purified directly via silica gel chromatography (7:3 pentane:ether) to obtain $70.5 \mathrm{mg}$ of a clear oil (98\% yield). ${ }^{1} \mathrm{H}$ NMR (300 MHz, $\left.\mathrm{CDCl}_{3}, \mathrm{ppm}\right): \delta 7.90(1 \mathrm{H}, \mathrm{dd}, J=8.3,1.1 \mathrm{~Hz})$, $7.80(2 \mathrm{H}, \mathrm{m}), 7.38(1 \mathrm{H}, \mathrm{ddd}, J=8.4,6.8,2.0 \mathrm{~Hz}), 7.07(1 \mathrm{H}, \mathrm{dt}, J=15.9,1.7 \mathrm{~Hz}), 6.34$ $(1 \mathrm{H}, \mathrm{dt}, J=15.6,5.3 \mathrm{~Hz}), 4.37(2 \mathrm{H}, \mathrm{dd}, J=5.3,1.7 \mathrm{~Hz}), 2.31(1 \mathrm{H}, \mathrm{br}) .{ }^{13} \mathrm{C} \mathrm{NMR}(300$ 
$\left.\mathrm{MHz}, \mathrm{CDCl}_{3}, \mathrm{ppm}\right): \delta 147.9,134.3,133.3,132.7,128.9,128.3,125.9,124.7,63.4$. HRMS (EI) calcd. for $\mathrm{C}_{9} \mathrm{H}_{9} \mathrm{NO}_{3}$ : 179.0582, found: 179.0584 .

(E)-3-(2-methoxyphenyl)prop-2-en-1-ol (6c). Followed same procedure as for $\mathbf{3}$ using $\mathbf{1}$ (4 $\mathrm{mg}, 0.008 \mathrm{mmol}), \mathbf{5 c}(65.6 \mathrm{mg}, 0.4 \mathrm{mmol})$, and ether $(2 \mathrm{~mL})$. Purified via silica gel chromatography (7:3 pentane:ether) to obtain $42.3 \mathrm{mg}$ of an oil (65\% yield). ${ }^{1} \mathrm{H}$ NMR (300 $\left.\mathrm{MHz}, \mathrm{CDCl}_{3}, \mathrm{ppm}\right): \delta 7.45(1 \mathrm{H}, \mathrm{dd}, J=7.7,1.7 \mathrm{~Hz}), 7.25(1 \mathrm{H}, \mathrm{ddd}, J=8.1,7.4,1.8 \mathrm{~Hz})$, $6.93(3 \mathrm{H}, \mathrm{m}), 6.39(1 \mathrm{H}, \mathrm{dt}, J=16.2,5.9 \mathrm{~Hz}), 4.33(1 \mathrm{H}, \mathrm{dd}, J=6.0,1.5 \mathrm{~Hz}), 3.86(3 \mathrm{H}, \mathrm{s})$, $1.74(1 \mathrm{H}, \mathrm{br}) .{ }^{13} \mathrm{C} \mathrm{NMR}\left(300 \mathrm{MHz}, \mathrm{CDCl}_{3}, \mathrm{ppm}\right): \delta 156.9,129.5,128.9,127.2,126.3$, 125.9, 120.8, 111.0, 64.4, 55.6. HRMS (EI) calcd. for $\mathrm{C}_{10} \mathrm{H}_{12} \mathrm{O}_{2}$ : 164.0837, found: 164.0837.

(E)-1-phenylnon-2-en-1-ol (7a). Followed same procedure as for 2 using 1-phenyl-2propenyl acetate $(2.4 \mathrm{~mL}, 15 \mathrm{mmol}), 1$-octene $(2.0 \mathrm{~mL}, 12.7 \mathrm{mmol})$, $\mathrm{RuCl}_{2}\left(\mathrm{PCy}_{3}\right)\left(\mathrm{H}_{2} \mathrm{IMes}\right) \mathrm{CHPh}(270 \mathrm{mg}, 0.32 \mathrm{mmol})$, and $\mathrm{CH}_{2} \mathrm{Cl}_{2}(40 \mathrm{~mL})$. Purified via silica gel chromatography (8:2 pentane:ether, 2 sequential columns) to obtain $1.5 \mathrm{~g}$ of a yellow oil (54\% yield). ${ }^{1} \mathrm{H}$ NMR (300 MHz, $\left.\mathrm{CDCl}_{3}, \mathrm{ppm}\right): \delta 7.35(5 \mathrm{H}, \mathrm{m}), 5.75(2 \mathrm{H}, \mathrm{m}), 5.18$ $(1 \mathrm{H}, \mathrm{dd}, J=6.0,2.4 \mathrm{~Hz}), 2.07(2 \mathrm{H}, \mathrm{dt}, J=6.7,6.7 \mathrm{~Hz}), 1.91(1 \mathrm{H}, \mathrm{d}, J=3.0 \mathrm{~Hz}), 1.3(8 \mathrm{H}$, m), $0.89(3 \mathrm{H}, \mathrm{t}, J=6.6 \mathrm{~Hz}) .{ }^{13} \mathrm{C} \mathrm{NMR}\left(300 \mathrm{MHz}, \mathrm{CDCl}_{3}, \mathrm{ppm}\right): \delta 143.6,133.1,132.4$, $128.7,127.7,126.4,75.4,32.4,31.9,29.2,29.1,22.8,14.3$. HRMS (EI) calcd. for $\mathrm{C}_{15} \mathrm{H}_{22} \mathrm{O}: 218.1671$, found: 218.1666 . 
(E)-1-(2-nitrophenyl)non-2-en-1-ol (7b). Followed same procedure as for $\mathbf{2}$ using 1-(2nitrophenyl)allyl acetate $(1.3 \mathrm{~mL}, 7.6 \mathrm{mmol}), 1$-octene $(1.0 \mathrm{~mL}, 6.4 \mathrm{mmol})$, $\mathrm{RuCl}_{2}\left(\mathrm{PCy}_{3}\right)\left(\mathrm{H}_{2} \mathrm{IMes}\right) \mathrm{CHPh}(135 \mathrm{mg}, 0.16 \mathrm{mmol})$, and $\mathrm{CH}_{2} \mathrm{Cl}_{2}(32 \mathrm{~mL})$. Purified via silica gel chromatography (7:3 pentane:ether) to obtain $650 \mathrm{mg}$ of an orange oil (39\% yield). ${ }^{1} \mathrm{H}$ NMR (300 MHz, $\left.\mathrm{CDCl}_{3}, \mathrm{ppm}\right): \delta 7.88(1 \mathrm{H}, \mathrm{dd}, J=8.4,1.2 \mathrm{~Hz}), 7.79(1 \mathrm{H}, \mathrm{dd}, J=8.0,1.4$ Hz), $7.63(1 \mathrm{H}, \mathrm{td}, J=7.6,1.3 \mathrm{~Hz}), 7.43(1 \mathrm{H}, \mathrm{ddd}, J=8.0,7.3,1.4 \mathrm{~Hz}), 5.8(2 \mathrm{H}, \mathrm{m}), 5.7$ $(1 \mathrm{H}, \mathrm{m}), 2.41(1 \mathrm{H}, \mathrm{br}), 2.05(2 \mathrm{H}, \mathrm{dt}, J=7.0,7.0 \mathrm{~Hz}), 1.3(8 \mathrm{H}, \mathrm{m}), 0.88(3 \mathrm{H}, \mathrm{t}, J=6.8 \mathrm{~Hz})$. ${ }^{13} \mathrm{C}$ NMR (300 MHz, $\left.\mathrm{CDCl}_{3}, \mathrm{ppm}\right): \delta 148.5,138.4,134.4,133.5,129.9,128.7,128.4$, 124.7, 70.2, 32.4, 31.9, 29.1, 29.0, 22.8, 14.3. HRMS (EI) calcd. for $\mathrm{C}_{15} \mathrm{H}_{21} \mathrm{NO}_{3}-\mathrm{H}$ : 262.1438, found: 262.1439 .

(E)-1-(2-methoxyphenyl)non-2-en-1-ol (7c). Followed same procedure as for 2 using 1-(2methoxyphenyl)prop-2-en-1-ol (2.5 mL, $14.5 \mathrm{mmol})$, 1-octene $(2.0 \mathrm{~mL}, 12.7 \mathrm{mmol})$, $\mathrm{RuCl}_{2}\left(\mathrm{PCy}_{3}\right)\left(\mathrm{H}_{2} \mathrm{IMes}\right) \mathrm{CHPh}(270 \mathrm{mg}, 0.32 \mathrm{mmol})$, and $\mathrm{CH}_{2} \mathrm{Cl}_{2}(40 \mathrm{~mL})$. Purified via silica gel chromatography (8:2 pentane:ether) to obtain $1.5 \mathrm{~g}$ of a yellow oil (48\% yield). ${ }^{1} \mathrm{H}$ NMR (300 MHz, $\left.\mathrm{CDCl}_{3}, \mathrm{ppm}\right): \delta 7.20(2 \mathrm{H}, \mathrm{m}), 6.86(2 \mathrm{H}, \mathrm{m}), 5.65(2 \mathrm{H}, \mathrm{m}), 5.28(1 \mathrm{H}, \mathrm{d}, J$ $=5.7 \mathrm{~Hz}), 3.79(3 \mathrm{H}, \mathrm{s}), 2.68(1 \mathrm{H}, \mathrm{d}, J=6.0 \mathrm{~Hz}), 1.97(2 \mathrm{H}, \mathrm{m}), 1.25(8 \mathrm{H}, \mathrm{m}), 0.80(3 \mathrm{H}, \mathrm{t}, J$ $=6.8 \mathrm{~Hz}) .{ }^{13} \mathrm{C} \mathrm{NMR}\left(300 \mathrm{MHz}, \mathrm{CDCl}_{3}, \mathrm{ppm}\right): \delta 156.9,132.4,131.8,131.2,128.7,127.6$, 121.0, 110.9, 71.9, 55.6, 32.5, 31.9, 29.3, 29.1, 22.8, 14.3. HRMS (EI) calcd. for $\mathrm{C}_{16} \mathrm{H}_{24} \mathrm{O}_{2}: 248.1776$, found: 248.1780 . 
(E)-1-phenylnon-1-en-3-ol (8a). Followed same procedure as for $\mathbf{3}$ using $\mathbf{1}$ (4 mg, 0.008 $\mathrm{mmol}), 7 \mathbf{a}(84.8 \mathrm{mg}, 0.4 \mathrm{mmol})$, and ether $(2 \mathrm{~mL})$. Purified via silica gel chromatography (8:2 pentane:ether) to obtain $83.6 \mathrm{mg}$ of a clear oil (98\% yield). ${ }^{1} \mathrm{H}$ NMR $(300 \mathrm{MHz}, \mathrm{CD}-$ $\left.\mathrm{Cl}_{3}, \mathrm{ppm}\right): \delta 7.35(5 \mathrm{H}, \mathrm{m}), 6.60(1 \mathrm{H}, \mathrm{d}, J=15.9 \mathrm{~Hz}), 6.25(1 \mathrm{H}, \mathrm{dd}, J=15.9,6.9 \mathrm{~Hz}), 4.30$ $(1 \mathrm{H}, \mathrm{dt}, J=6.3,6.3 \mathrm{~Hz}), 1.65(3 \mathrm{H}, \mathrm{m}), 1.4(8 \mathrm{H}, \mathrm{m}), 0.91(3 \mathrm{H}, \mathrm{t}, J=6.8 \mathrm{~Hz}) .{ }^{13} \mathrm{C} \mathrm{NMR}$ (300 $\left.\mathrm{MHz}, \mathrm{CDCl}_{3}, \mathrm{ppm}\right): \delta 137.0,132.8,130.4,128.8,127.8,126.7,73.3,37.6,32.0$, 29.5, 25.6, 22.8, 14.3. HRMS (EI) calcd. for $\mathrm{C}_{15} \mathrm{H}_{22} \mathrm{O}: 218.1671$, found: 218.1670 .

When performed in $\mathrm{CH}_{2} \mathrm{Cl}_{2}$ at room temperature, the reaction resulted in the following:<smiles>OC(/C=C/C=[W]=[W])c1ccccc1</smiles>
$(E: Z=11: 1)$

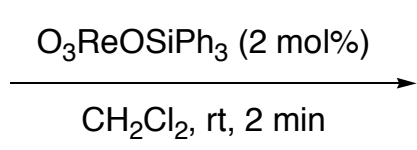

$\mathrm{CH}_{2} \mathrm{Cl}_{2}, \mathrm{rt}, 2 \mathrm{~min}$<smiles>O=C(O)NCC(O)C=Cc1ccccc1</smiles>
$(E: Z>20: 1)$<smiles>CCCCCCCCCCCCCCCCCCC(=CC=Cc1ccccc1)OC(C=Cc1ccccc1)c1ccccc1</smiles><smiles>O=C(O)CC=CC(OC(C=Cc1ccccc1)c1ccccc1)c1ccccc1</smiles>
$55 \%$<smiles>OCCOC=CC=Cc1ccccc1</smiles>
$30 \%$ $(E: Z=2: 1)$

Note that these numbers do not represent a quantitative determination of yield. They were calculated from the relative amounts of the various products observed in the crude reaction mixture (after quenching with triethylamine) by ${ }^{1} \mathrm{H}$ NMR spectroscopy. No starting material was visible by ${ }^{1} \mathrm{H}$ NMR spectroscopy in this mixture. 
(E)-1-(2-nitrophenyl)non-1-en-3-ol (8b). Followed same procedure as for $\mathbf{6 b}$ using $\mathbf{1}$ (4 mg, $0.008 \mathrm{mmol})$, 7b (104.8 mg, $0.4 \mathrm{mmol})$, and ether $(2 \mathrm{~mL})$. Purified via silica gel chromatography (1:1 pentane:ether) to obtain $104.2 \mathrm{mg}$ of a reddish oil (98\% yield). ${ }^{1} \mathrm{H}$ NMR (300 MHz, $\left.\mathrm{CDCl}_{3}, \mathrm{ppm}\right): \delta 7.91(1 \mathrm{H}, \mathrm{dd}, J=8.3,0.8 \mathrm{~Hz}), 7.57(2 \mathrm{H}, \mathrm{m}), 7.38(1 \mathrm{H}$, ddd, $J=8.4,6.8,2.0 \mathrm{~Hz}), 7.02(1 \mathrm{H}, \mathrm{dd}, J=15.6,0.6 \mathrm{~Hz}), 6.20(1 \mathrm{H}, \mathrm{dd}, J=15.9,6.6 \mathrm{~Hz})$, $4.33(1 \mathrm{H}, \mathrm{dt}, J=6.2,6.2 \mathrm{~Hz}), 2.1(1 \mathrm{H}, \mathrm{br}), 1.65(2 \mathrm{H}, \mathrm{m}), 1.35(8 \mathrm{H}, \mathrm{m}), 0.88(3 \mathrm{H}, \mathrm{t}, J=6.8$ $\mathrm{Hz}) .{ }^{13} \mathrm{C}$ NMR $\left(300 \mathrm{MHz}, \mathrm{CDCl}_{3}, \mathrm{ppm}\right): \delta 148.0,138.3,133.2,132.8,128.9,128.2$, 125.4, 124.7, 77.7, 37.3, 31.9, 29.4, 25.5, 22.8, 14.3. HRMS (EI) calcd. for $\mathrm{C}_{15} \mathrm{H}_{21} \mathrm{NO}_{3}-$ H: 262.1438 , found: 262.1439 .

(E)-1-(2-methoxyphenyl)non-1-en-3-ol (8c). Followed same procedure as for $\mathbf{3}$ using $\mathbf{1}$ (4 mg, $0.008 \mathrm{mmol}), 7 \mathbf{c}(99.5 \mathrm{mg}, 0.4 \mathrm{mmol})$, and ether $(2 \mathrm{~mL})$. Purified via silica gel chromatography (8:2 pentane:ether) to obtain $67.4 \mathrm{mg}$ of a clear oil (68\% yield). ${ }^{1} \mathrm{H}$ NMR (300 MHz, $\left.\mathrm{CDCl}_{3}, \mathrm{ppm}\right): \delta 7.45(1 \mathrm{H}, \mathrm{dd}, J=7.5,1.8 \mathrm{~Hz}), 7.24(1 \mathrm{H}, \mathrm{m}), 6.90(3 \mathrm{H}, \mathrm{m})$, $6.24(1 \mathrm{H}, \mathrm{dd}, J=16.1,7.1 \mathrm{~Hz}), 4.29(1 \mathrm{H}, \mathrm{dt}, J=6.6,6.6 \mathrm{~Hz}), 3.86(3 \mathrm{H}, \mathrm{s}), 1.5(11 \mathrm{H}, \mathrm{m})$, $0.90(3 \mathrm{H}, \mathrm{t}, J=6.8 \mathrm{~Hz}) .{ }^{13} \mathrm{C} \mathrm{NMR}\left(300 \mathrm{MHz}, \mathrm{CDCl}_{3}, \mathrm{ppm}\right): \delta 156.9,133.5,128.9,127.0$, 125.9, 125.2, 120.8, 111.0, 73.8, 55.6, 37.5, 32.0, 29.5, 25.7, 22.8, 14.3. HRMS (EI) calcd. for $\mathrm{C}_{16} \mathrm{H}_{24} \mathrm{O}_{2}$ : 248.1776, found: 248.1783 .

(E)-1-(thiophen-2-yl)non-2-en-1-ol (9). Step 1. To flame-dried, round-bottomed flask under argon atmosphere, added 1-octyne (5 mL, $34 \mathrm{mmol})$ and ether $(30 \mathrm{~mL})$. Placed in dry ice/acetone bath and let stir for approximately 10 minutes. Added a 1.6 hexanes solution of $n$-butyllithium ( $16 \mathrm{~mL}, 26 \mathrm{mmol})$ dropwise and let stir at $-78{ }^{\circ} \mathrm{C}$ for 1 hour. 
Added a solution of 2-thiophene-carboxaldehyde (2 mL, $22 \mathrm{mmol})$ and ether $(5 \mathrm{~mL})$ dropwise and let stir at $-78{ }^{\circ} \mathrm{C}$ for 1 hour. Removed dry ice/acetone bath and let stir for 1.5 hours. Placed in ice bath, slowly added $50 \mathrm{~mL}$ aqueous ammonium chloride, extracted 3 times with $50 \mathrm{~mL}$ ether, and dried with $\mathrm{Na}_{2} \mathrm{SO}_{4}$. Purified via silica gel chromatography (8:2 pentane:ether) to obtain $3.4 \mathrm{~g}(69 \%$ yield) of 1-(thiophen-2-yl)non-2-yn-1-olii as a bright yellow oil (contained ca. 15\% 2-thiophene-carboxaldehyde). Step 2. Added this product mixture and THF (120 mL) to flame-dried, round-bottomed flask under argon atmosphere. Placed in ice bath and let stir for approximately 10 minutes. Added a 1.0 THF solution of lithium aluminum hydride $(50 \mathrm{~mL}, 50 \mathrm{mmol})$ dropwise and removed ice bath shortly thereafter. Let stir at room temperature for 28 hours. Placed in ice bath, slowly added $100 \mathrm{~mL}$ ethyl acetate and several scoops of $\mathrm{Na}_{2} \mathrm{SO}_{4} \bullet \mathrm{H}_{2} \mathrm{O}$. Removed ice bath, let stir for approximately 20 minutes, and then filtered through Celite, rinsing with ether. Purified via silica gel chromatography (8:2 pentane:ether) to obtain $2.3 \mathrm{~g}$ of a yellow oil (67\% yield). ${ }^{1} \mathrm{H}$ NMR (300 $\left.\mathrm{MHz}, \mathrm{CDCl}_{3}, \mathrm{ppm}\right): \delta 7.26(1 \mathrm{H}, \mathrm{m}), 6.98(2 \mathrm{H}, \mathrm{m}), 5.80(2 \mathrm{H}$, m), $5.39(1 \mathrm{H}, \mathrm{m}), 2.08(3 \mathrm{H}, \mathrm{m}), 1.34(8 \mathrm{H}, \mathrm{m}), 0.89(3 \mathrm{H}, \mathrm{t}, J=6.9 \mathrm{~Hz}) .{ }^{13} \mathrm{C} \mathrm{NMR}(300$ $\left.\mathrm{MHz}, \mathrm{CDCl}_{3}, \mathrm{ppm}\right): \delta 147.9,133.7,131.6,126.9,125.2,124.2,71.3,32.3,31.9,29.1$, 29.0, 22.8, 14.3. HRMS (EI) calcd. for $\mathrm{C}_{13} \mathrm{H}_{20} \mathrm{OS}$ : 224.1235, found: 224.1233 .

(E)-1-(thiophen-2-yl)non-1-en-3-ol (10). Followed same procedure as for $\mathbf{3}$ using $\mathbf{1}$ (4 mg, $0.008 \mathrm{mmol}), 9(89.9 \mathrm{mg}, 0.4 \mathrm{mmol})$, and ether $(2 \mathrm{~mL})$ with a 15 minute reaction time. Purified via silica gel chromatography (8:2 pentane:ether) to obtain $89.6 \mathrm{mg}$ of an oil (92\% yield). ${ }^{1} \mathrm{H} \mathrm{NMR}\left(300 \mathrm{MHz}, \mathrm{CDCl}_{3}, \mathrm{ppm}\right): \delta 7.16(1 \mathrm{H}, \mathrm{m}), 6.96(2 \mathrm{H}, \mathrm{m}), 6.71(1 \mathrm{H}, \mathrm{dd}, J=$ 15.8, $0.8 \mathrm{~Hz}), 6.07(1 \mathrm{H}, \mathrm{dd}, J=15.9,6.6 \mathrm{~Hz}), 4.24(1 \mathrm{H}, \mathrm{dt}, J=6.6,6.6 \mathrm{~Hz}), 1.76(1 \mathrm{H}, \mathrm{br})$, 
$1.6(2 \mathrm{H}, \mathrm{m}), 1.35(8 \mathrm{H}, \mathrm{m}), 0.90(3 \mathrm{H}, \mathrm{t}, J=6.8 \mathrm{~Hz}) .{ }^{13} \mathrm{C} \mathrm{NMR}\left(300 \mathrm{MHz}, \mathrm{CDCl}_{3}, \mathrm{ppm}\right): \delta$ $142.1,132.5,127.5,125.9,124.4,123.5,73.0,37.5,32.0,29.4,25.6,22.8,14.3$. HRMS (EI) calcd. for $\mathrm{C}_{13} \mathrm{H}_{20} \mathrm{OS}: 224.1235$, found: 224.1229 .

2-phenylbut-3-en-2-ol (11). To flame-dried, round-bottomed flask under argon atmosphere, added acetophenone $(6 \mathrm{~mL}, 51 \mathrm{mmol})$ and ether $(100 \mathrm{~mL})$. Placed in ice bath and let stir for approximately 10 minutes. Added a $1.0 \mathrm{M}$ THF solution of vinylmagnesium bromide $(100 \mathrm{~mL}, 100 \mathrm{mmol})$ dropwise. Let sir for 30 minutes at $0{ }^{\circ} \mathrm{C}$ and 1 hour at room temperature. Placed in ice bath, slowly added $100 \mathrm{~mL}$ aqueous ammonium chloride, extracted 3 times with $100 \mathrm{~mL}$ ether, and dried with $\mathrm{Na}_{2} \mathrm{SO}_{4}$. The crude product contained a small amount of the self-aldol product, 3-hydroxy-1,3diphenylbutan-1-one, which was difficult to separate by column chromatography. The following procedure was employed to convert this side product into the more separable 1,3-diphenylbut-2-en-1-one: Removed solvent in vacuo, then added a 3.0 M aqueous solution of $\mathrm{NaOH}(12 \mathrm{~mL}, 36 \mathrm{mmol})$, THF $(100 \mathrm{~mL})$, and $\mathrm{MeOH}(20 \mathrm{~mL})$. Let stir at room temperature for approximately 15 hours and worked up as before. Purified via silica gel chromatography (8:2 pentane:ether) to obtain approximately $2.2 \mathrm{~g}$ of a yellow oil (30\% yield). ${ }^{1} \mathrm{H}$ NMR (300 MHz, $\left.\mathrm{CDCl}_{3}, \mathrm{ppm}\right): \delta 7.55(2 \mathrm{H}, \mathrm{m}), 7.40(2 \mathrm{H}, \mathrm{m}), 7.30(1 \mathrm{H}, \mathrm{m})$, $6.22(1 \mathrm{H}, \mathrm{dd}, J=17.3,10.7 \mathrm{~Hz}), 5.34(1 \mathrm{H}, \mathrm{dd}, J=17.4,1.2 \mathrm{~Hz}), 5.19(1 \mathrm{H}, \mathrm{dd}, J=10.8$, $1.1 \mathrm{~Hz}), 1.93(1 \mathrm{H}, \mathrm{br}), 1.70(3 \mathrm{H}, \mathrm{s}) .{ }^{13} \mathrm{C}$ NMR $\left(300 \mathrm{MHz}, \mathrm{CDCl}_{3}, \mathrm{ppm}\right): \delta$ 146.6, 145.1, 128.5, 127.2, 125.4, 112.6, 75.0, 29.6. HRMS (EI) calcd. for $\mathrm{C}_{10} \mathrm{H}_{12} \mathrm{O}: 148.0888$, found: 148.0885 . 
3-phenylbut-2-en-1-ol (12). In glove box, added 1 (4 mg, $0.008 \mathrm{mmol})$ to 4-mL vial. Removed from glove box, added ether $(2 \mathrm{~mL})$ and $N, O$-bis(trimethylsilyl)-acetamide (120 $\mu \mathrm{L}, 0.485 \mathrm{mmol})$. Placed in Cryotrol set to $-10{ }^{\circ} \mathrm{C}$ and let stir for approximately 10 minutes. Added $11(59.4 \mathrm{mg}, 0.4 \mathrm{mmol})$ via syringe and let stir at $-10{ }^{\circ} \mathrm{C}$ for 30 minutes. Removed from cold bath, immediately added $20 \mu \mathrm{L}$ triethylamine, and removed solvent in vacuo. Added $\mathrm{MeOH}(2 \mathrm{~mL})$ and $\mathrm{K}_{2} \mathrm{CO}_{3}(110 \mathrm{mg}, 0.8 \mathrm{mmol})$, then let stir at room temperature for 1 hour. Added $2 \mathrm{~mL}$ aqueous ammonium chloride, extracted several times with $\mathrm{CH}_{2} \mathrm{Cl}_{2}$, and dried with $\mathrm{Na}_{2} \mathrm{SO}_{4}$. Purified via silica gel chromatography (8:2 pentane:ether) to obtain $54.4 \mathrm{mg}$ of an oil (92\% yield). (E-isomer). ${ }^{1} \mathrm{H}$ NMR $(300 \mathrm{MHz}$, $\left.\mathrm{CDCl}_{3}, \mathrm{ppm}\right): \delta 7.45(2 \mathrm{H}, \mathrm{m}), 7.34(3 \mathrm{H}, \mathrm{m}), 6.01(1 \mathrm{H}, \mathrm{dt}, J=6.68,1.4 \mathrm{~Hz}), 4.40(2 \mathrm{H}, \mathrm{d}, J$ $=6.6 \mathrm{~Hz}), 2.12(3 \mathrm{H}, \mathrm{s}), 1.74(1 \mathrm{H}, \mathrm{br}) .{ }^{13} \mathrm{C} \mathrm{NMR}\left(300 \mathrm{MHz}, \mathrm{CDCl}_{3}, \mathrm{ppm}\right): \delta$ 143.0, 138.0, 128.5, 127.5, 126.7, 126.0, 60.1, 16.2. HRMS (EI) calcd. for $\mathrm{C}_{10} \mathrm{H}_{12} \mathrm{O}:$ 148.0888, found: 148.0887. (Z-isomer). ${ }^{1} \mathrm{H} \mathrm{NMR}\left(300 \mathrm{MHz}, \mathrm{CDCl}_{3}, \mathrm{ppm}\right): \delta 7.35(3 \mathrm{H}, \mathrm{m}), 7.21(2 \mathrm{H}, \mathrm{m})$, $5.74(1 \mathrm{H}, \mathrm{dt}, J=7.05,1.3 \mathrm{~Hz}), 4.10(2 \mathrm{H}, \mathrm{dd}, J=6.9,1.2 \mathrm{~Hz}), 2.12(3 \mathrm{H}, \mathrm{s}), 1.53(1 \mathrm{H}, \mathrm{br})$. ${ }^{13} \mathrm{C}$ NMR (300 MHz, $\left.\mathrm{CDCl}_{3}, \mathrm{ppm}\right): \delta 141.0,140.4,128.3,127.9,127.4,126.3,60.5,25.5$. HRMS (EI) calcd. for $\mathrm{C}_{10} \mathrm{H}_{12} \mathrm{O}: 148.0888$, found: 148.0891 .

2-cyclohexylbut-3-en-2-ol (13). Followed same procedure as for 11 using cyclohexyl methyl ketone $(9 \mathrm{~mL}, 70 \mathrm{mmol})$, ether $(100 \mathrm{~mL})$, and a 1.0 THF solution of vinylmagnesium bromide $(100 \mathrm{~mL}, 100 \mathrm{mmol})$. Purified via silica gel chromatography (8:2 pentane:ether) to obtain $4.3 \mathrm{~g}$ of a yellow oil (40\% yield). ${ }^{1} \mathrm{H}$ NMR $(300 \mathrm{MHz}, \mathrm{CDCl}-$ $\left.{ }_{3}, \mathrm{ppm}\right): \delta 5.92(1 \mathrm{H}, \mathrm{dd}, J=17.4,10.8 \mathrm{~Hz}), 5.19(1 \mathrm{H}, \mathrm{dd}, J=17.4,1.5 \mathrm{~Hz}), 5.07(1 \mathrm{H}, \mathrm{dd}, J$ $=10.7,1.4 \mathrm{~Hz}), 1.7(5 \mathrm{H}, \mathrm{m}), 1.24(3 \mathrm{H}, \mathrm{s}), 1.2(7 \mathrm{H}, \mathrm{m}) \cdot{ }^{13} \mathrm{C} \mathrm{NMR}\left(300 \mathrm{MHz}, \mathrm{CDCl}_{3}\right.$, 
ppm): $\delta 144.6,112.1,75.5,48.2,27.6,27.2,26.8,26.7,26.6,25.3$. HRMS (EI) calcd. for $\mathrm{C}_{10} \mathrm{H}_{18} \mathrm{O}: 154.1358$, found: 154.1353 .

(E)-3-cyclohexylbut-2-en-1-ol (14). Followed same procedure as for 12 using 1 (4 mg, $0.008 \mathrm{mmol}), 13$ (61.9 mg, $0.4 \mathrm{mmol}), \mathrm{N}, O$-bis(trimethylsilyl)-acetamide (120 $\mu \mathrm{L}, 0.485$ $\mathrm{mmol})$, and ether $(2 \mathrm{~mL})$ with a reaction temperature of $0{ }^{\circ} \mathrm{C}$. Purified via silica gel chromatography (8:2 pentane:ether) to obtain $55.1 \mathrm{mg}$ of an oil (89\% yield). ${ }^{1} \mathrm{H}$ NMR (300 MHz, $\left.\mathrm{CDCl}_{3}, \mathrm{ppm}\right): \delta 5.38(1 \mathrm{H}, \mathrm{t}, J=6.8 \mathrm{~Hz}), 4.15(2 \mathrm{H}, \mathrm{d}, J=6.6 \mathrm{~Hz}), 1.7(7 \mathrm{H}, \mathrm{m})$, $1.64(3 \mathrm{H}, \mathrm{s}), 1.2(5 \mathrm{H}, \mathrm{m}) .{ }^{13} \mathrm{C} \mathrm{NMR}\left(300 \mathrm{MHz}, \mathrm{CDCl}_{3}, \mathrm{ppm}\right): \delta 144.9,121.7,59.6,47.3$, 31.9, 26.8, 26.5, 14.8. HRMS (EI) calcd. for $\mathrm{C}_{10} \mathrm{H}_{18} \mathrm{O}: 154.1358$, found: 154.1352 .

3,4,4-trimethylpent-1-en-3-ol (15). Followed same procedure as for $\mathbf{1 1}$ using pinacolone (6.5 mL, $52 \mathrm{mmol})$, ether $(100 \mathrm{~mL}, 100 \mathrm{mmol})$, and a $1.0 \mathrm{THF}$ solution of vinylmagnesium bromide (100 mL). Purified via silica gel chromatography (9:1 pentane:ether) to obtain 2.7 g of a yellow oil (40\% yield). ${ }^{1} \mathrm{H} \mathrm{NMR}\left(300 \mathrm{MHz}, \mathrm{CDCl}_{3}, \mathrm{ppm}\right): \delta 6.09(1 \mathrm{H}, \mathrm{dd}, J=17.6$, $10.7 \mathrm{~Hz}), 5.23(1 \mathrm{H}, \mathrm{dd}, J=17.4,1.5 \mathrm{~Hz}), 5.09(1 \mathrm{H}, \mathrm{dd}, J=11.0,1.7 \mathrm{~Hz}), 1.41(1 \mathrm{H}, \mathrm{br})$, $1.25(3 \mathrm{H}, \mathrm{s}), 0.95(9 \mathrm{H}, \mathrm{s}) .{ }^{13} \mathrm{C} \mathrm{NMR}\left(300 \mathrm{MHz}, \mathrm{CDCl}_{3}, \mathrm{ppm}\right): \delta 143.5,112.5,77.5,37.4$, 25.5, 23.5. HRMS (EI) calcd. for $\mathrm{C}_{8} \mathrm{H}_{16} \mathrm{O}: 128.1201$, found: 128.1196 .

(E)-3,4,4-trimethylpent-2-en-1-ol (16). Followed same procedure as for $\mathbf{1 2}$ using $\mathbf{1}$ (8 $\mathrm{mg}$, $0.016 \mathrm{mmol}), 15$ (50.9 mg, $0.4 \mathrm{mmol}), N, O$-bis(trimethylsilyl)-acetamide $(120 \mu \mathrm{L}, 0.485$ $\mathrm{mmol})$, and ether $(2 \mathrm{~mL})$ with a reaction temperature of $0{ }^{\circ} \mathrm{C}$ and a reaction time of 1 hour. Purified via silica gel chromatography (8:2 pentane:ether) to obtain $40.7 \mathrm{mg}$ of an oil ( $80 \%$ 
yield). ${ }^{1} \mathrm{H}$ NMR $\left(300 \mathrm{MHz}, \mathrm{CDCl}_{3}, \mathrm{ppm}\right): \delta 5.45(1 \mathrm{H}, \mathrm{tq}, J=6.5,1.1 \mathrm{~Hz}), 4.19(2 \mathrm{H}, \mathrm{dd}, J$ $=6.5,0.8 \mathrm{~Hz}), 1.66(3 \mathrm{H}, \mathrm{m}), 1.45(1 \mathrm{H}, \mathrm{br}), 1.05(9 \mathrm{H}, \mathrm{s}) .{ }^{13} \mathrm{C} \mathrm{NMR}\left(300 \mathrm{MHz}, \mathrm{CDCl}_{3}\right.$, ppm): $\delta 147.3,120.6,60.2,36.3,29.0,13.0$. HRMS (EI) calcd. for $\mathrm{C}_{8} \mathrm{H}_{16} \mathrm{O}: 128.1201$, found: 128.1207 .

3-methylhept-1-en-3-ol (17). Followed same procedure as for 11 using 2-hexanone (6.5 $\mathrm{mL}, 53 \mathrm{mmol})$, ether $(100 \mathrm{~mL})$, and a $1.0 \mathrm{THF}$ solution of vinylmagnesium bromide (100 $\mathrm{mL}, 100 \mathrm{mmol})$. Purified via silica gel chromatography (8:2 pentane:ether) to obtain $5.1 \mathrm{~g}$ of a yellow oil (67\% yield). ${ }^{1} \mathrm{H}$ NMR $\left(300 \mathrm{MHz}, \mathrm{CDCl}_{3}, \mathrm{ppm}\right): \delta 5.93(1 \mathrm{H}, \mathrm{dd}, J=17.3$, $10.7 \mathrm{~Hz}), 5.21(1 \mathrm{H}, \mathrm{dd}, J=17.4,1.2 \mathrm{~Hz}), 5.05(1 \mathrm{H}, \mathrm{dd}, J=10.7,1.4 \mathrm{~Hz}), 1.55(2 \mathrm{H}, \mathrm{m})$, $1.45(1 \mathrm{H}, \mathrm{br}), 1.3(4 \mathrm{H}, \mathrm{m}), 1.28(3 \mathrm{H}, \mathrm{s}), 0.91(3 \mathrm{H}, \mathrm{t}, J=6.9 \mathrm{~Hz}) .{ }^{13} \mathrm{C} \mathrm{NMR}(300 \mathrm{MHz}$, $\left.\mathrm{CDCl}_{3}, \mathrm{ppm}\right): \delta 145.5,111.7,73.5,42.3,27.9,26.3,23.3,14.3$. HRMS (EI) calcd. for $\mathrm{C}_{8} \mathrm{H}_{16} \mathrm{O}: 128.1201$, found: 128.1204 .

3-methylhept-2-en-1-ol (18). Followed same procedure as for 12 using $\mathbf{1}$ (41 mg, 0.08 mmol), 17 (513 mg, $4.0 \mathrm{mmol})$, N,O-bis(trimethylsilyl)-acetamide (1.19 mL, $4.79 \mathrm{mmol}$ ), and ether $(20 \mathrm{~mL})$ with a reaction temperature of $0{ }^{\circ} \mathrm{C}$. Purified via silica gel chromatography (7:3 pentane:ether) to obtain $485.7 \mathrm{mg}$ of an oil (93\% yield). ( $\boldsymbol{E}$-isomer). ${ }^{1} \mathrm{H} \mathrm{NMR}\left(300 \mathrm{MHz}, \mathrm{CDCl}_{3}, \mathrm{ppm}\right): \delta 5.40(1 \mathrm{H}, \mathrm{td}, J=6.9,0.9 \mathrm{~Hz}), 4.15(2 \mathrm{H}, \mathrm{d}, J=6.9$ $\mathrm{Hz}), 2.01(2 \mathrm{H}, \mathrm{t}, J=7.4 \mathrm{~Hz}), 1.67(3 \mathrm{H}, \mathrm{s}), 1.3(5 \mathrm{H}, \mathrm{m}), 0.90(3 \mathrm{H}, \mathrm{t}, J=7.1 \mathrm{~Hz}) .{ }^{13} \mathrm{C}$ NMR (300 MHz, $\left.\mathrm{CDCl}_{3}, \mathrm{ppm}\right): \delta 140.4,123.3,59.6,39.4,30.1,22.6,16.3,14.2$. HRMS (EI) calcd. for $\mathrm{C}_{8} \mathrm{H}_{16} \mathrm{O}: 128.1201$, found: 128.1195 . (Z-isomer). ${ }^{1} \mathrm{H}$ NMR (300 MHz, $\mathrm{CDCl}_{3}$, ppm): $\delta 5.42(1 \mathrm{H}, \mathrm{tt}, J=7.1,0.8 \mathrm{~Hz}), 4.13(2 \mathrm{H}, \mathrm{dd}, J=7.2,0.9 \mathrm{~Hz}), 2.08(2 \mathrm{H}, \mathrm{t}, J=7.4$ 
$\mathrm{Hz}), 1.74(3 \mathrm{H}, \mathrm{dt}, J=1.1,1.1 \mathrm{~Hz}), 1.35(5 \mathrm{H}, \mathrm{m}), 0.91(3 \mathrm{H}, \mathrm{t}, J=7.1 \mathrm{~Hz}) .{ }^{13} \mathrm{C}$ NMR $(300$ $\left.\mathrm{MHz}, \mathrm{CDCl}_{3}, \mathrm{ppm}\right): \delta 140.8,124.1,59.3,31.9,30.7,23.7,22.8,14.2$. HRMS (EI) calcd. for $\mathrm{C}_{8} \mathrm{H}_{16} \mathrm{O}: 128.1201$, found: 128.1195 .

$(R, E)$-1-phenylnon-2-en-1-ol (19). Step 1. Prepared 1-phenylnon-2-yn-1-oliii via the same procedure employed with 9 using 1-octyne (14 mL, $95 \mathrm{mmol})$, benzaldehyde $(6 \mathrm{~mL}, 59$ mmol), a 1.6 hexanes solution of $n$-butyllithium ( $40 \mathrm{~mL}, 64 \mathrm{mmol}$ ), and ether (100 mL). Purified via silica gel chromatography ( $8: 2$ pentane:ether) to obtain $10.6 \mathrm{~g}$ of an oil ( $83 \%$ yield). Step 2. To flame-dried, round-bottomed flask under argon atmosphere, added 1phenylnon-2-yn-1-ol (10.4 g, $48 \mathrm{mmol}), \mathrm{MnO}_{2}(49 \mathrm{~g}, 480 \mathrm{mmol})$, and benzene (200 mL). Let stir at room temperature for approximately 18 hours, then filtered through Celite, rinsing with ether. Purified via silica gel chromatography (9:1 pentane:ether) to obtain 9.0 $\mathrm{g}$ of 1-phenylnon-2-yn-1-one $\mathrm{i}^{\mathrm{iii}}$ as a yellow oil (87\% yield). Step 3. To a 3-neck, roundbottomed flask, added $4 \AA$ molecular sieves $(1 \mathrm{~g})$ and flame-dried under vacuum. Let cool to room temperature, placed under argon atmosphere, added 1-phenylnon-2-yn-1-one (2 $\mathrm{mL}, 9.9 \mathrm{mmol})$ and THF $(50 \mathrm{~mL})$, and let stir at room temperature for 3 hours. Added a 1.0 M toluene solution of (S)-2-methyl-CBS-oxazaborolidine $(25 \mathrm{~mL}, 25 \mathrm{mmol})$ and placed in dry ice/ethylene glycol:ethanol (8:2) bath. (Note: cold bath becomes solid, so flask should be placed in bath prior to dry ice addition.) When temperature had reached -30 to $-40{ }^{\circ} \mathrm{C}$ range, added a $2.0 \mathrm{M}$ THF solution of borane-methyl sulfide complex (25 $\mathrm{mL}, 50 \mathrm{mmol}$ ) dropwise, over approximately 15 minutes. Let stir at -30 to $-40{ }^{\circ} \mathrm{C}$ for 3 hours, then, very slowly, added $40 \mathrm{~mL} \mathrm{MeOH}$ and let warm to room temperature. Diluted with $150 \mathrm{~mL}$ ether, washed twice with $75 \mathrm{~mL}$ aqueous ammonium chloride, twice with 75 
$\mathrm{mL}$ aqueous sodium bicarbonate, twice with $75 \mathrm{~mL}$ brine, and dried with $\mathrm{Na}_{2} \mathrm{SO}_{4}$. Purified via silica gel chromatography (8:2 pentane:ether) to obtain $2.0 \mathrm{~g}$ of $(S)$-1-phenylnon-2-yn1-ol as a yellow oil (93\% yield). Enantiomeric excess was determined to be $99 \%$ by chiral HPLC (OD-H column, 4\% $i$-PrOH in hexanes, $1 \mathrm{~mL} / \mathrm{min}$ ). Step 4. Followed same procedure as for 9 using $(S)-1$-phenylnon-2-yn-1-ol (1.9 g, $8.9 \mathrm{mmol})$, a 1.0 M THF solution of lithium aluminum hydride $(27 \mathrm{~mL}, 27 \mathrm{mmol})$, and THF (60 mL) with a reaction time of 41 hours. Purified via silica gel chromatography (8:2 pentane:ether) to obtain 1.65 $\mathrm{g}$ of a yellow oil (85\% yield). Spectral data same as for 7a. Enantiomeric excess was determined by chiral HPLC (OD-H column, $2 \% i$-PrOH in hexanes, $1 \mathrm{~mL} / \mathrm{min}) .[\alpha]_{\mathrm{D}}=$ $-34.2\left(28{ }^{\circ} \mathrm{C}, \mathrm{CHCl}_{3}, \mathrm{c}=1.0\right)$. Literature value ${ }^{\mathrm{iv}}$ for $S$-enantiomer of $\mathbf{1 9}\left(94 \%\right.$ ee, $20{ }^{\circ} \mathrm{C}$, $\left.\mathrm{CHCl}_{3}, \mathrm{c}=2.0\right)=+34.4$.

$(R, E)$-1-phenylnon-1-en-3-ol (20) and (S,E)-1-phenylnon-1-en-3-ol (22). Followed same procedure as for 3 using $19(87.3 \mathrm{mg}, 0.4 \mathrm{mmol}), \mathbf{1}(6 \mathrm{mg}, 0.012 \mathrm{mmol})$, and ether $(2 \mathrm{~mL})$ with a reaction temperature of $-78^{\circ} \mathrm{C}$ and a reaction time of 2 hours. Purified via silica gel chromatography (8:2 pentane:ether) to obtain $81.2 \mathrm{mg}$ of $\mathbf{2 0}$ as a white solid (93\% yield). Spectral data same as for 8a. Enantiomeric excess determined by chiral HPLC (OJ column, 3\% I-PrOH in hexanes, $1 \mathrm{~mL} / \mathrm{min})$. Absolute stereochemistry confirmed by conversion of $\mathbf{2 0}$ to $\mathbf{2 0}$ ' according to the following procedure: To a $25-\mathrm{mL}$ round-

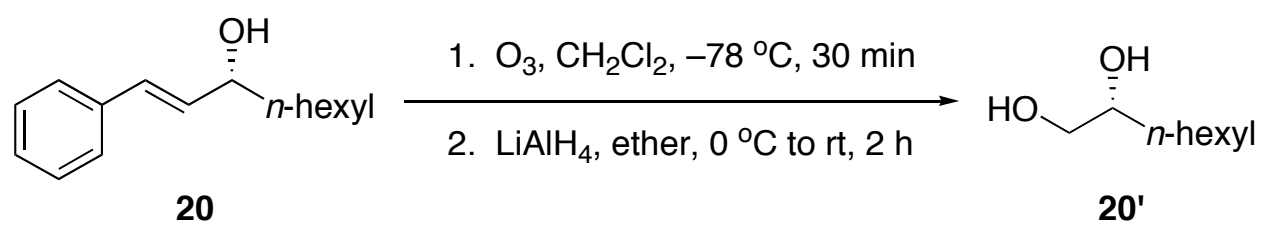
bottomed flask, added 20 ( $84 \%$ ee, $85 \mathrm{mg}, 0.4 \mathrm{mmol})$ and $\mathrm{CH}_{2} \mathrm{Cl}_{2}(5 \mathrm{~mL})$. Placed in dry ice/acetone bath and bubbled $\mathrm{O}_{3}$ through the solution. Monitored by TLC, and when all of 
20 had been consumed (about 30 minutes), stopped $\mathrm{O}_{3}$ flow, purged with $\mathrm{N}_{2}$ for 5 minutes, and placed in ice bath under argon atmosphere. Added ether $(5 \mathrm{~mL})$, and then slowly added a 1.0 ether solution of lithium aluminum hydride ( $800 \mu \mathrm{L}, 0.8 \mathrm{mmol})$. Removed ice bath and let stir for 2 hours. Replaced ice bath, slowly added $3 \mathrm{~mL}$ ethyl acetate and a little $\mathrm{Na}_{2} \mathrm{SO}_{4} \cdot \mathrm{H}_{2} \mathrm{O}$, removed ice bath, let stir for 15 minutes, and then filtered through Celite, rinsing with ether. Purified via silica gel chromatography (100\% ether) to obtain 27 mg of 20' (50\% yield). $[\alpha]_{\mathrm{D}}=+7.8\left(28^{\circ} \mathrm{C}, \mathrm{EtOH}, \mathrm{c}=0.9\right)$. Literature value ${ }^{\mathrm{v}}$ for $S$ enantiomer of 20' $\left(>99 \%\right.$ ee, $\left.25^{\circ} \mathrm{C}, \mathrm{EtOH}, \mathrm{c}=0.33\right)=-15.4$.

(R,Z)-1-phenylnon-2-en-1-ol (21). To a flame-dried, round-bottomed flask under argon atmosphere, added (S)-1-phenylnon-2-yn-1-ol (synthesis described for 19, $400 \mathrm{mg}, 1.8$ mmol), $\mathrm{CH}_{2} \mathrm{Cl}_{2}(5 \mathrm{~mL})$, and $\mathrm{N}, \mathrm{O}$-bis(trimethylsilyl)-acetamide (670 $\left.\mu \mathrm{L}, 2.7 \mathrm{mmol}\right)$. Let stir at room temperature for 2 hours. Removed solvent and excess reagents in vacuo, added Lindlar catalyst (5\% $\mathrm{Pd}$ on $\mathrm{CaCO}_{3}$, poisoned with $\mathrm{Pb}, 170 \mathrm{mg}$ ) and methanol (5 $\mathrm{mL}$ ). Degassed via 3 freeze-pump-thaw cycles and placed under $\mathrm{H}_{2}$ atmosphere. Let stir at room temperature for 4 hours. Filtered through Celite, rinsing with ether. Dried with $\mathrm{Na}_{2} \mathrm{SO}_{4}$ and removed solvent in vacuo. Removed trimethylsilyl group as described for $\mathbf{1 2}$. Crude ${ }^{1} \mathrm{H}$ NMR shows $Z: E=3: 1$. Purified by silica gel chromatography (9:1 pentane:ether) which afforded (with the sacrifice of a lot of material) $276 \mathrm{mg}$ of $\mathbf{2 1}$ (28\% yield, $Z: E=11: 1$, ca. $1 \%(S)$-1-phenylnon-2-yn-1-ol). ${ }^{1} \mathrm{H} \mathrm{NMR}\left(300 \mathrm{MHz}, \mathrm{CDCl}_{3}\right.$, ppm): $\delta 7.35(5 \mathrm{H}, \mathrm{m}), 5.6(3 \mathrm{H}, \mathrm{m}), 2.23(2 \mathrm{H}, \mathrm{m}), 2.02(1 \mathrm{H}, \mathrm{br}), 1.35(8 \mathrm{H}, \mathrm{m}), 0.92(3 \mathrm{H}, \mathrm{t}, J=6.8$ $\mathrm{Hz}) .{ }^{13} \mathrm{C}$ NMR (300 MHz, $\left.\mathrm{CDCl}_{3}, \mathrm{ppm}\right): \delta 144.0,132.6,132.1,128.7,127.6,126.1,69.9$, 31.9, 29.7, 29.2, 27.9, 22.8, 14.3. HRMS (EI) calcd. for $\mathrm{C}_{15} \mathrm{H}_{22} \mathrm{O}: 218.1671$, found: 
218.1672. Enantiomeric excess was determined by chiral HPLC (OB-H column, $3 \% i$ PrOH in hexanes, $1 \mathrm{~mL} / \mathrm{min}) .[\alpha]_{\mathrm{D}}=-136.0\left(29^{\circ} \mathrm{C}, \mathrm{CHCl}_{3}, \mathrm{c}=1.1\right)$. Literature value ${ }^{\mathrm{vi}}$ for $S$-enantiomer of $21\left(90 \%\right.$ ee, $\left.20-28{ }^{\circ} \mathrm{C}, \mathrm{CHCl}_{3}, \mathrm{c}=0.3-1.7\right)=+168.7$.

(i) The solvent columns are composed of activated alumina (A-2) and supported copper redox catalyst (Q-5 reactant). See: Pangborn, A. B.; Giardello, M. A.; Grubbs, R. H.; Rosen, R. K.; Timmers, F. J. Organometallics 1996, 15, 15181520.

(ii) Prepared by analogous procedure to that reported in Morrill, C.; Grubbs, R. H. $J$. Org. Chem. 2003, 68, 6031-6034.

(iii) Luo, F. -T.; Bajji, A. C.; Jeevanandam, A. J. Org. Chem. 1999, 64, 1738-1740.

(iv) Oppolzer, W.; Radinov, R. N. Helv. Chim. Acta 1992, 75, 170-173.

(v) Burk, M. J.; Kalberg, C. S.; Pizzano, A. J. Am. Chem. Soc. 1998, 120, 43454353.

(vi) Oppolzer, W.; Radinov, R. N. Tetrahedron Lett. 1991, 32, 5777-5780. 

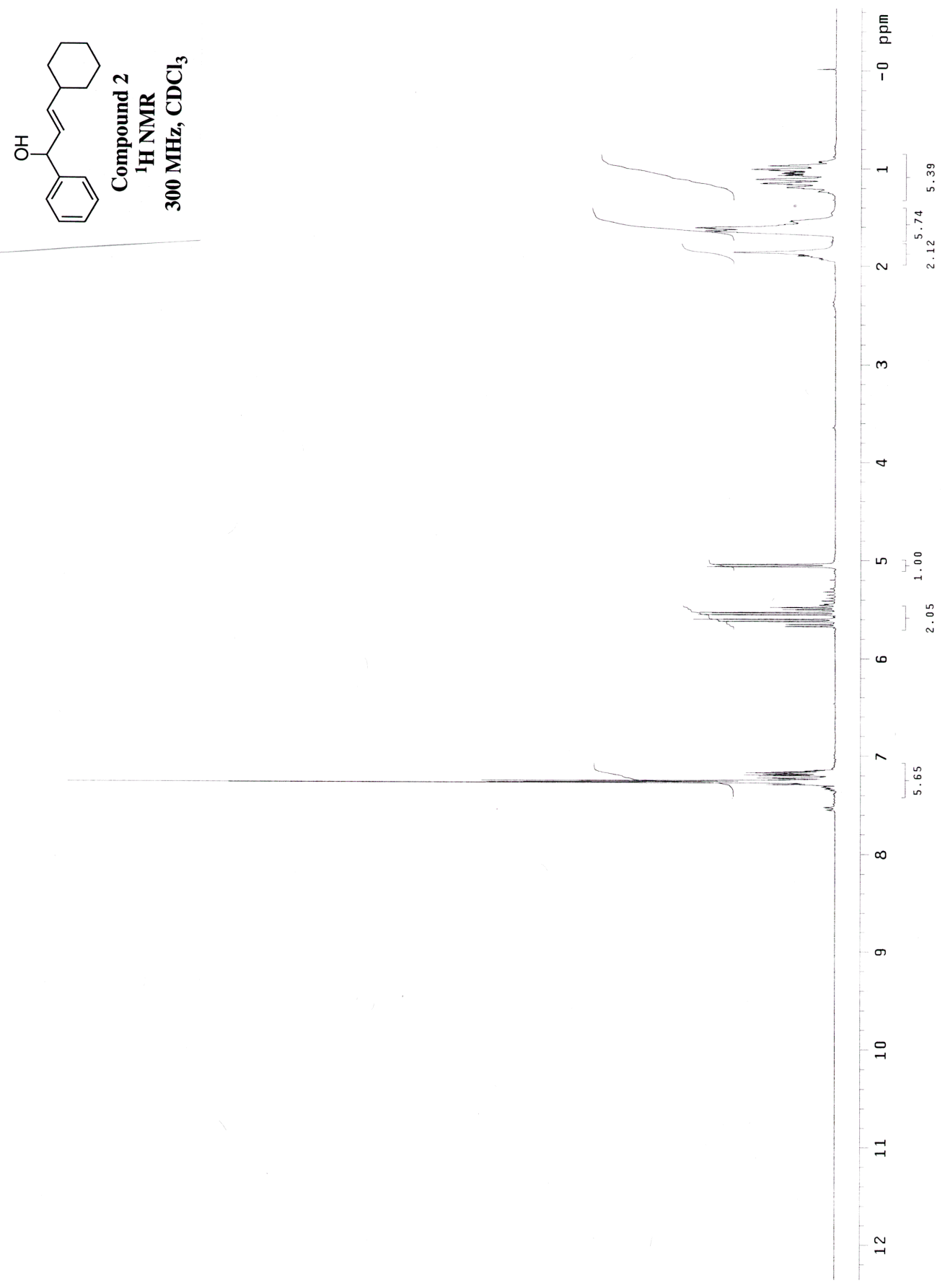

S19 

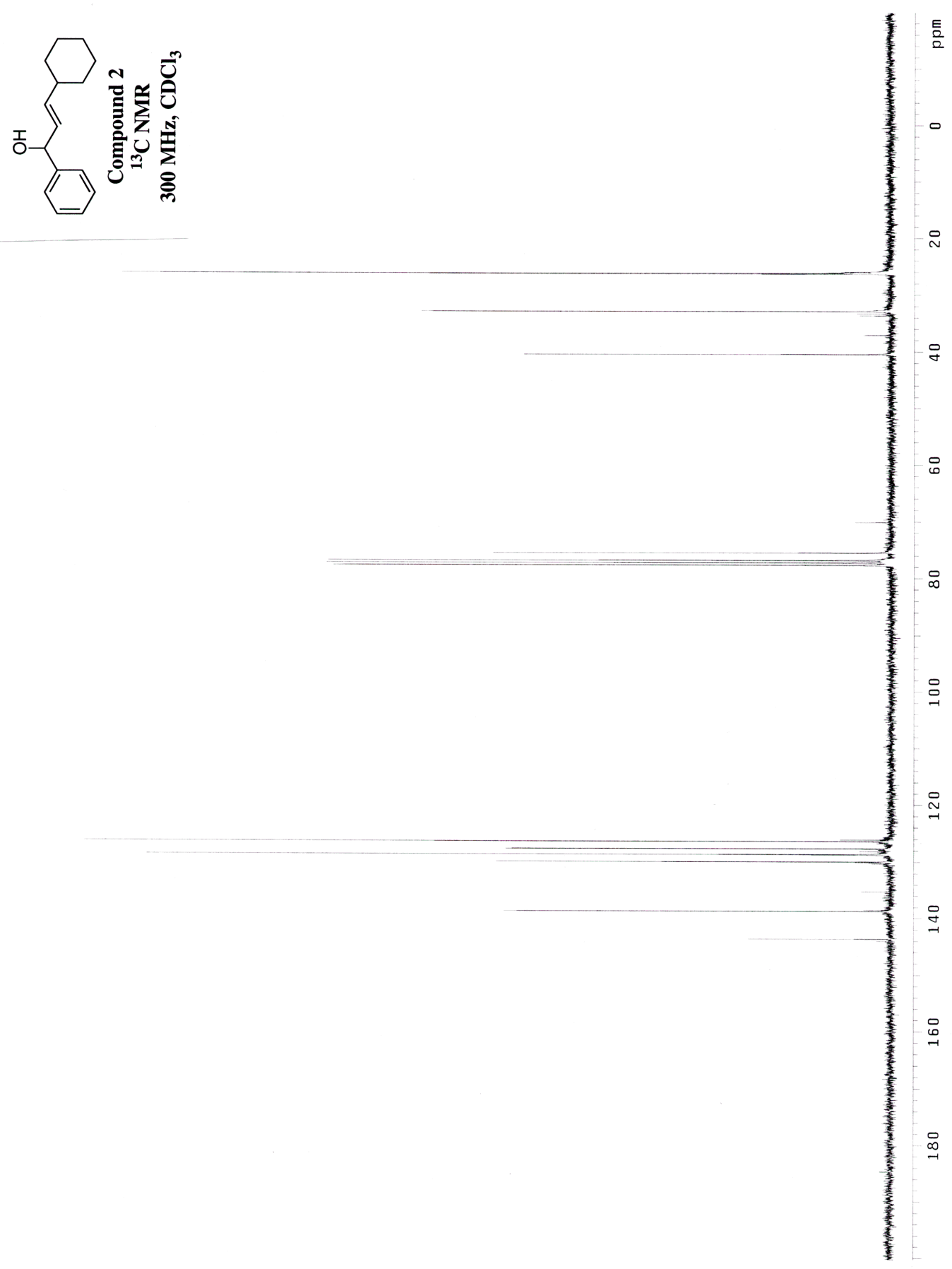


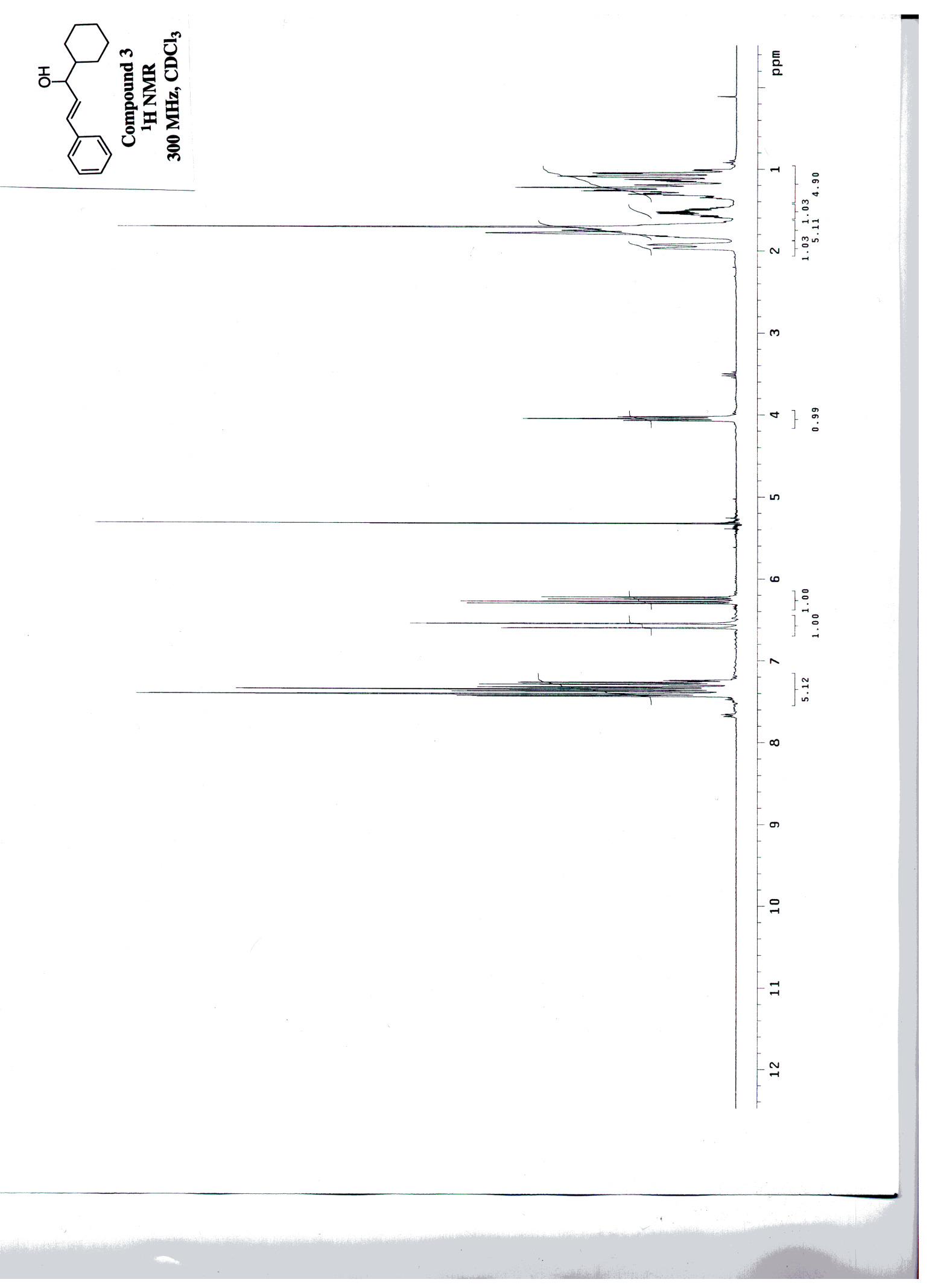



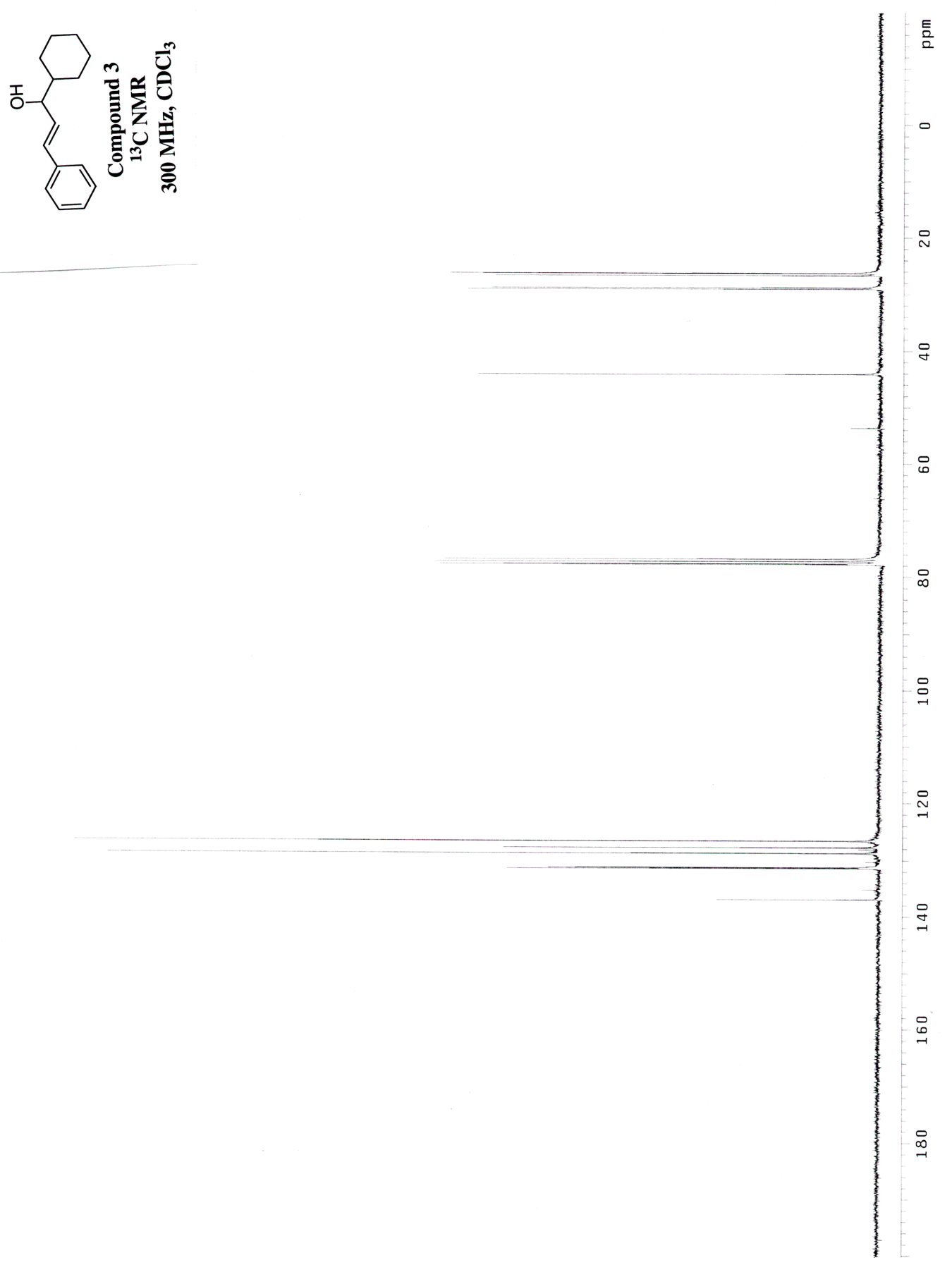

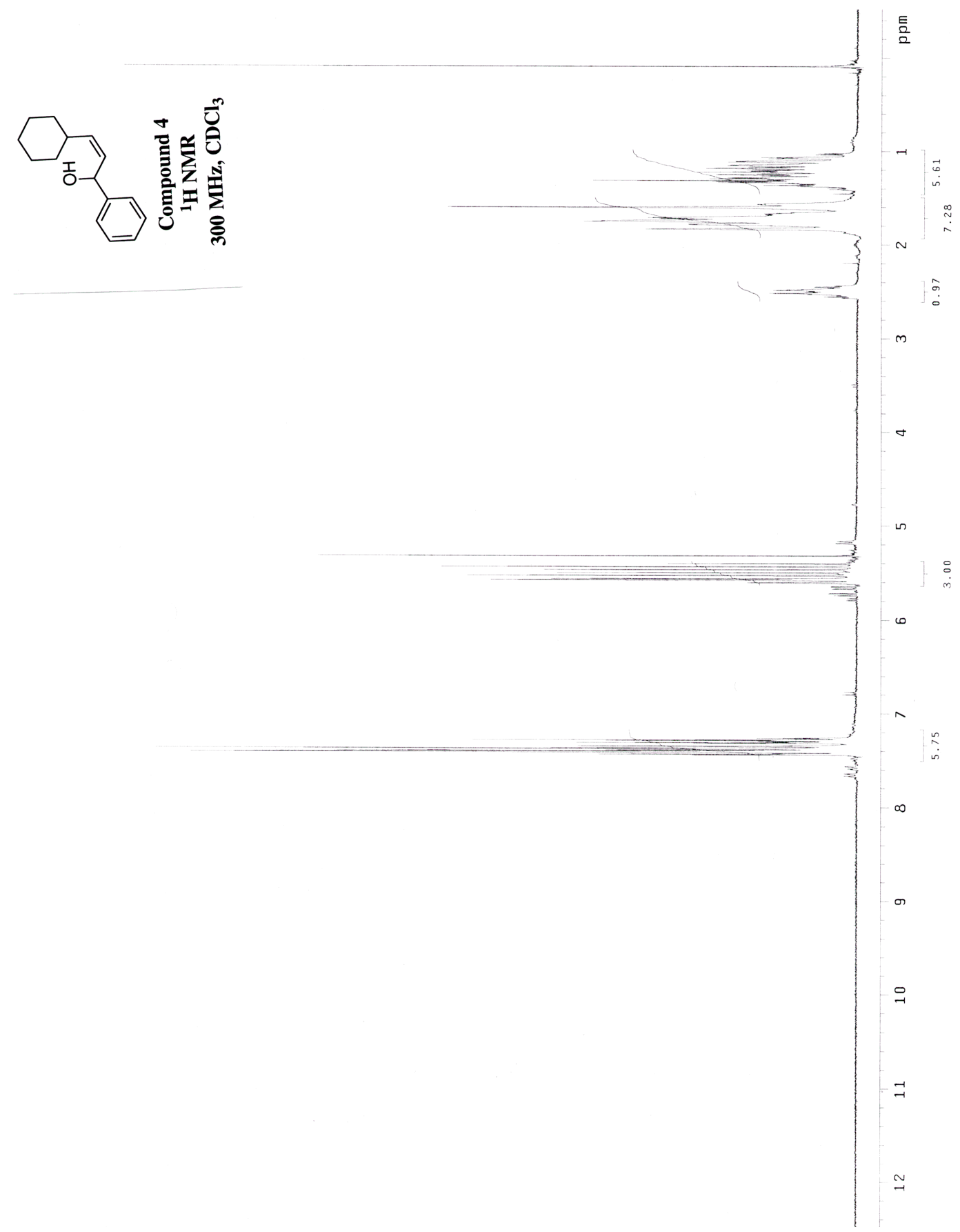

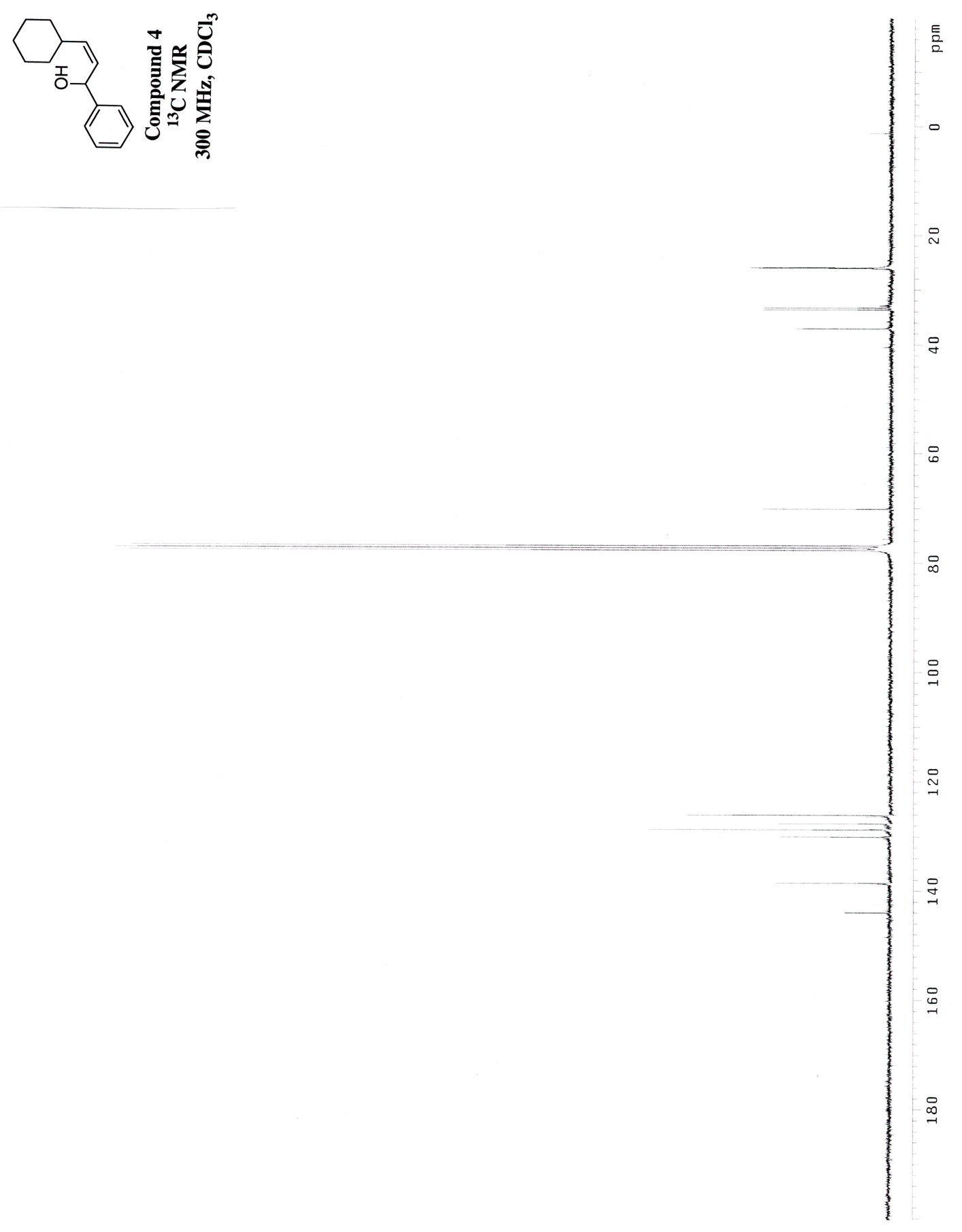

S? 4 
ปᄂ?

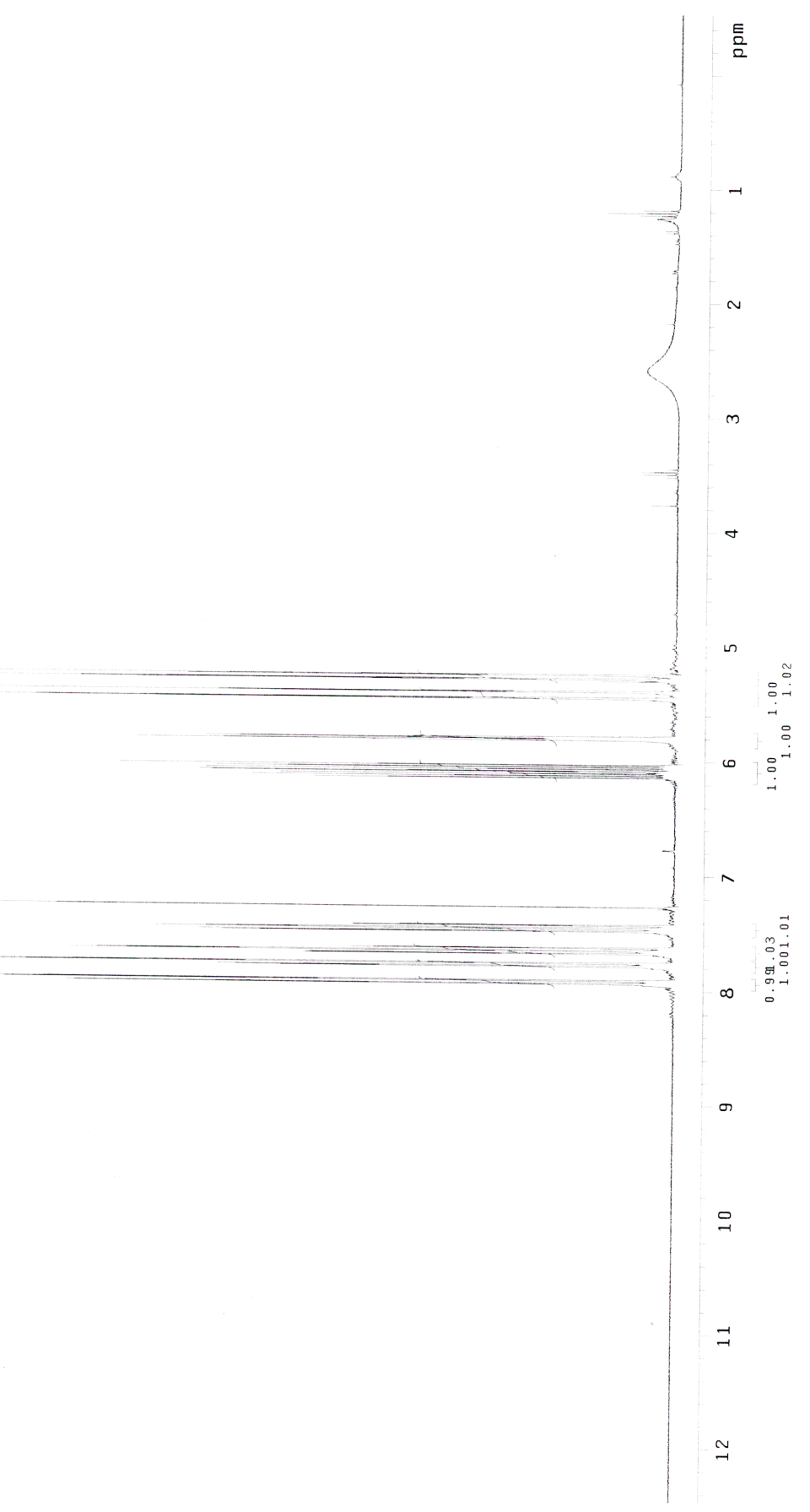

S25 
O-1

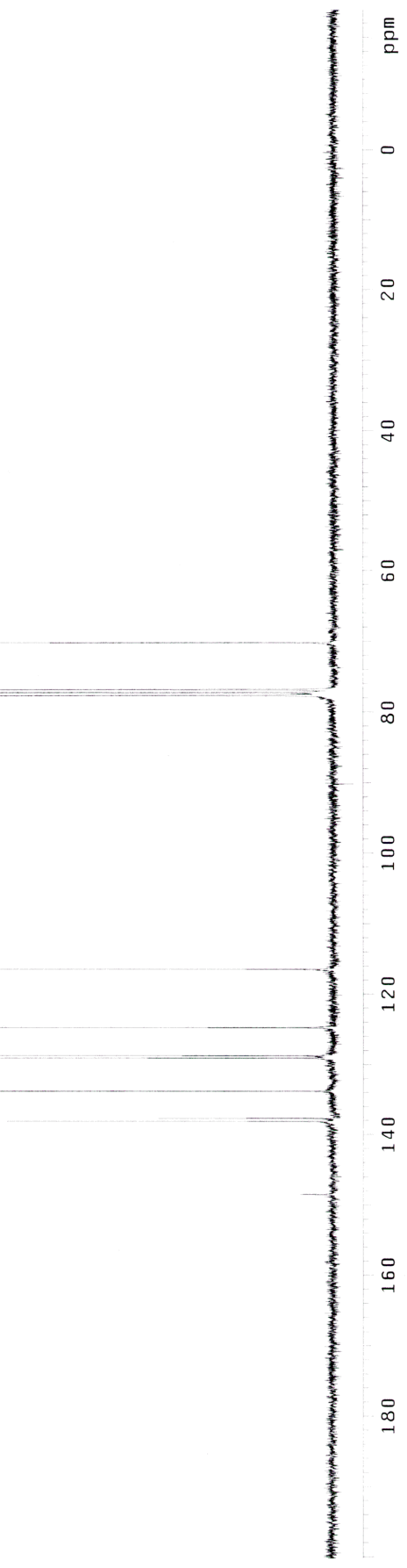


14:

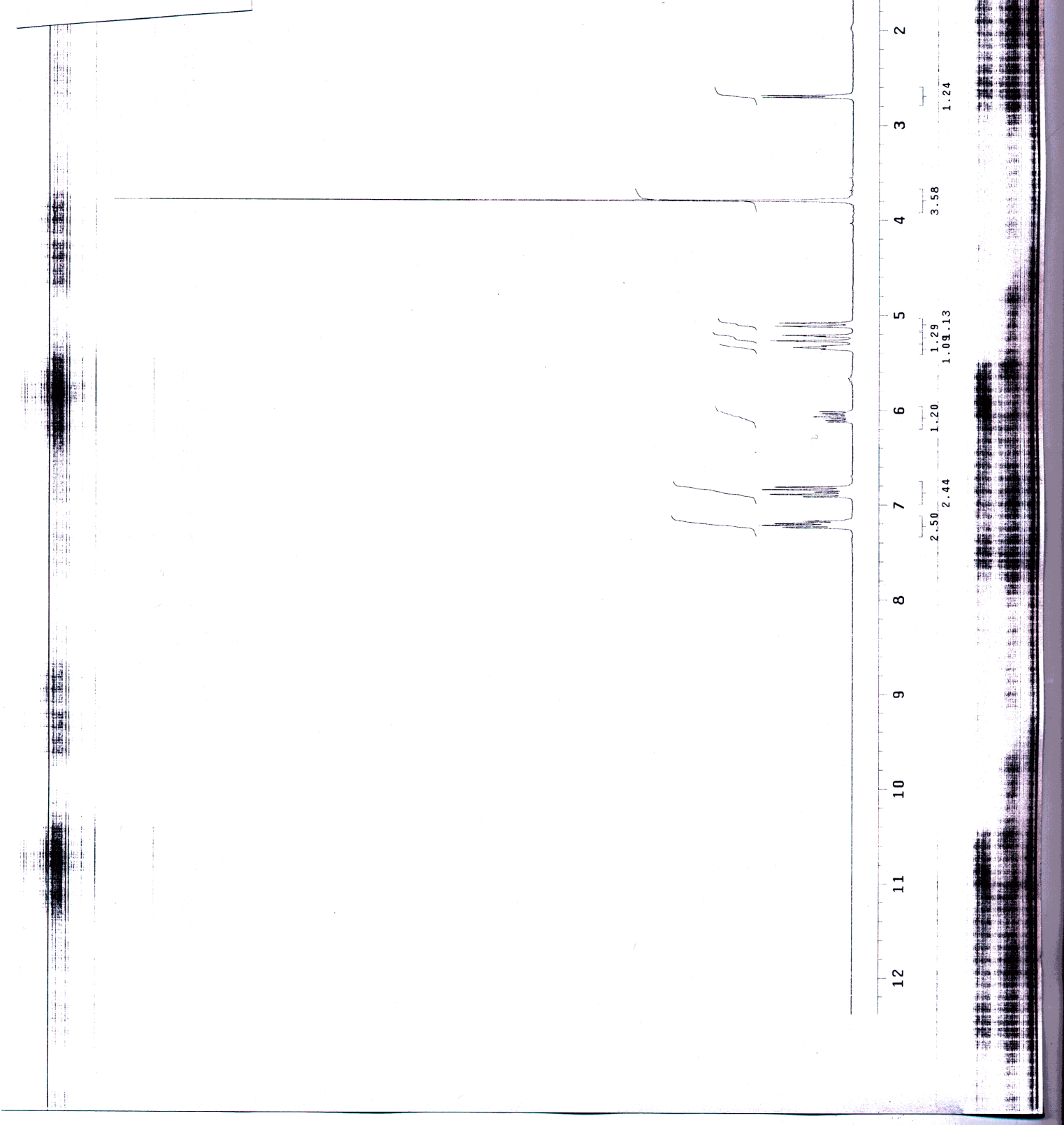


——_-
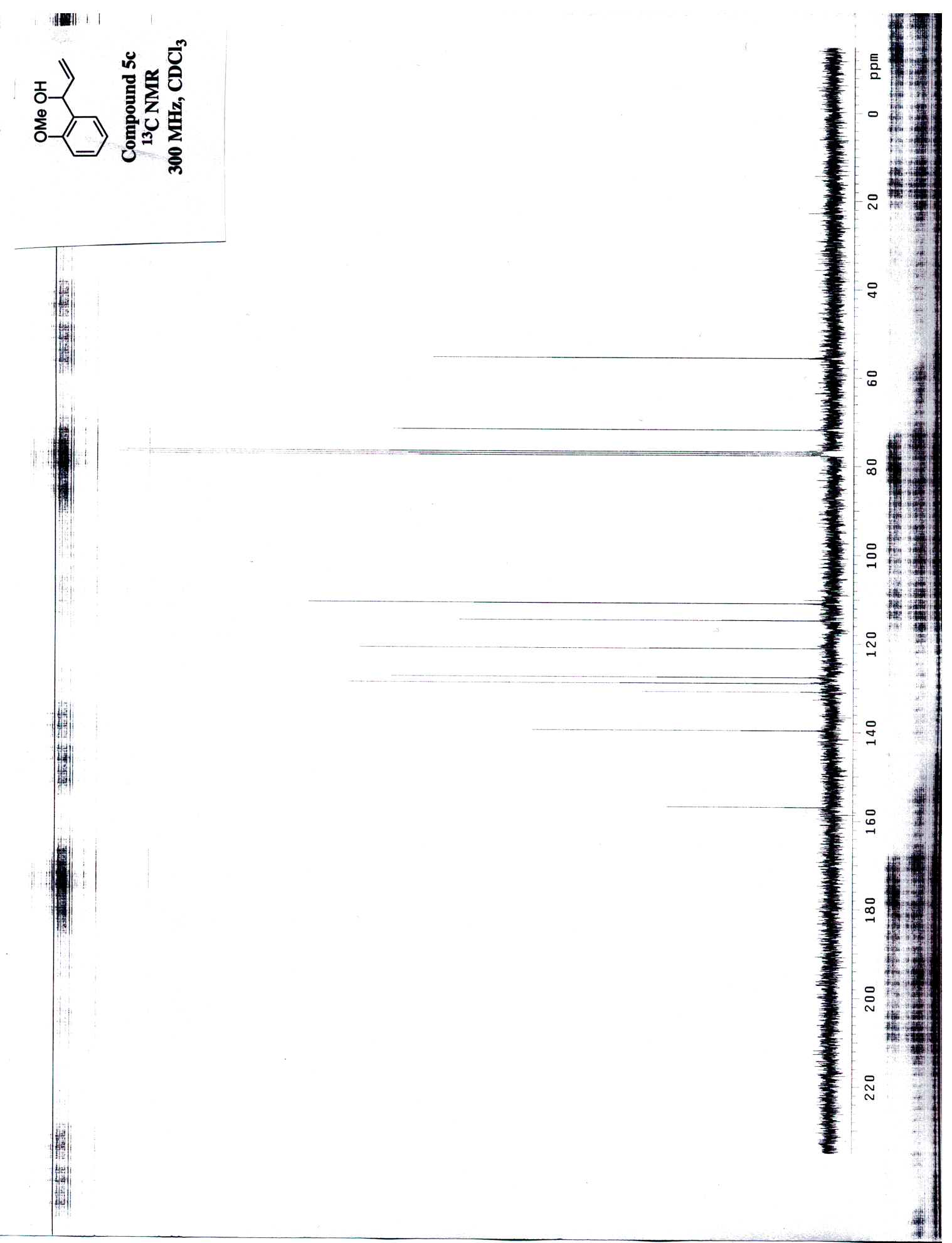
〈_—

$\left\{f^{\frac{E}{2}}\right.$

$-$ ]

$m$

$-\theta$

$\stackrel{a}{a}$

$-\ln$

1웅

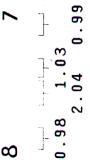
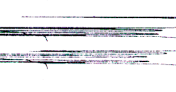

$\stackrel{ }{\rightarrow}$

$\exists$

$\approx$

S29 


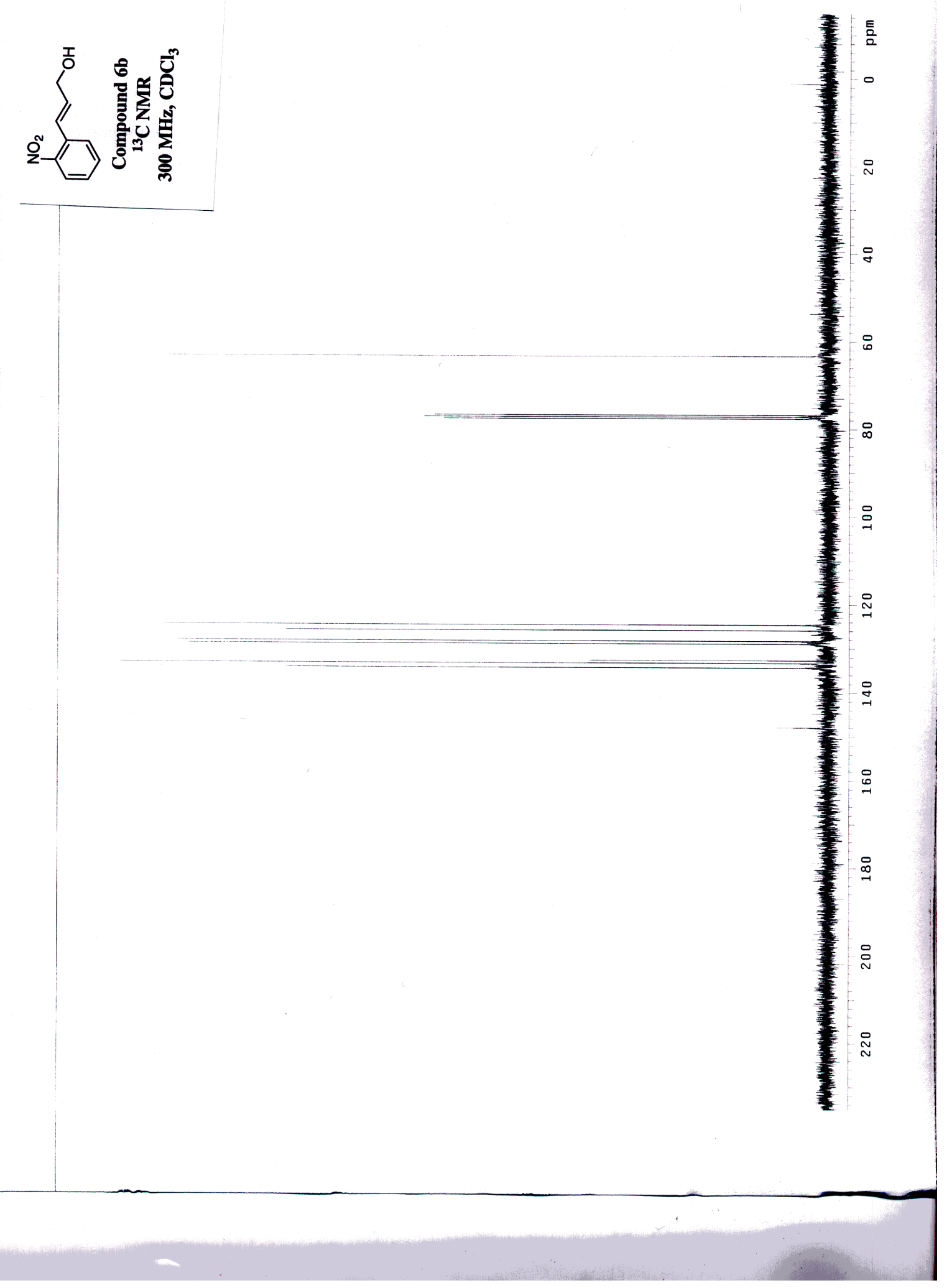


〈丶

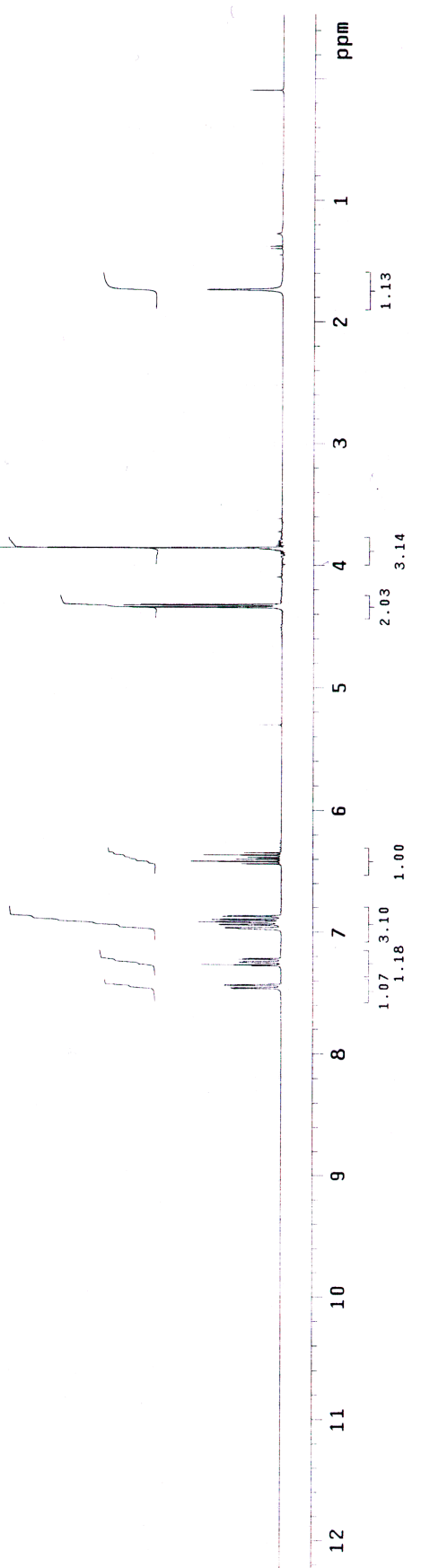




$$
4
$$



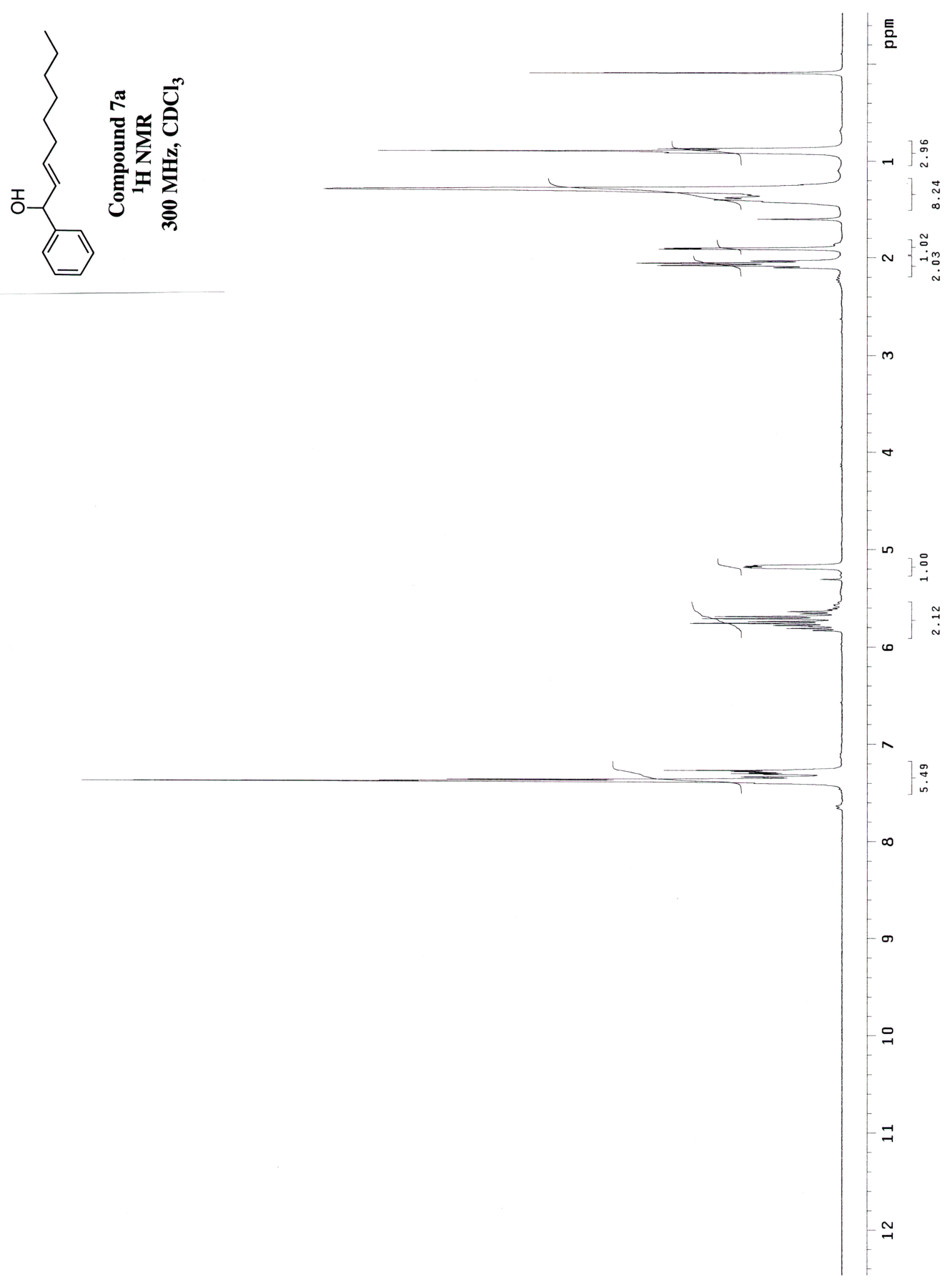


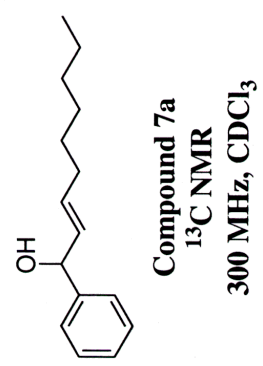

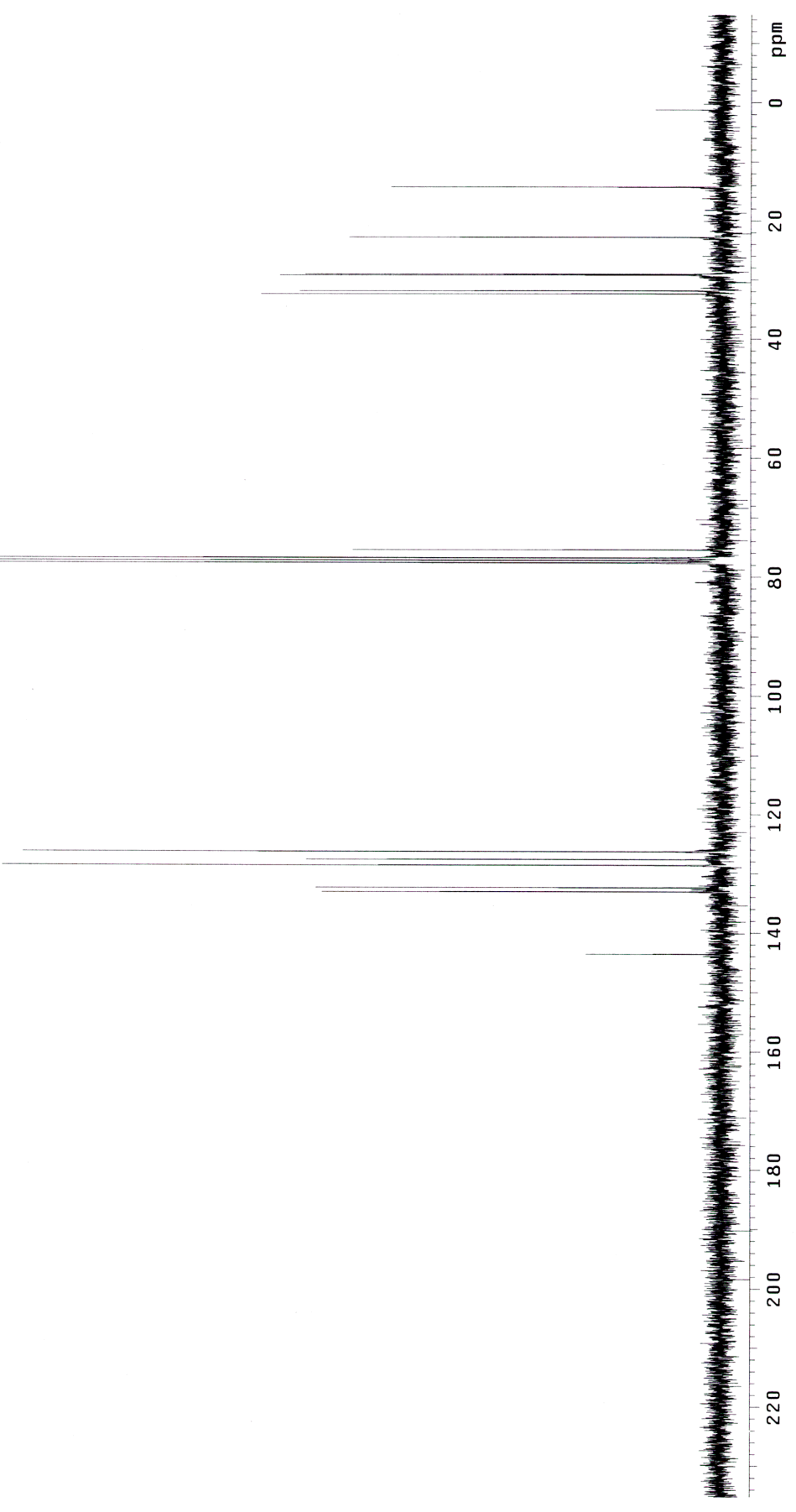




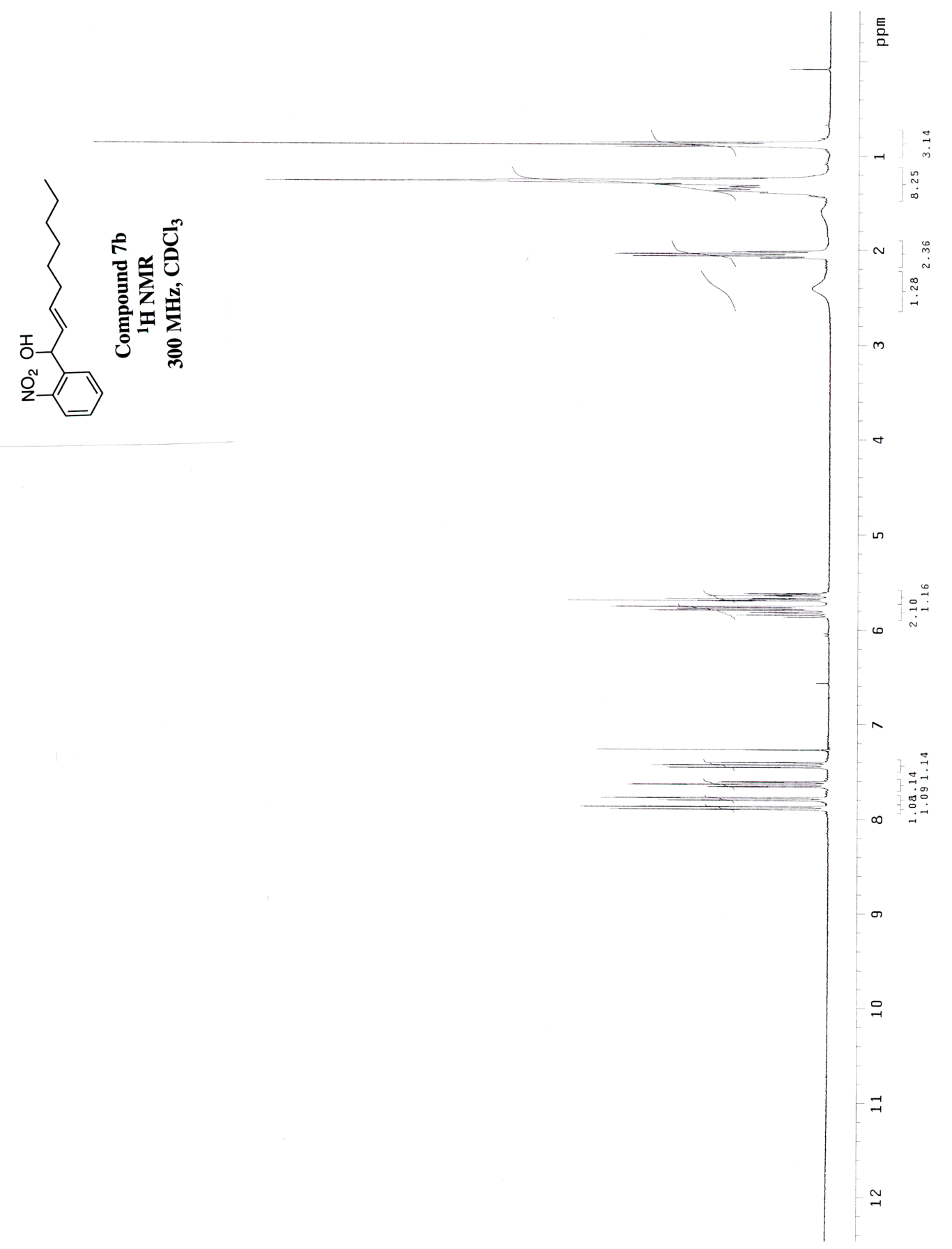



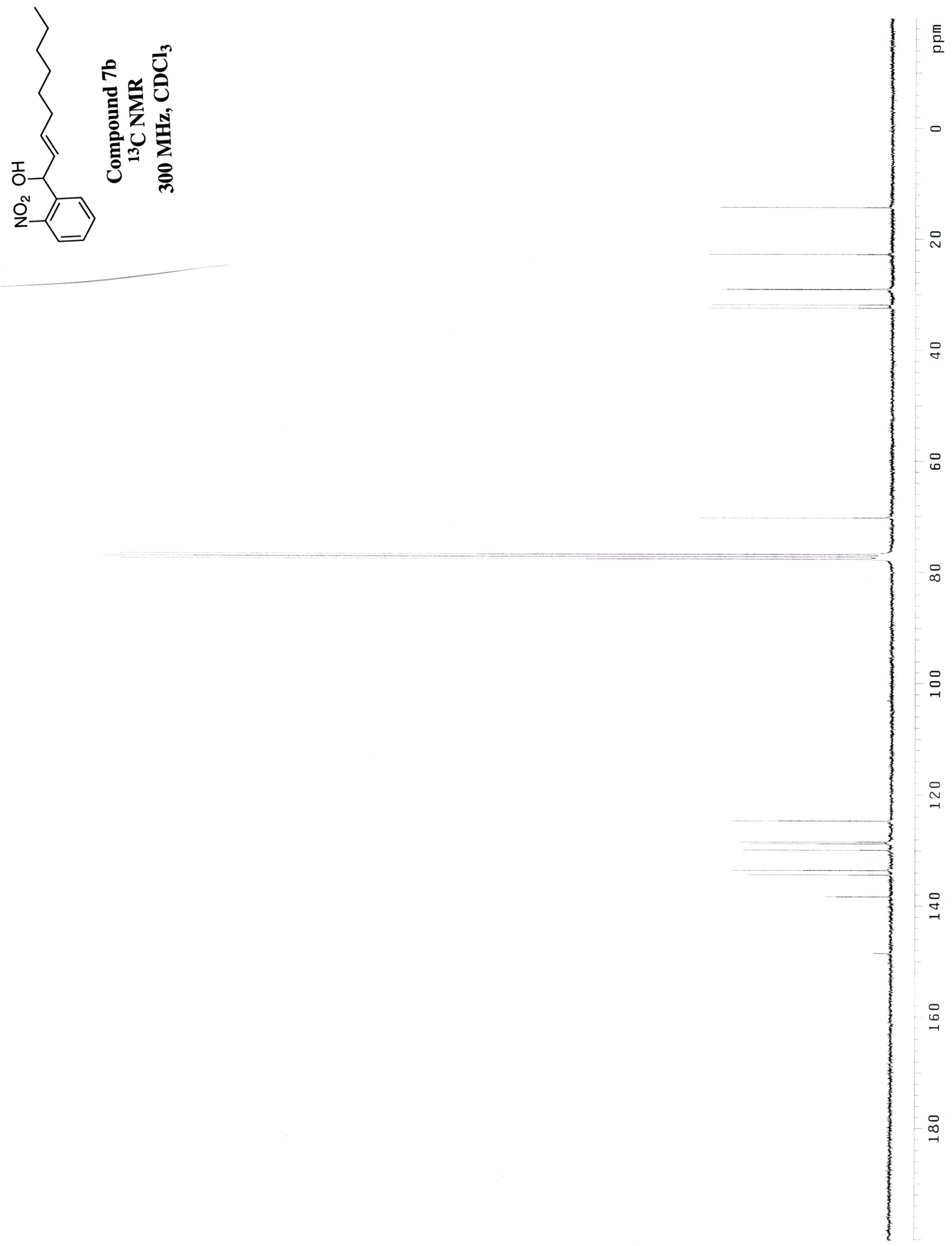

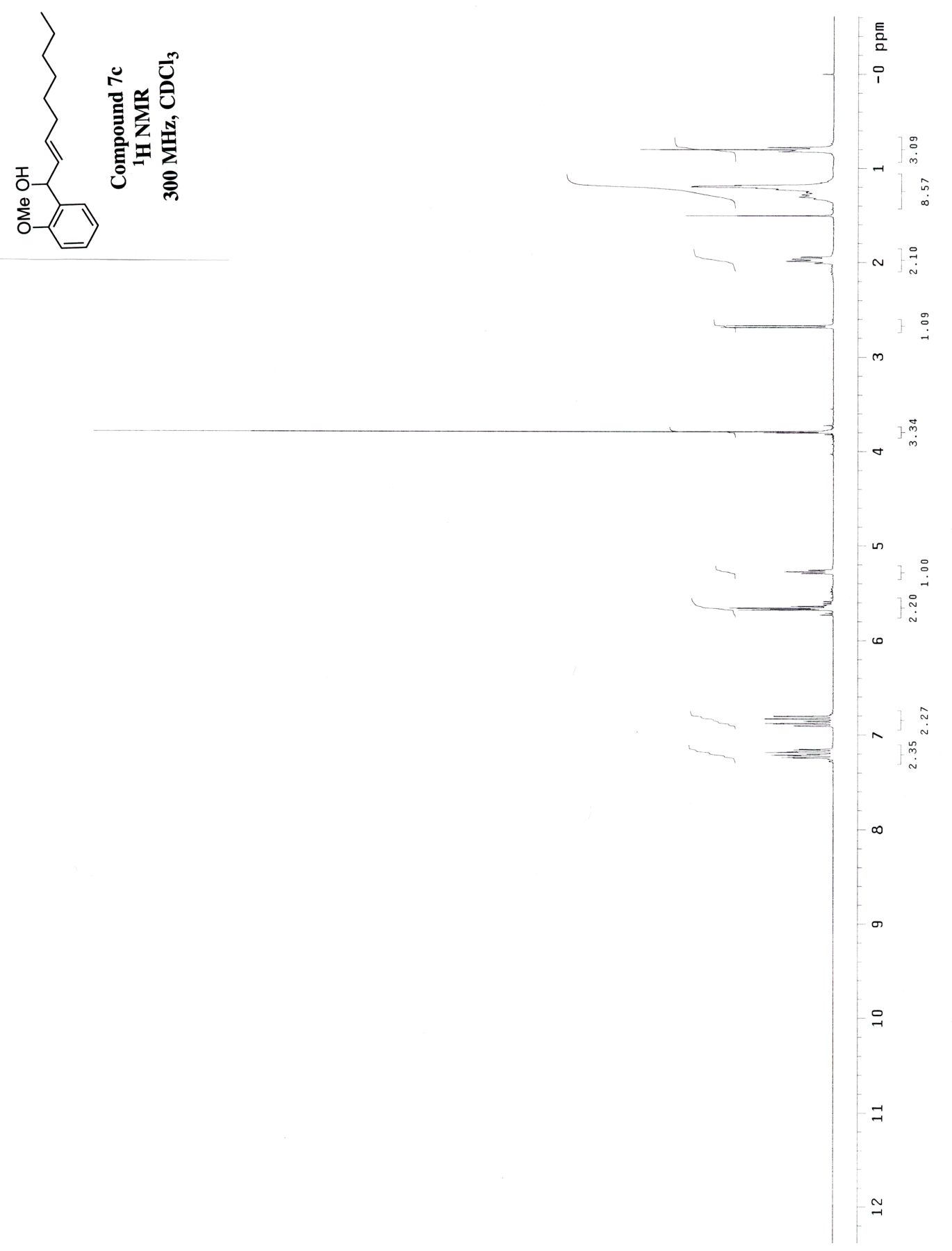


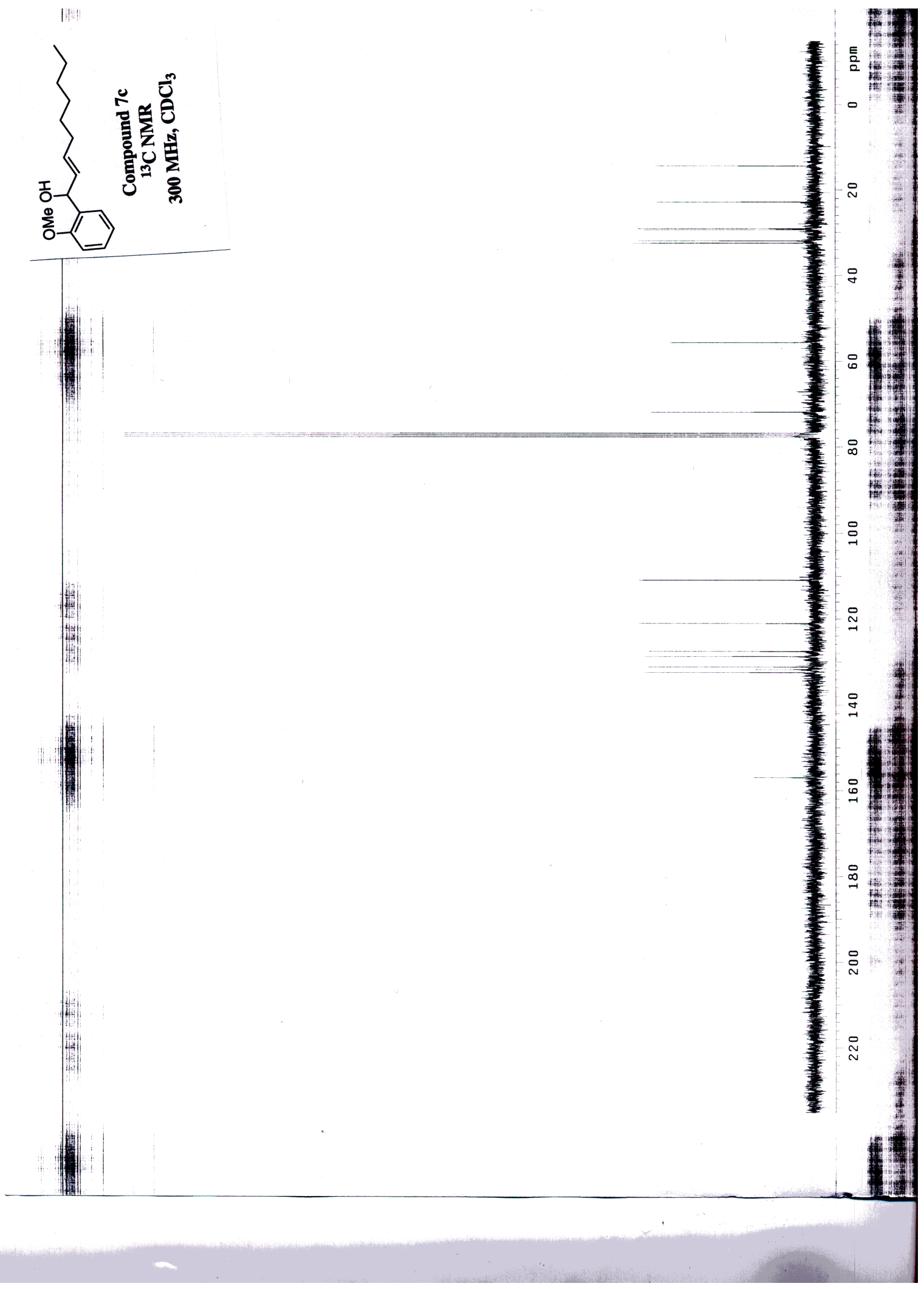

S38 


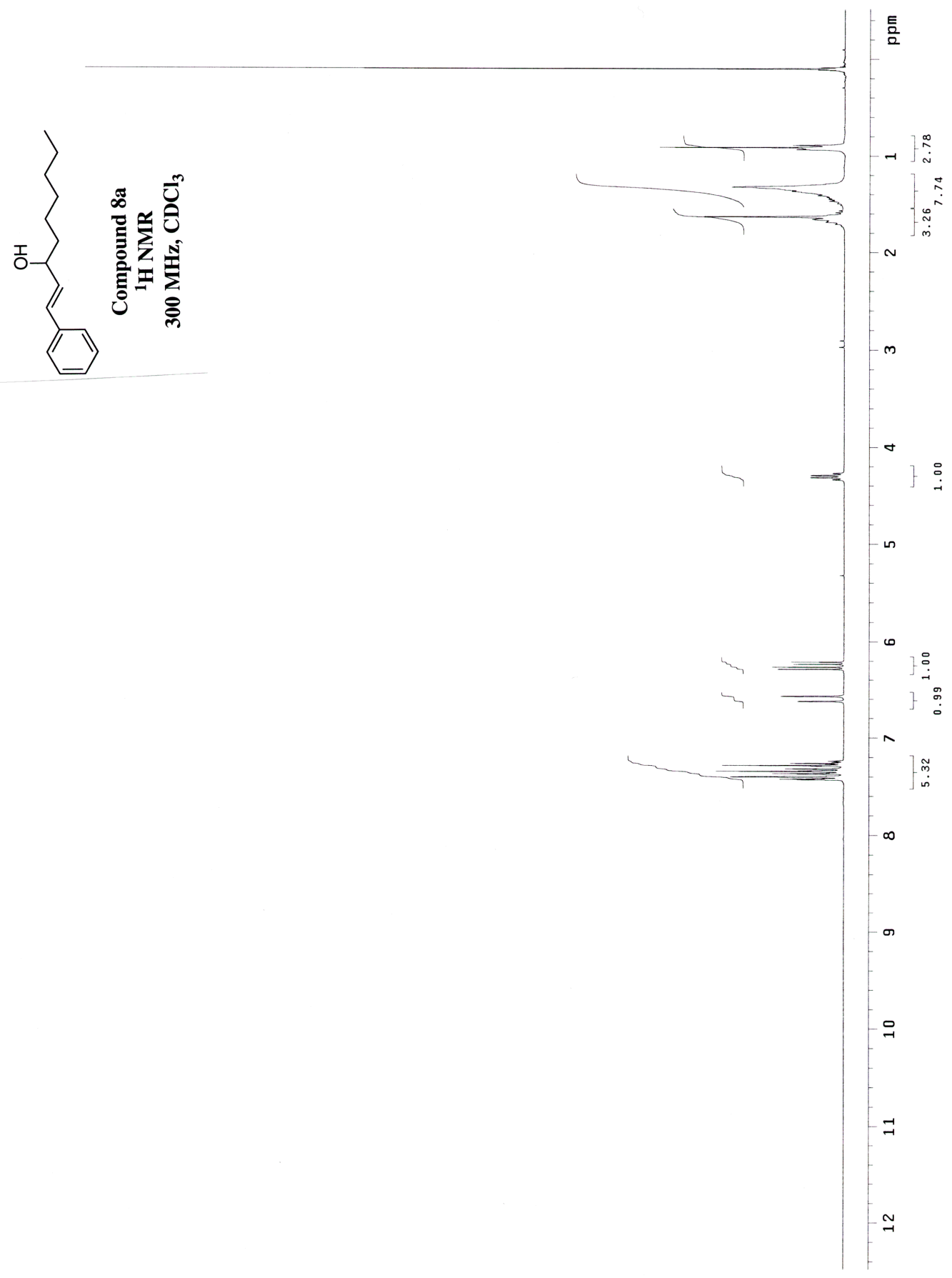




$$
1
$$




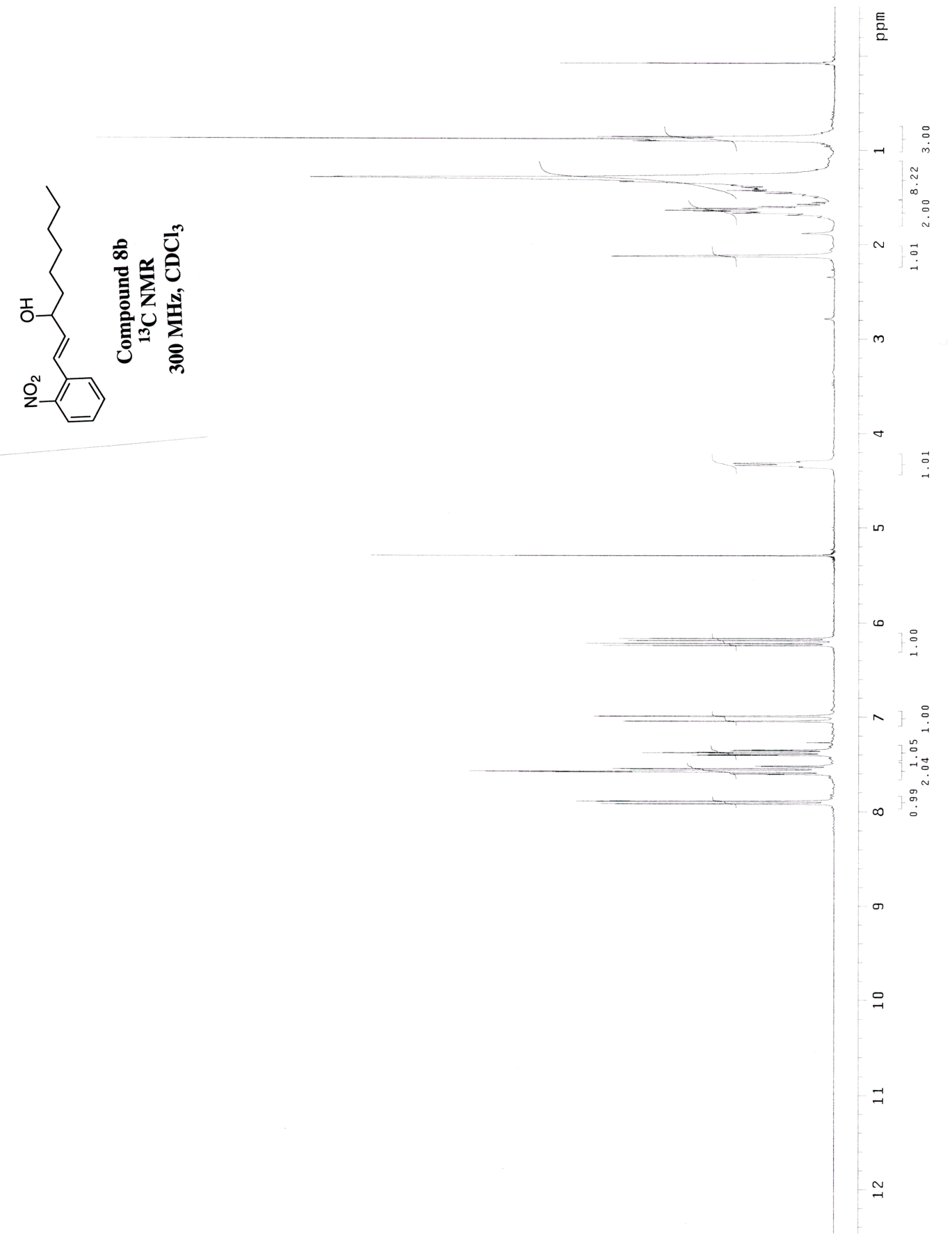




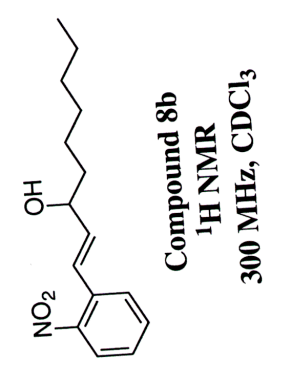


〈र

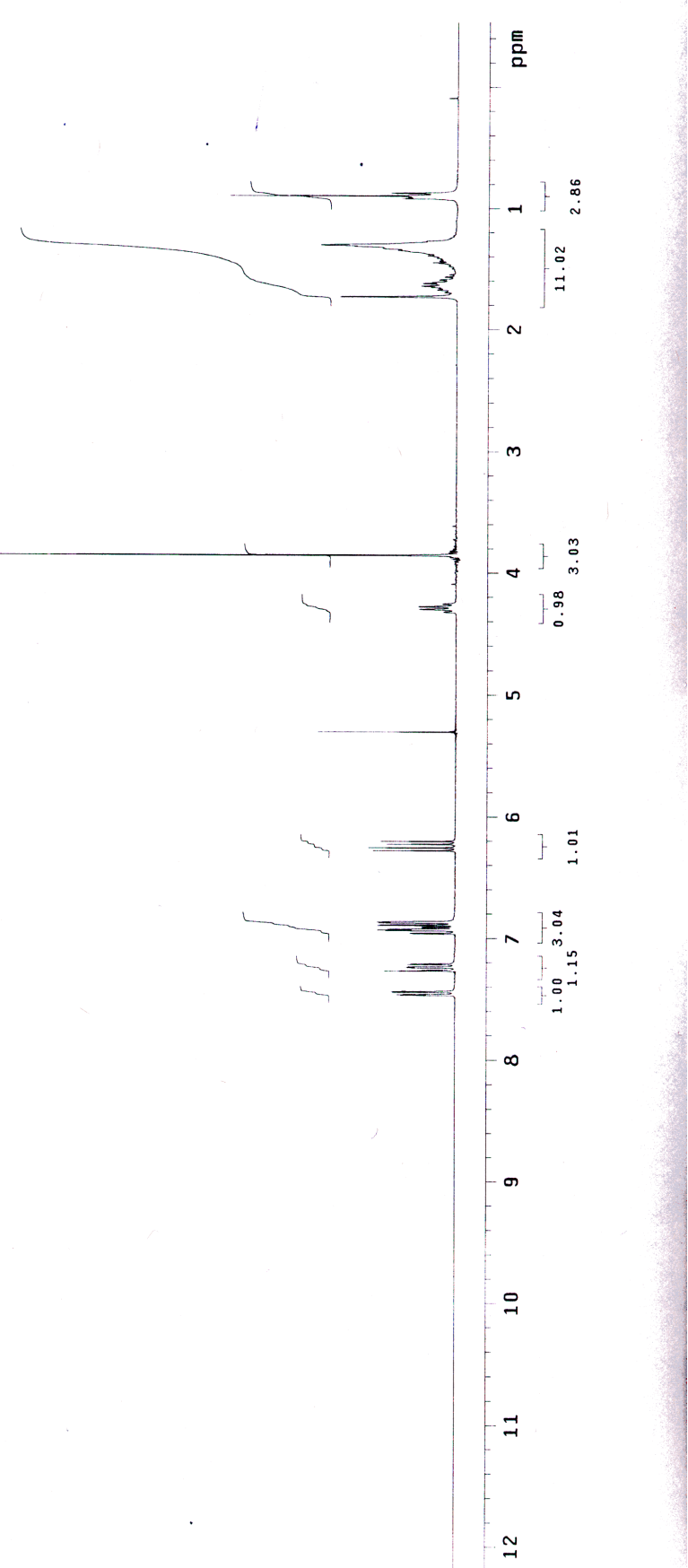




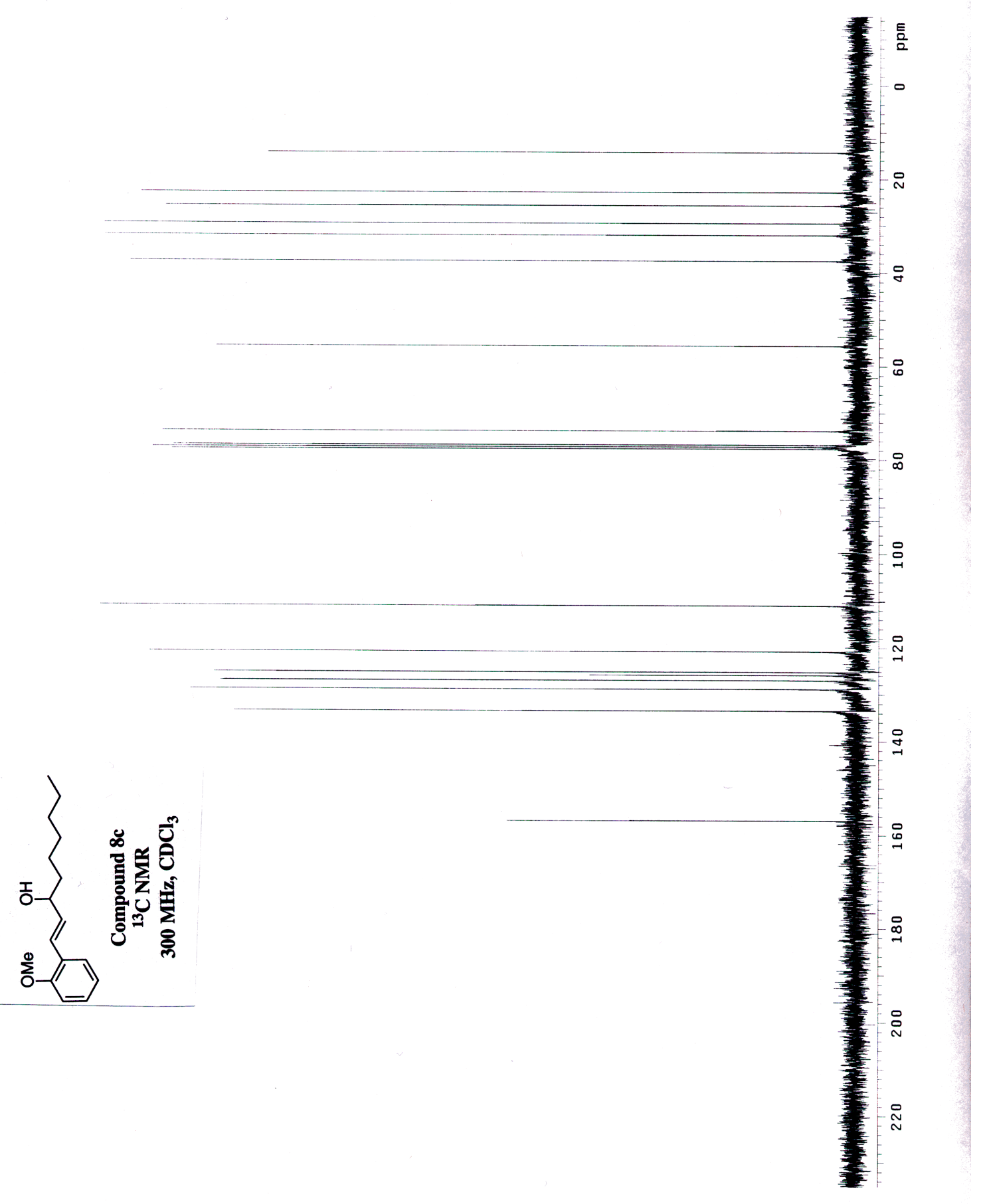


$\sum\langle 0$

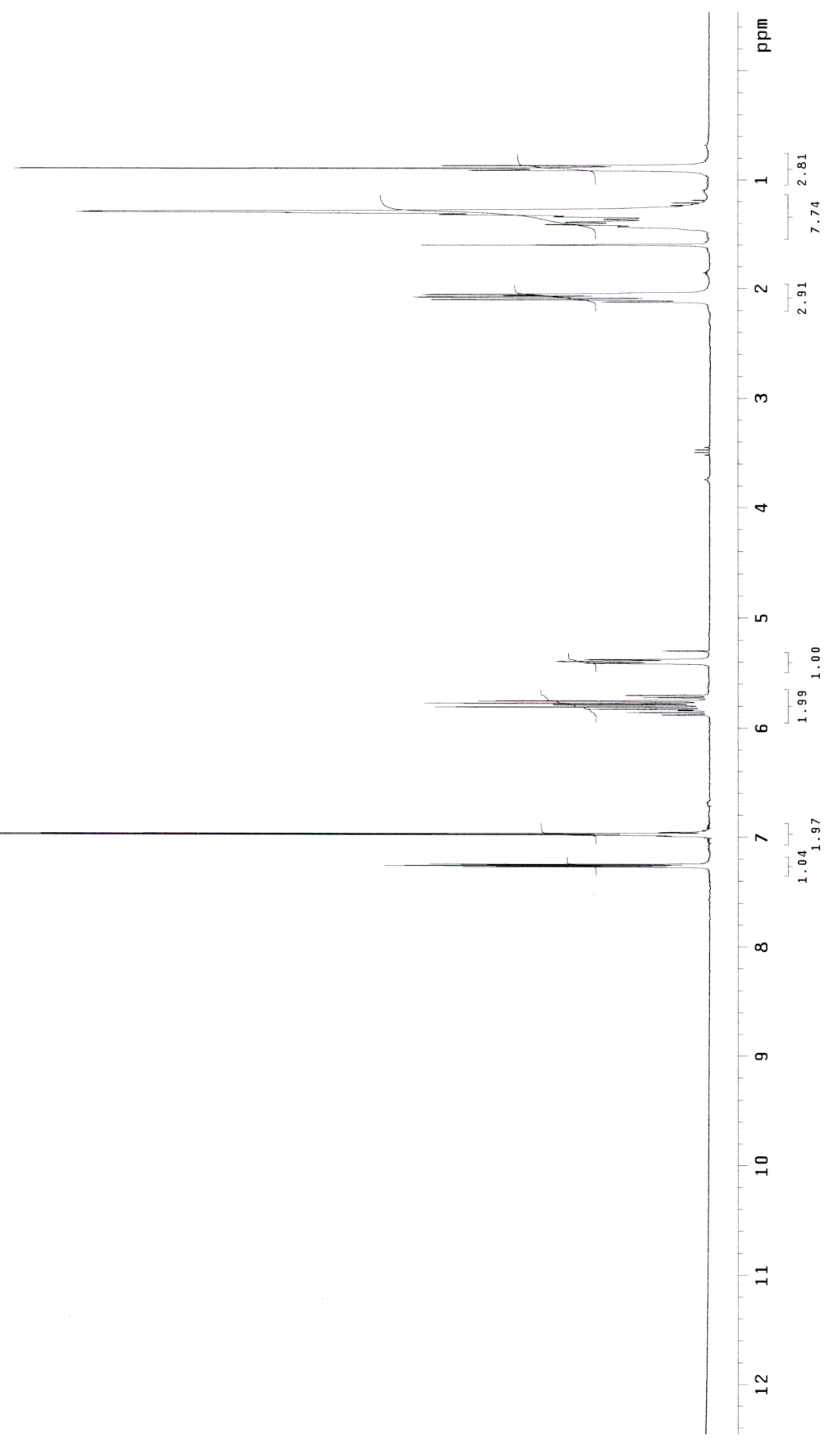




$$
4
$$



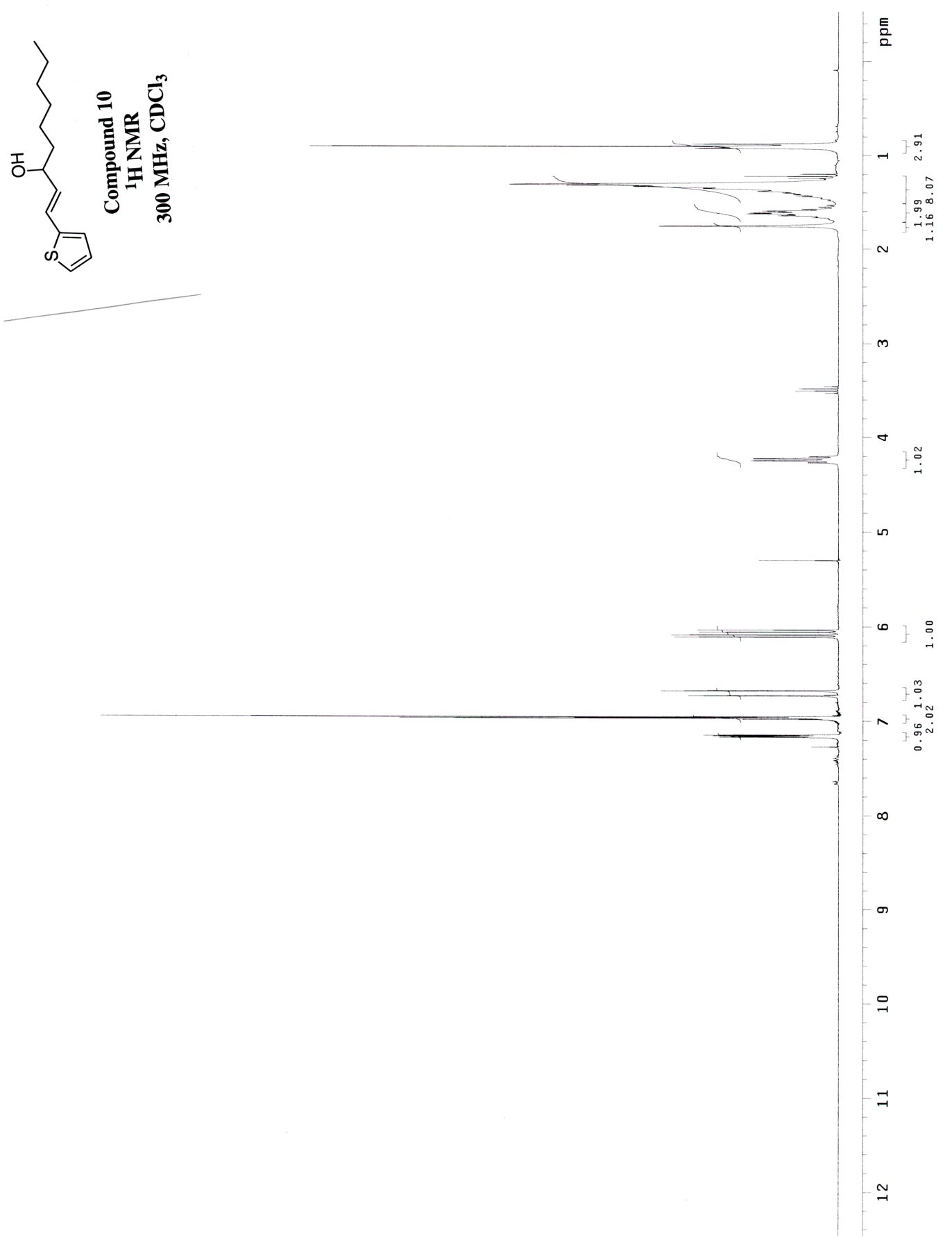


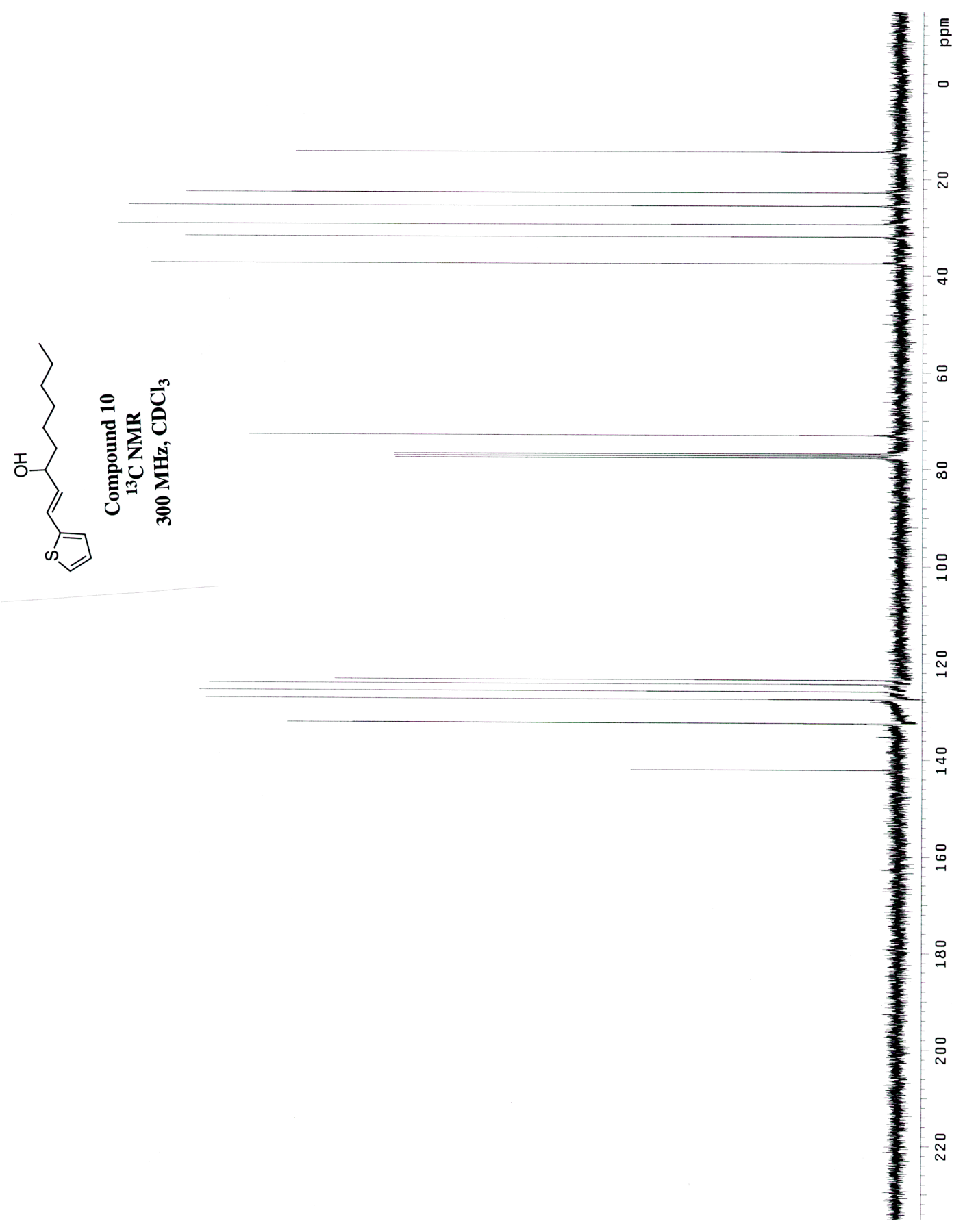


\1)

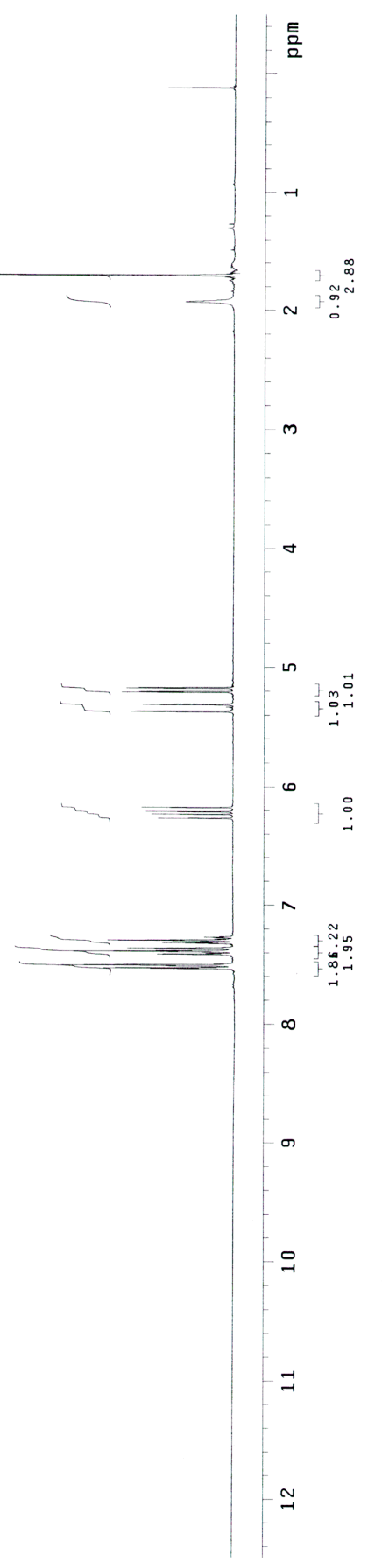


〈D

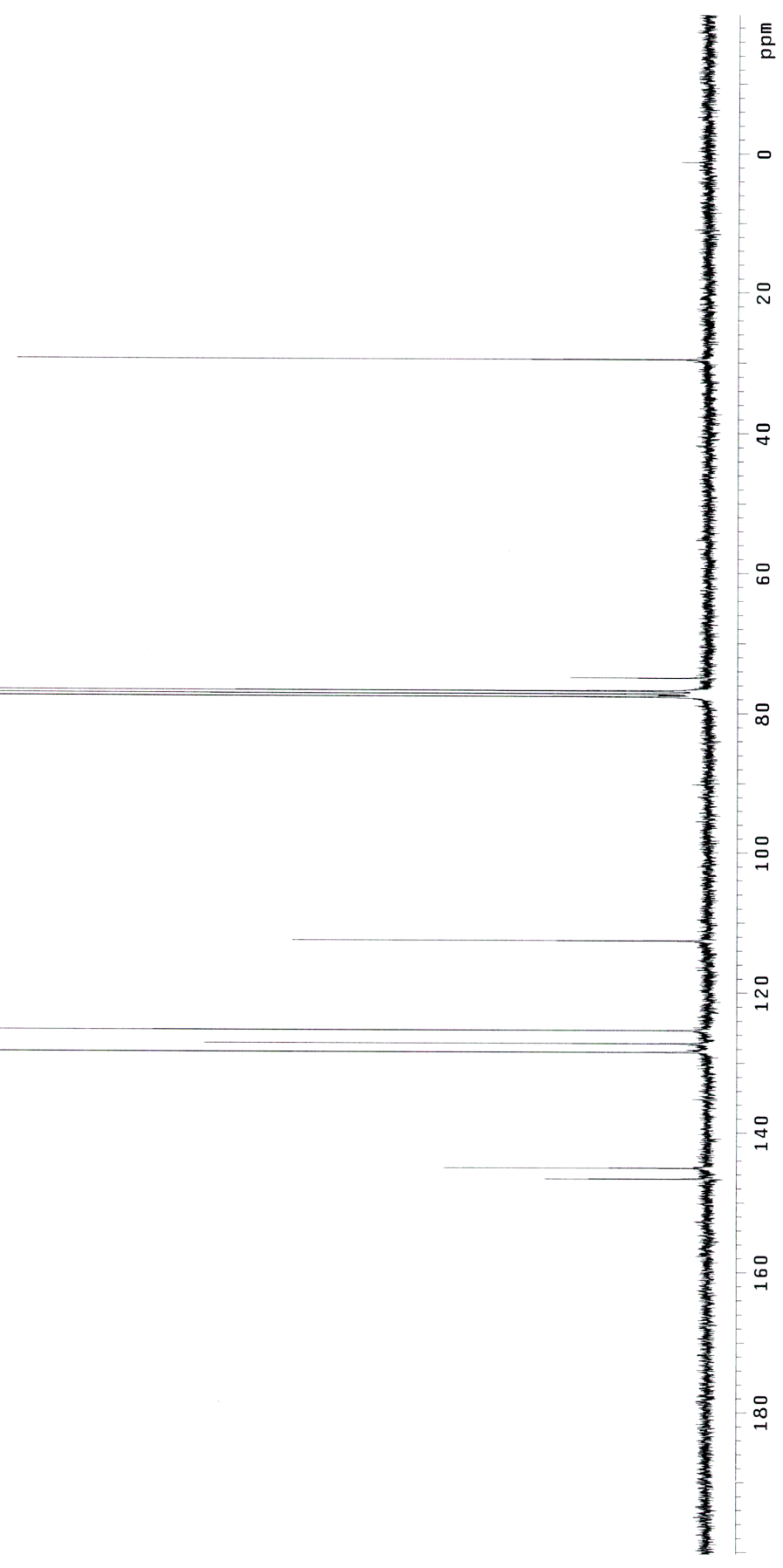




$$
\text { 〈1 }
$$

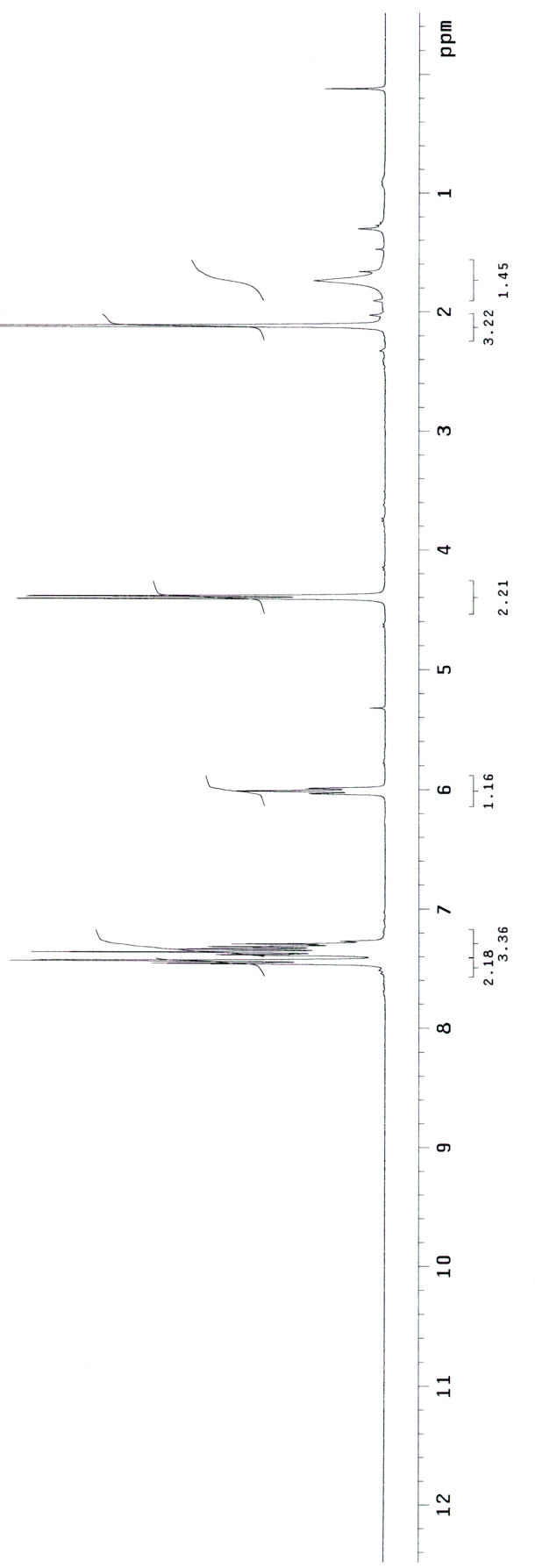



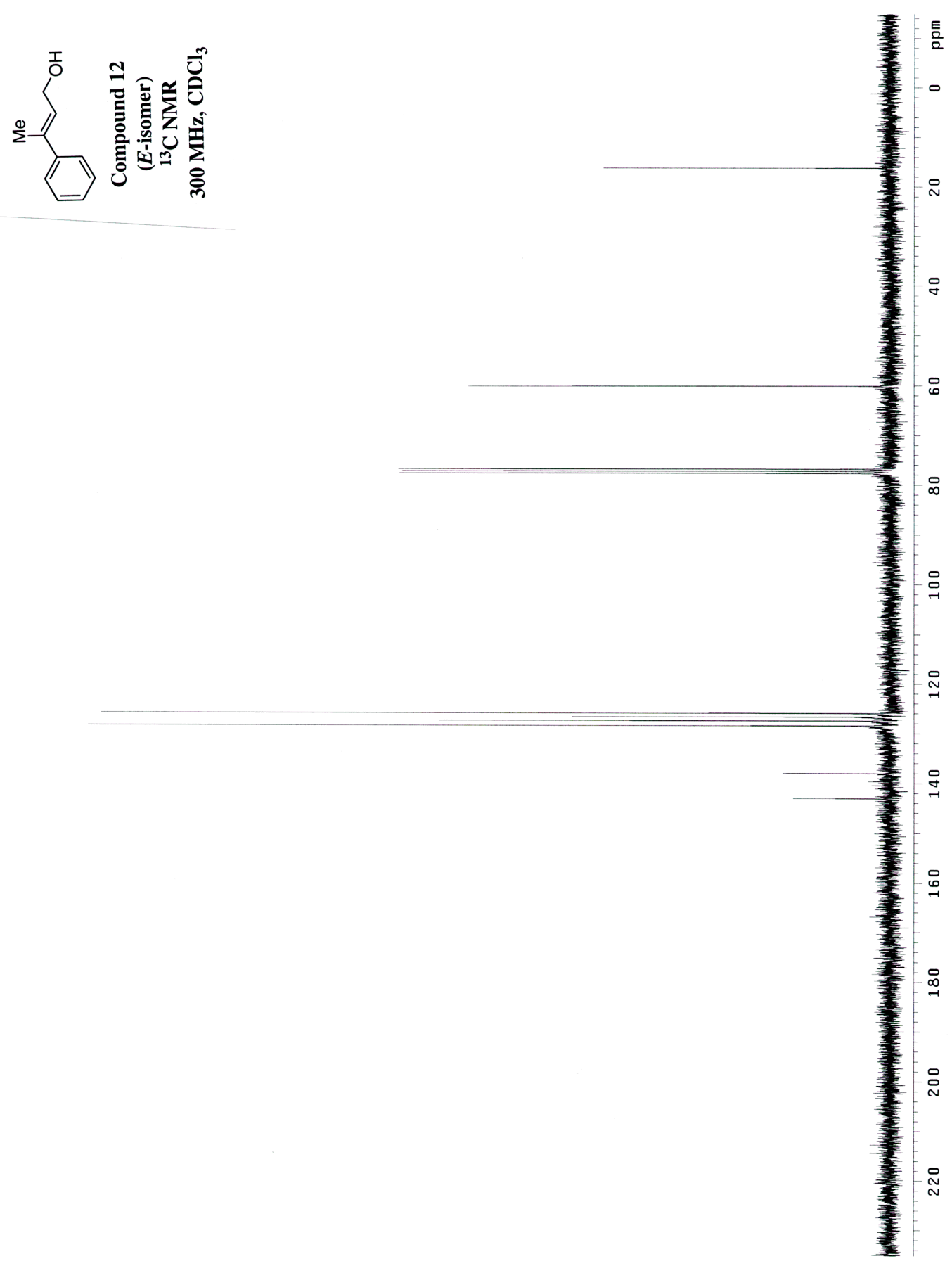

S52 

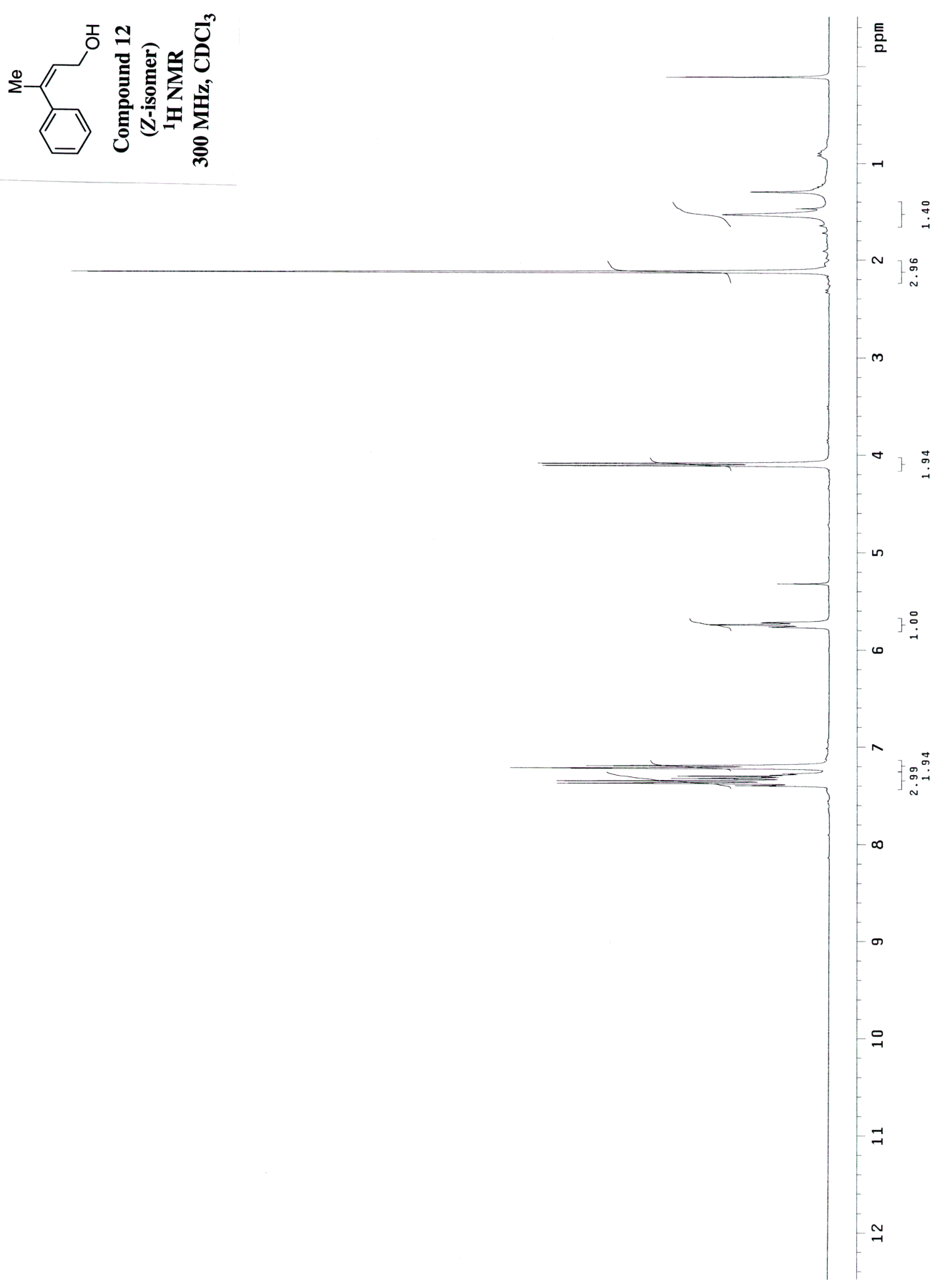

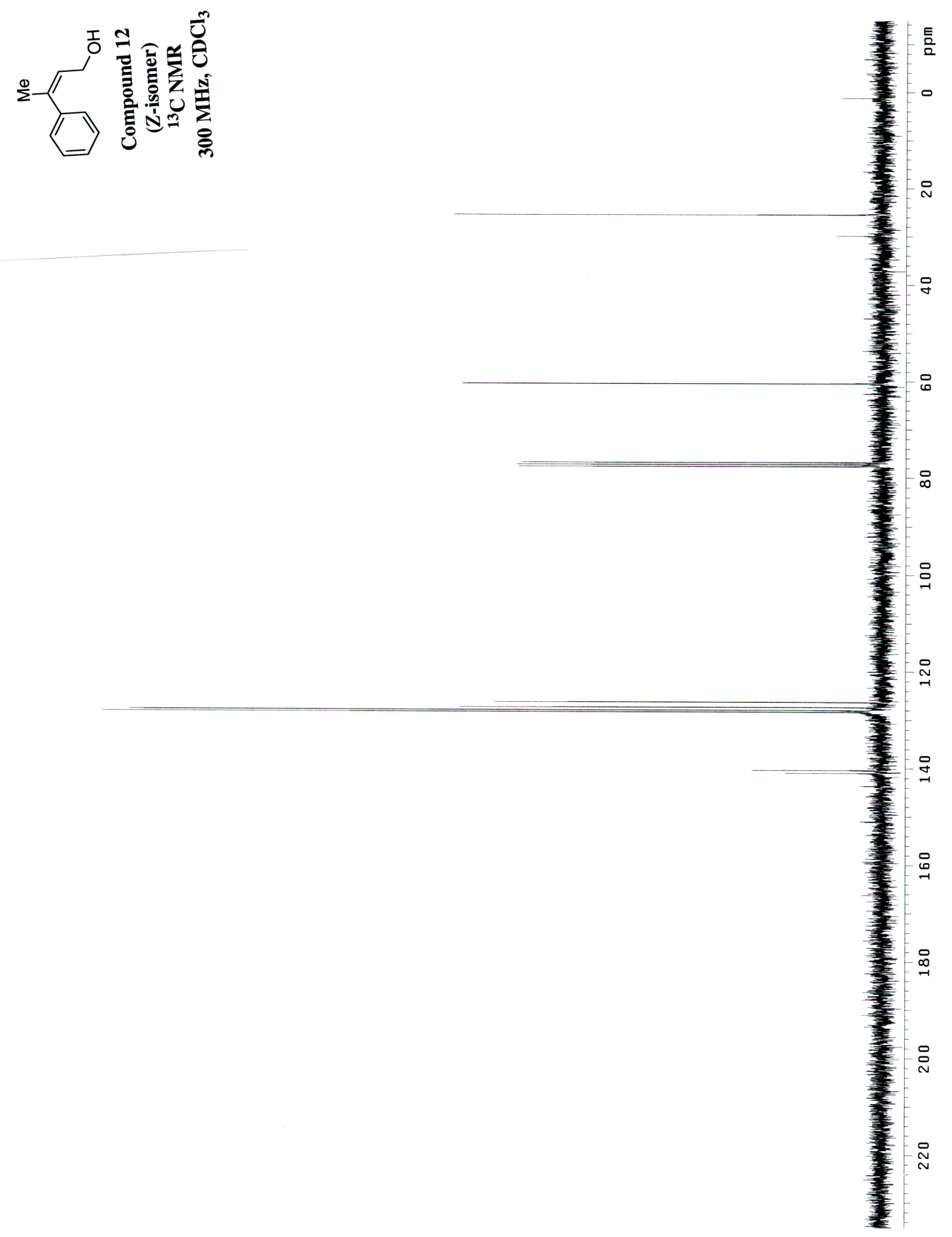

S54 


$$
\text { U }
$$




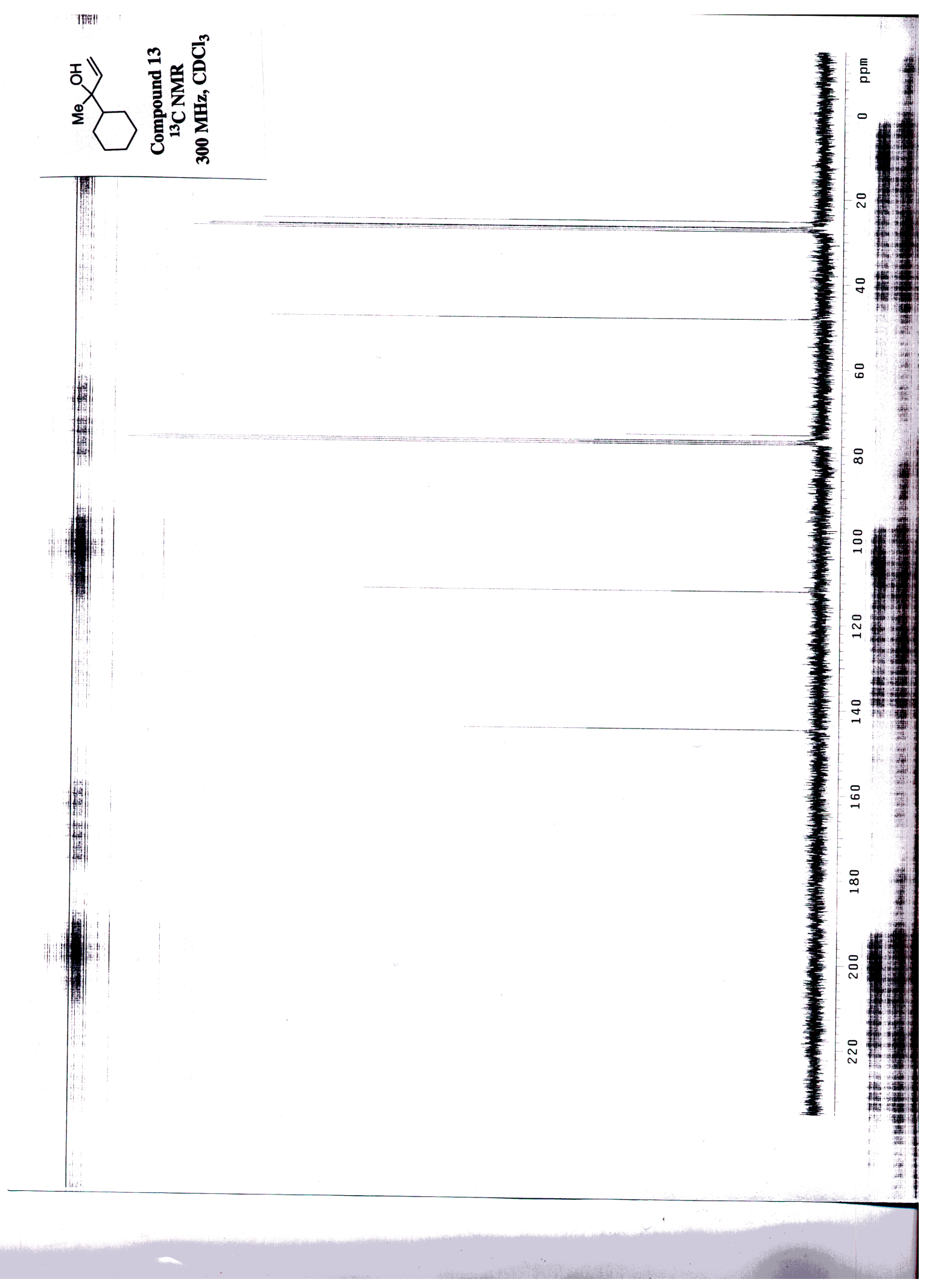




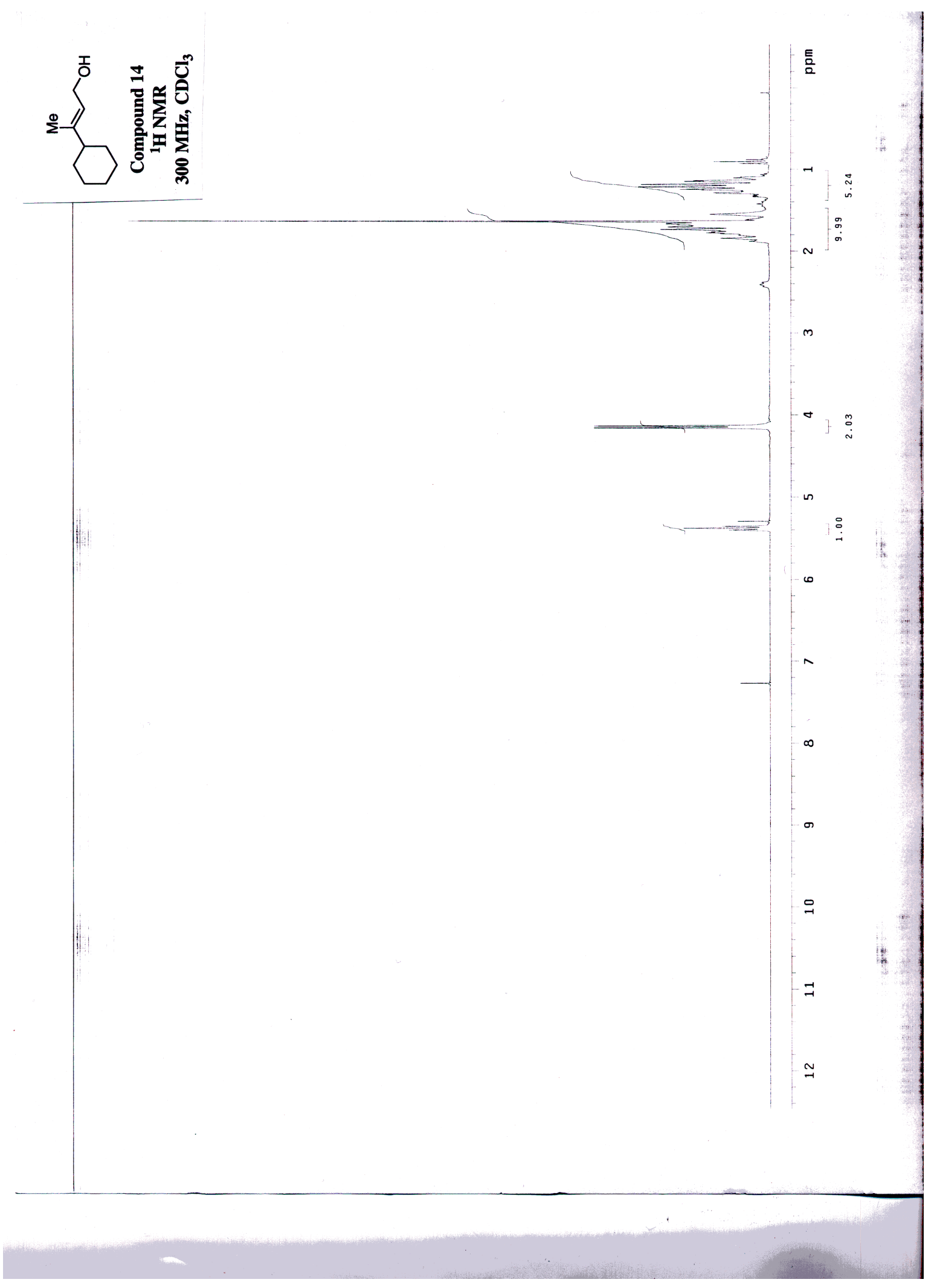




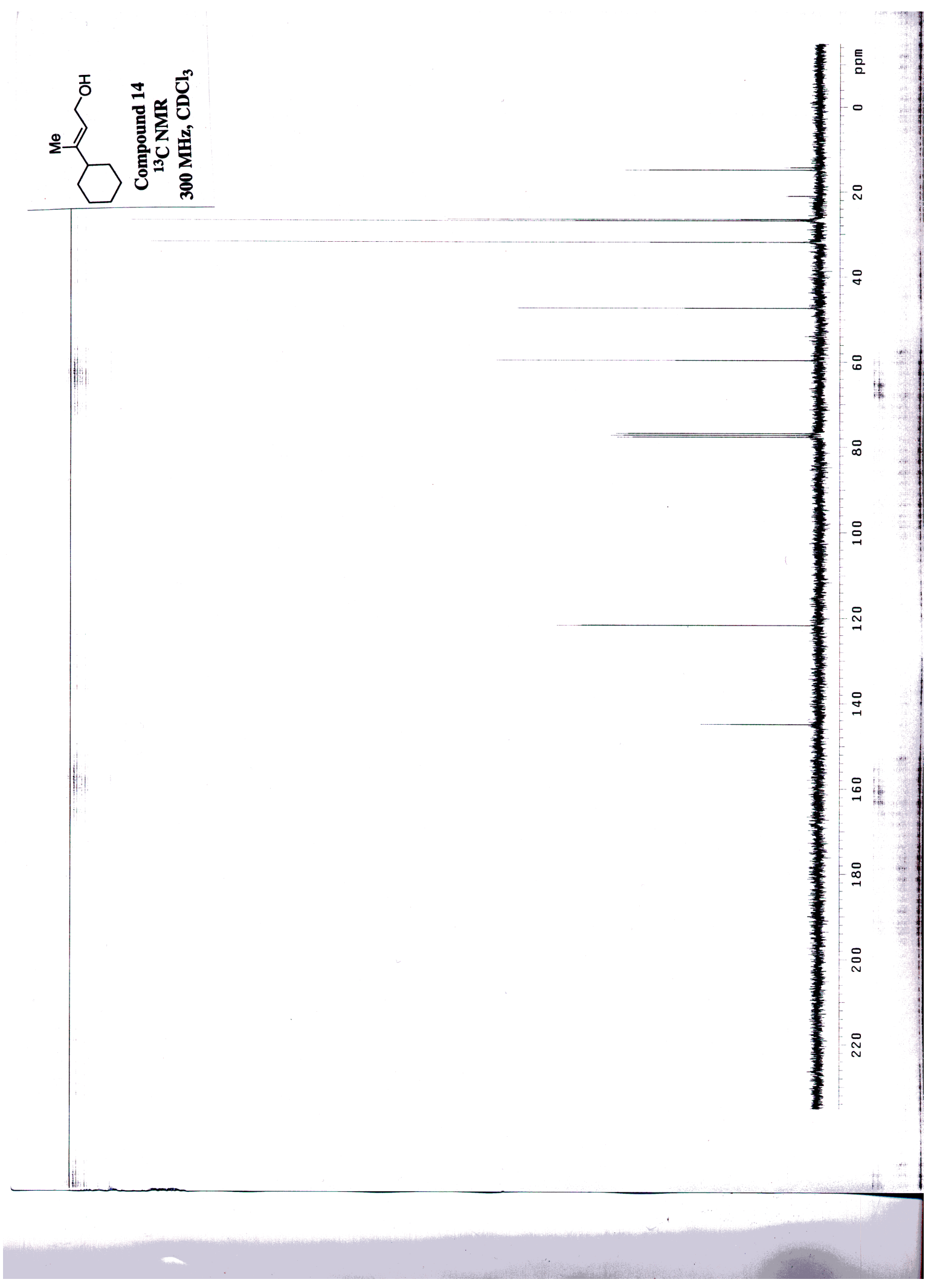




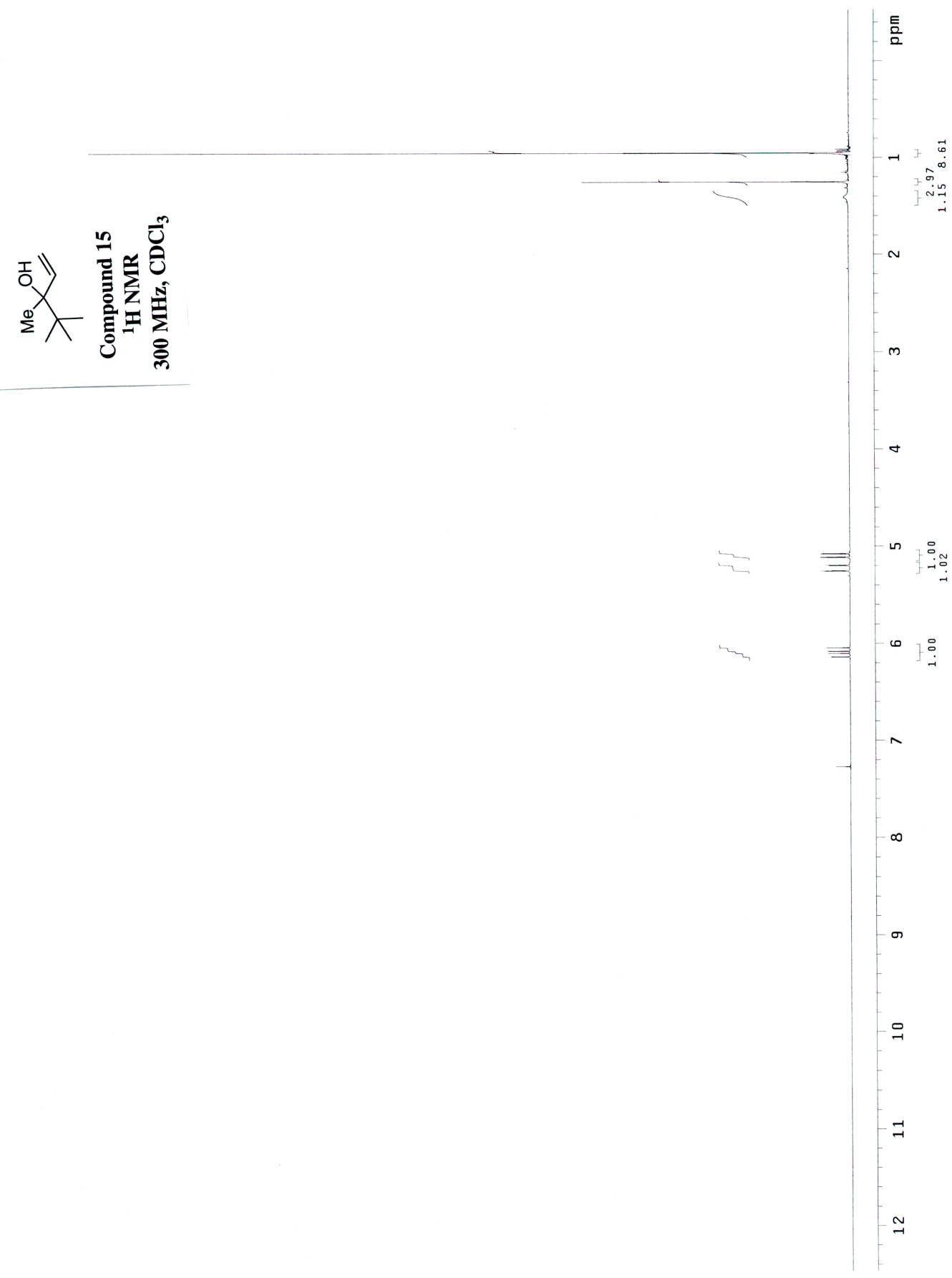




$$
\text { 文入 }
$$

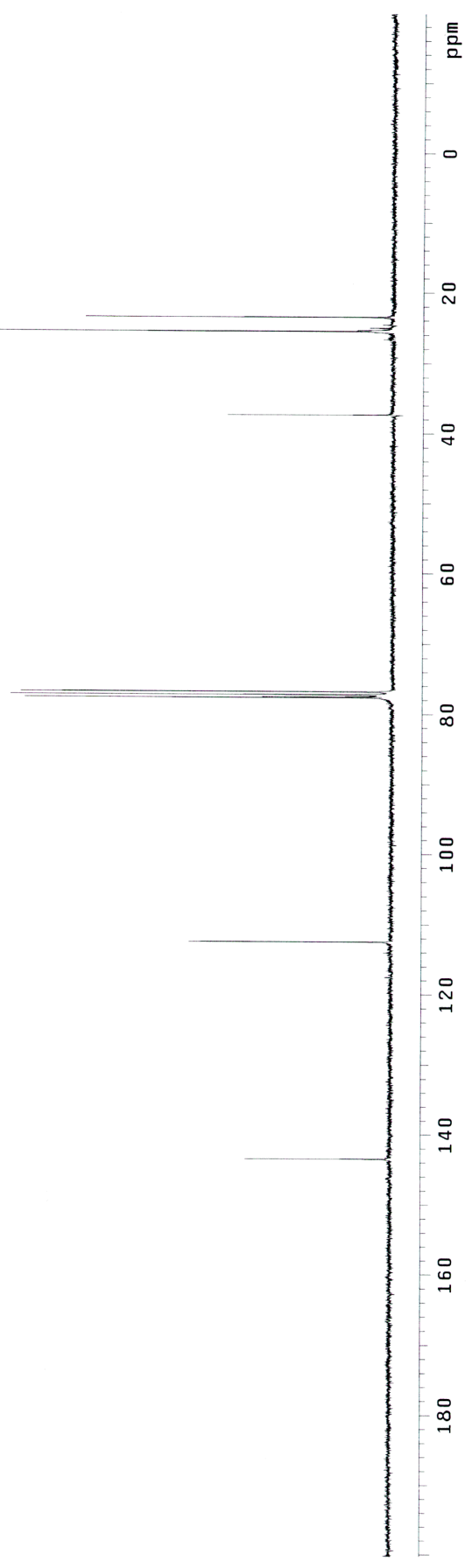


〈र

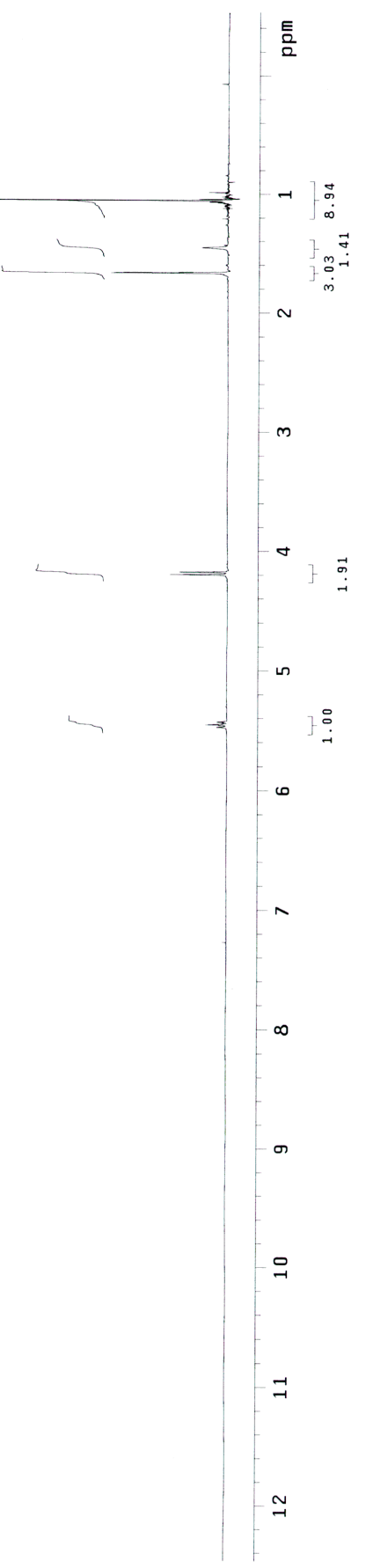



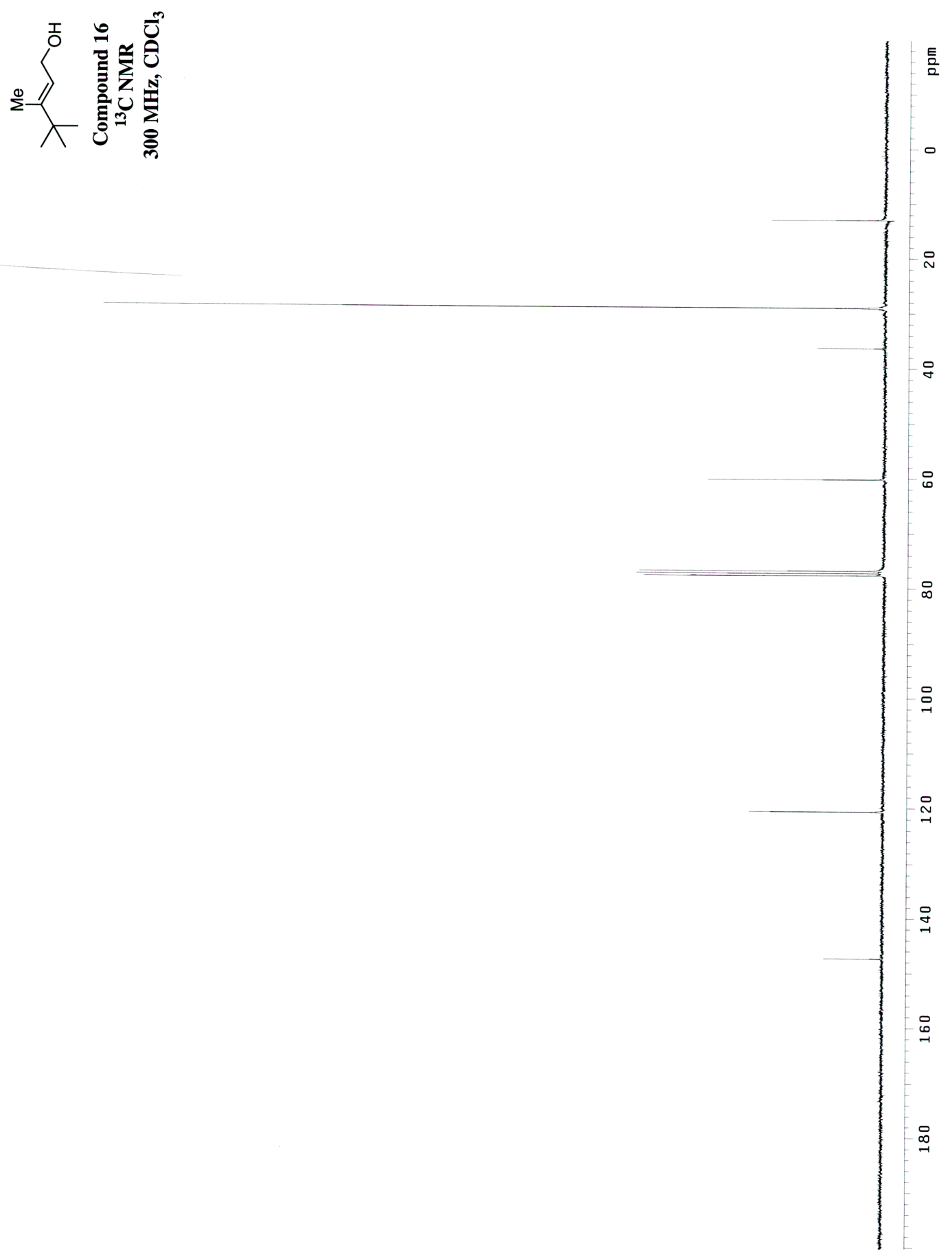


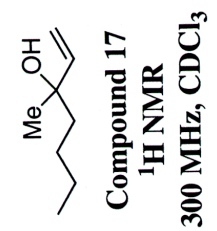

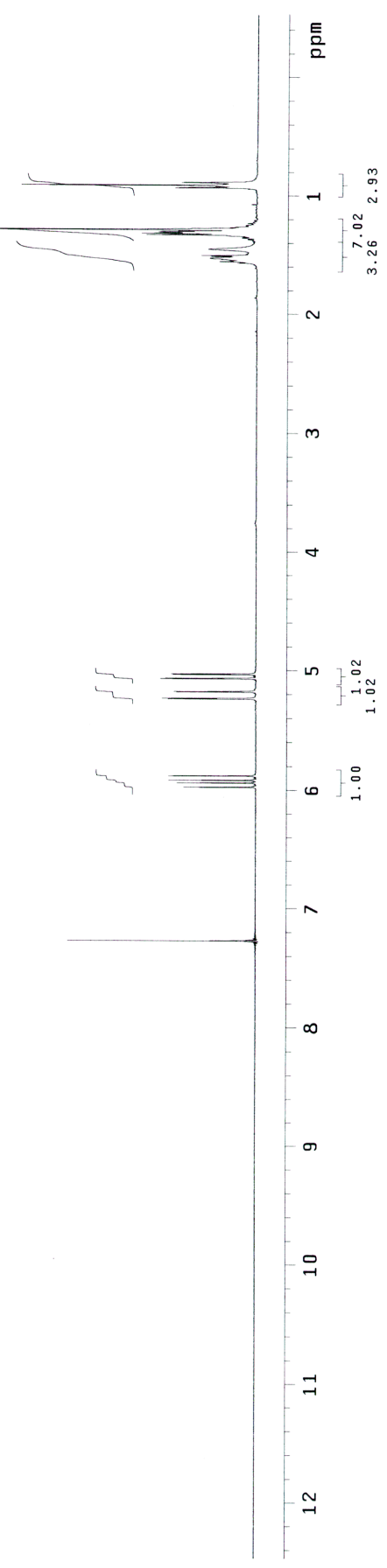


\〉

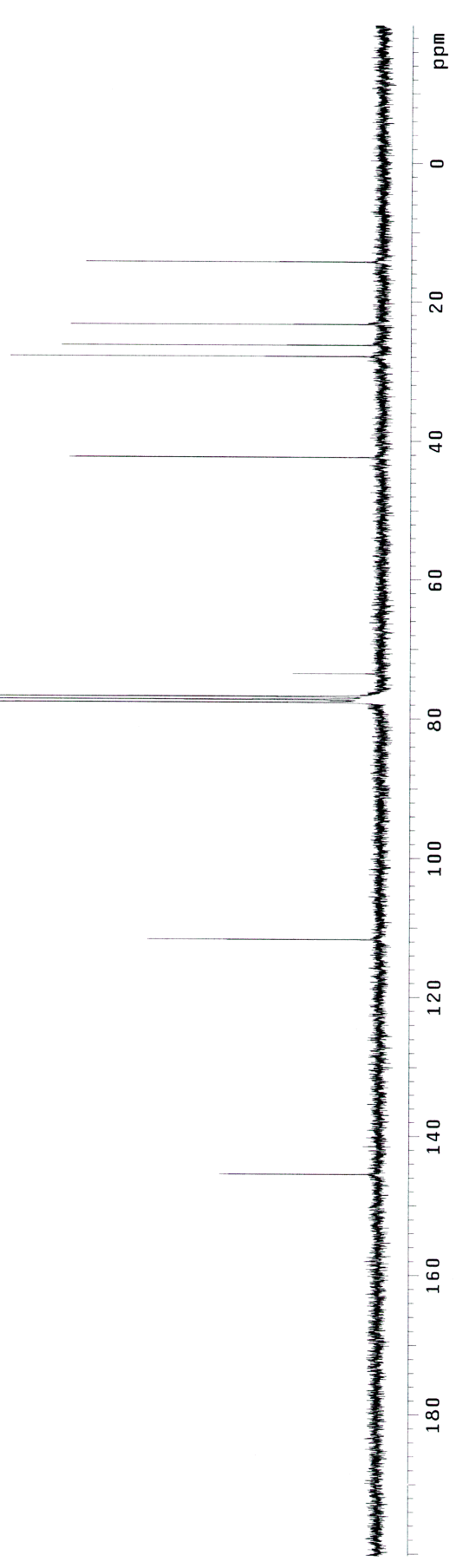

S64 


$$
\text { 〈丶 }
$$

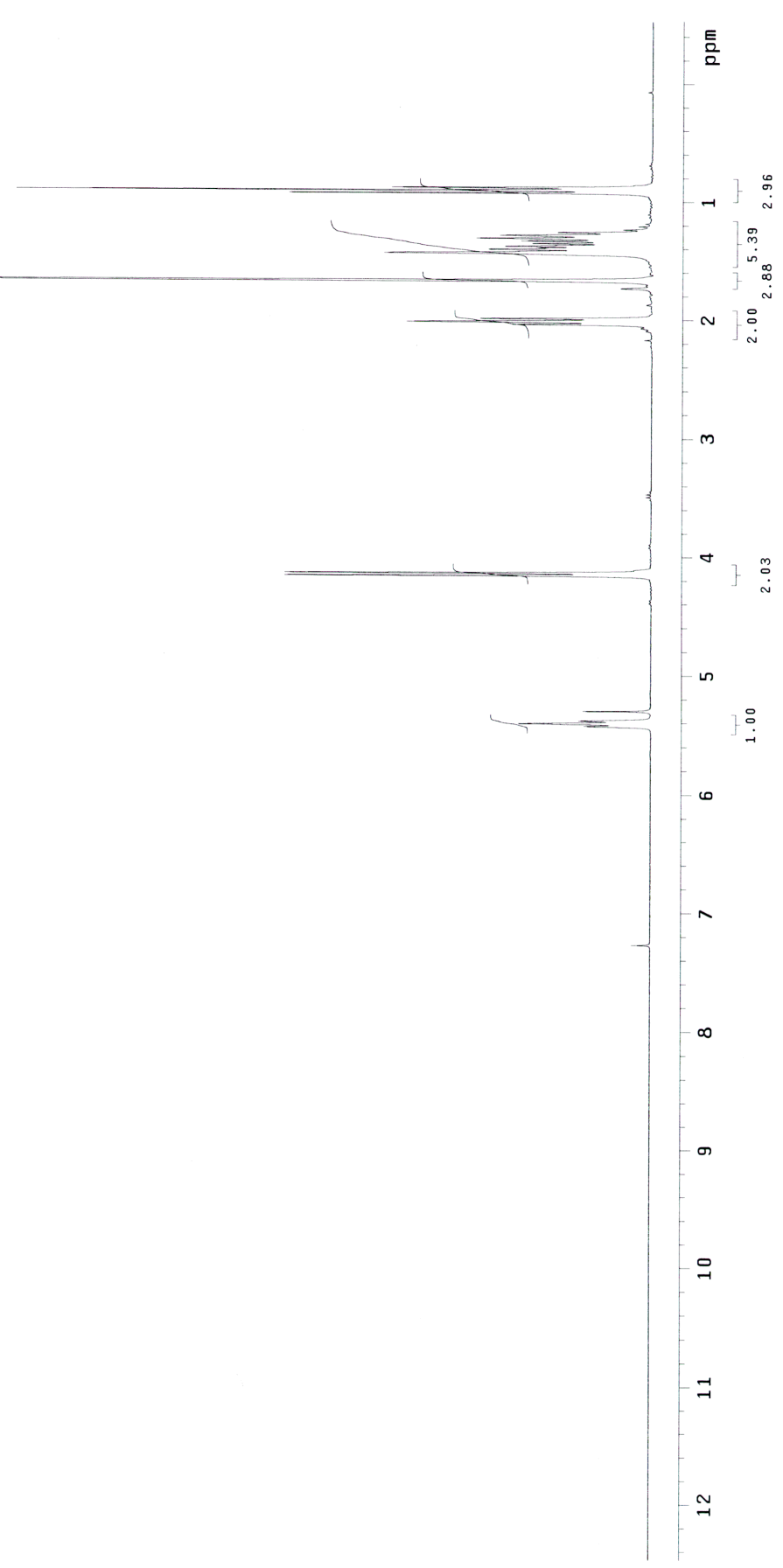


〈丶

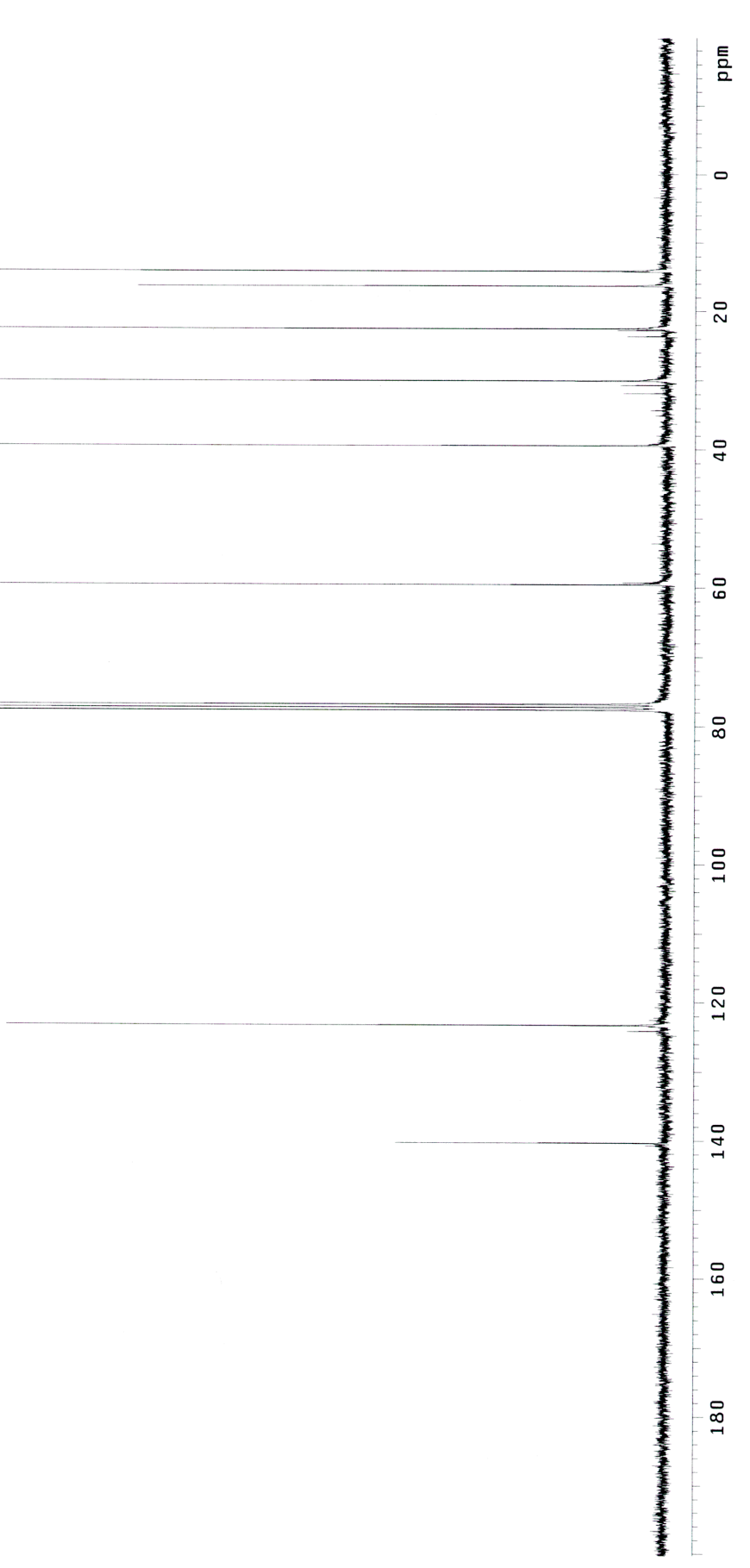




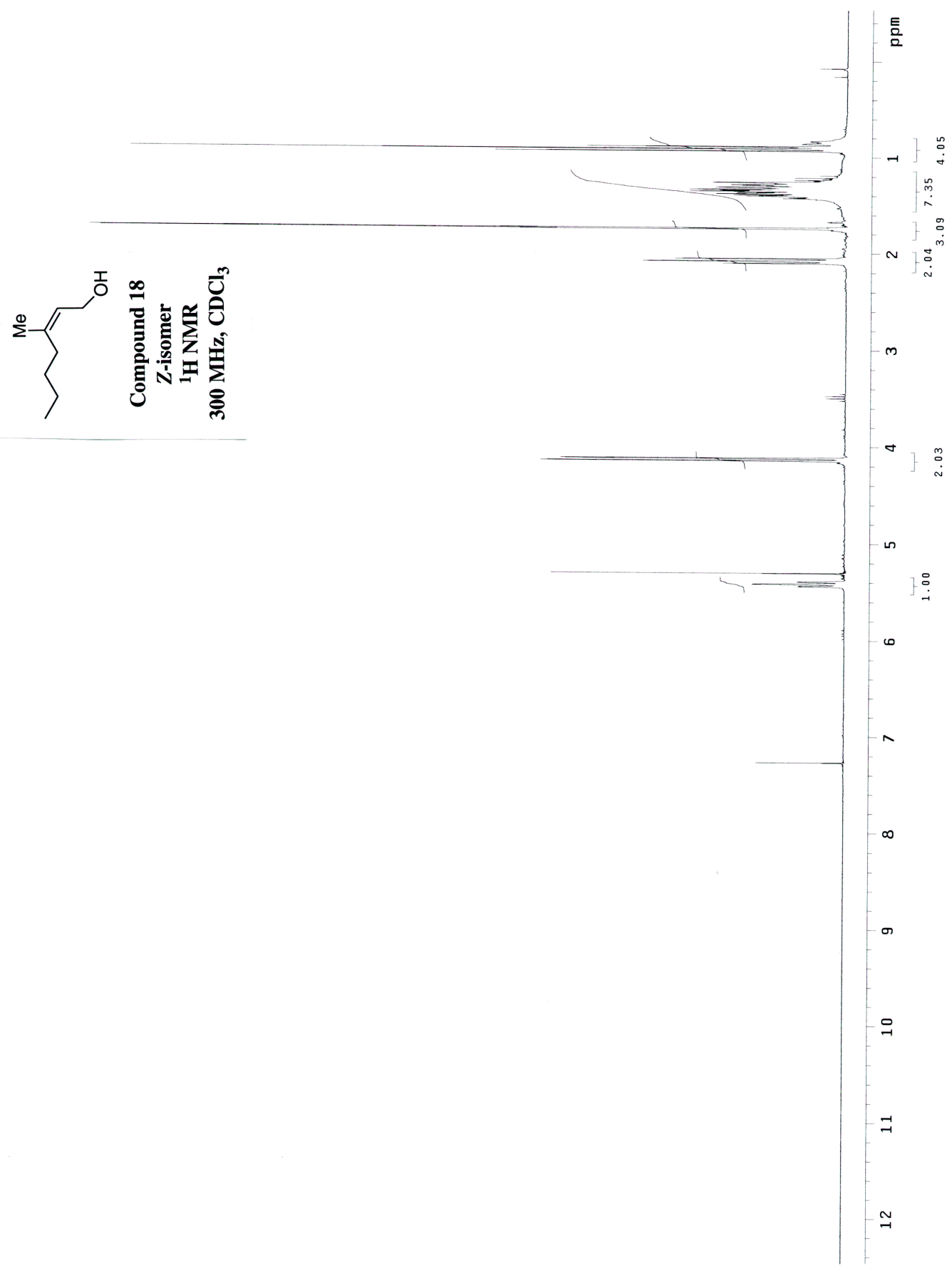




$$
\sum^{\infty} \underbrace{\infty}
$$

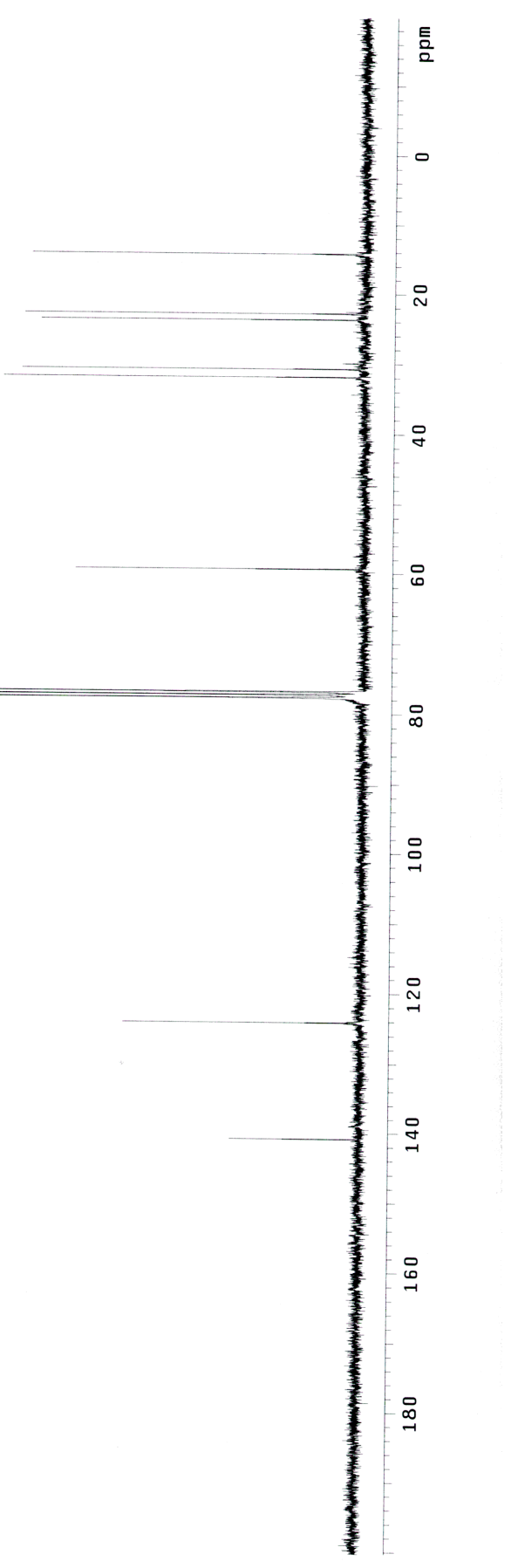




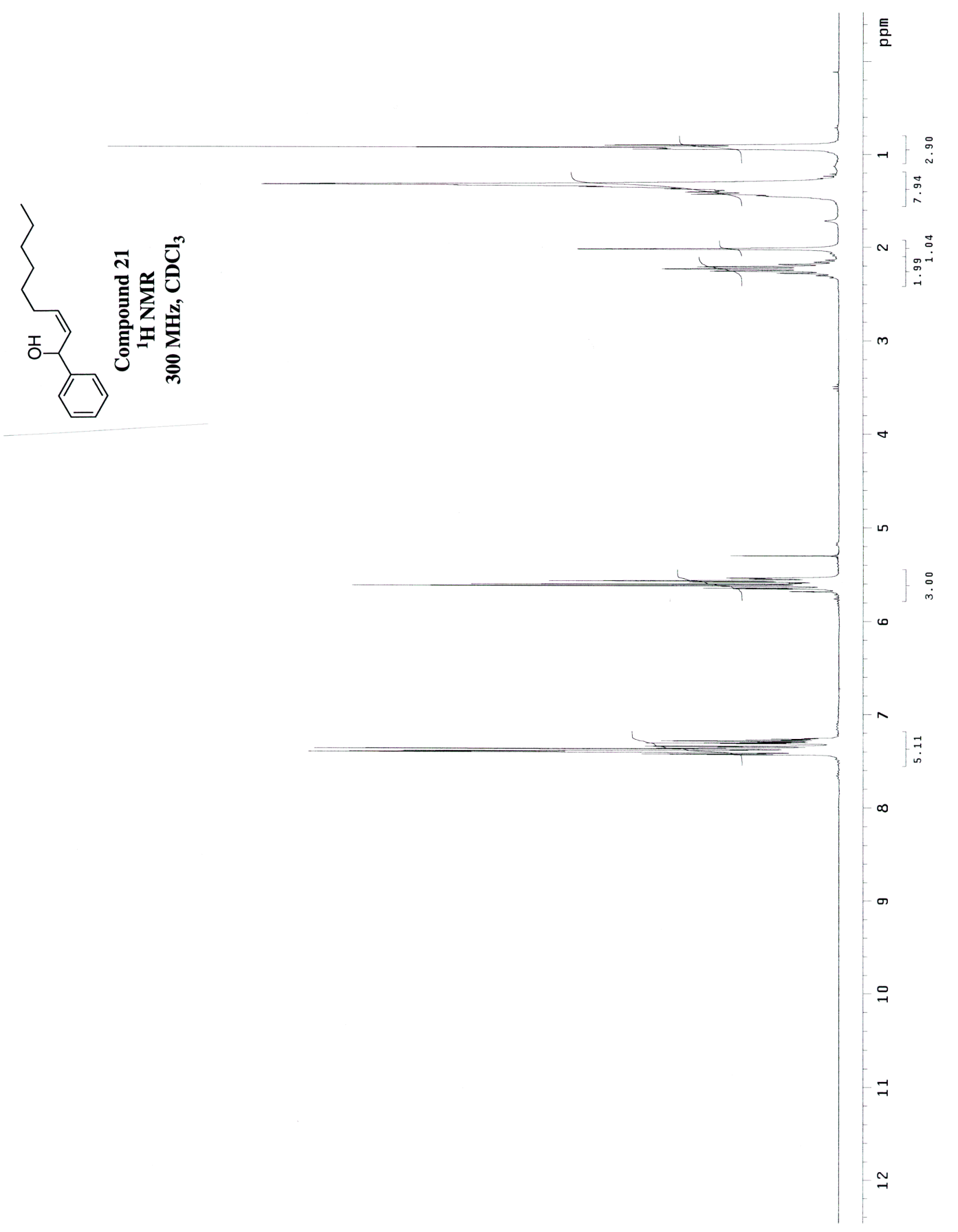



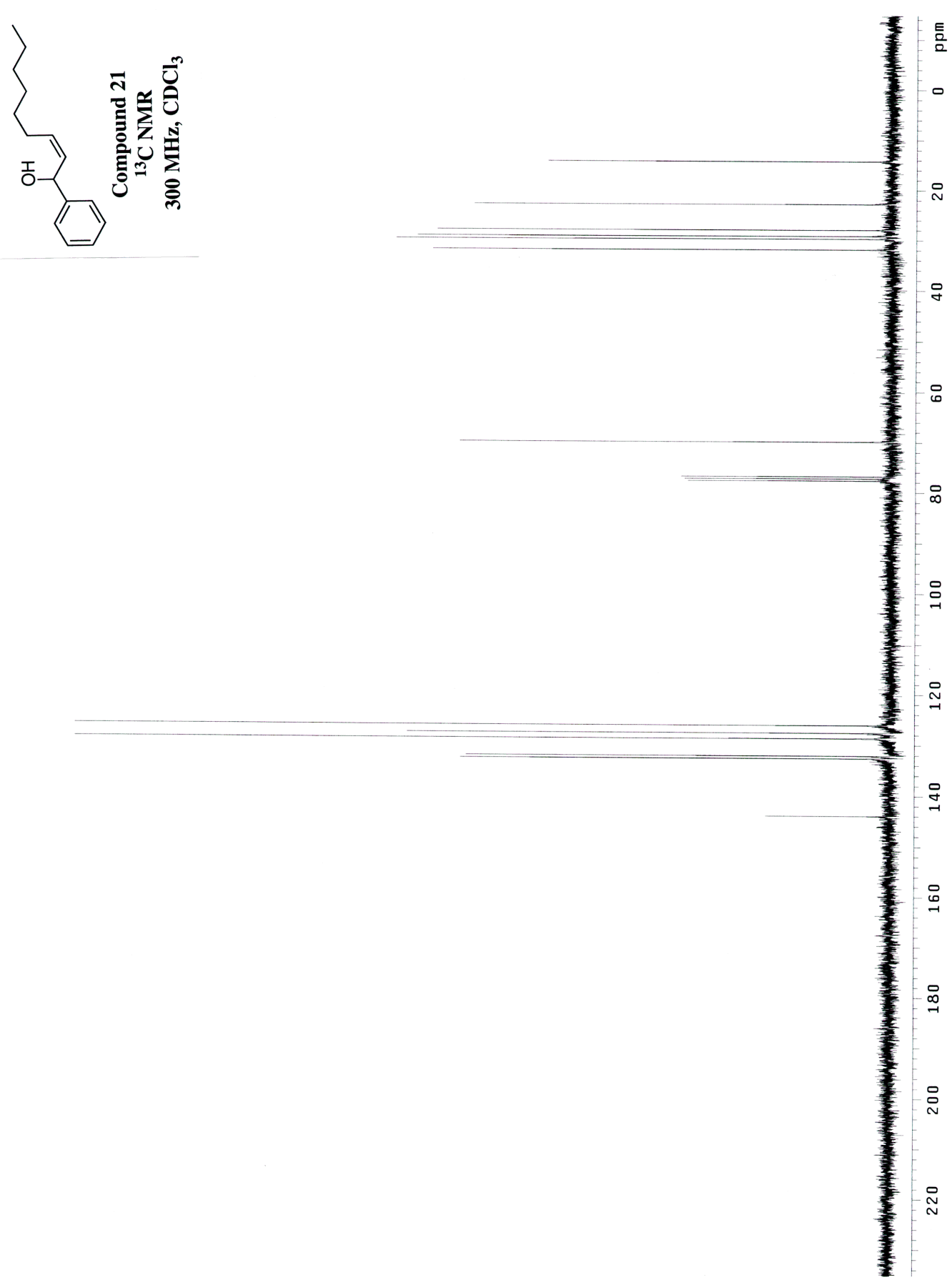

S70 